Portland State University

PDXScholar

$1-1-2011$

\title{
Biological Erosion of Marine Habitats and Structures by Burrowing Crustaceans
}

Timothy Mathias Davidson

Portland State University

Follow this and additional works at: https://pdxscholar.library.pdx.edu/open_access_etds Let us know how access to this document benefits you.

\section{Recommended Citation}

Davidson, Timothy Mathias, "Biological Erosion of Marine Habitats and Structures by Burrowing Crustaceans" (2011). Dissertations and Theses. Paper 383.

https://doi.org/10.15760/etd.383

This Dissertation is brought to you for free and open access. It has been accepted for inclusion in Dissertations and Theses by an authorized administrator of PDXScholar. Please contact us if we can make this document more accessible: pdxscholar@pdx.edu. 
Biological Erosion of Marine Habitats and Structures by Burrowing Crustaceans

by

Timothy Mathias Davidson

A dissertation submitted in partial fulfillment of the requirements for the degree of

\author{
Doctor of Philosophy \\ in \\ Environmental Sciences and Resources
}

Dissertation Committee:

Catherine E. de Rivera, Chair

Heejun Chang

Elise Granek

Gregory Ruiz

Mark Sytsma

Portland State University

(C)2011 


\begin{abstract}
Marine bioeroders, borers, and burrowers can have drastic effects to marine habitats and facilities. By physically altering the structure of marine habitats, these organisms may elicit ecosystem-level effects that cascade through the community. While borer damage is typically restricted to a few substratum types, burrowing isopods in the genus Sphaeroma attack a diversity of substrata in tropical and temperate systems. My dissertation examined how boring sphaeromatid isopods affect coastal habitats (saltmarshes, mangroves) and other estuarine substrata as well as marine structures. I used a combination of lab and mensurative field experiments to quantify the effects of boring by isopods and examine how select factors affect the colonization, hence burrowing damage by isopods. I explored these questions primarily using the temperate boring sphaeromatid, Sphaeroma quoianum, as a model organism. My initial lab experiments quantified the per capita erosion rates of $S$. quoianum in four commonly attacked estuarine substrata. I found marsh banks and Styrofoam substrata were the most affected per capita. I supplemented this lab experiment with a year-long mensurative field experiment examining how erosion rates differ between marshes infested and uninfested by boring isopods. Marshes infested with isopods eroded $300 \%$ faster than uninfested marshes. I further examined the boring effects on Styrofoam floats. I compiled surveys and observations and conducted a short experiment to describe how isopods affect Styrofoam floats used in floating docks. I observed dense colonies of isopods attacking floats and expelling millions of plastic particles in the ocean. The boring effects to simulated Styrofoam floats were also affected by seawater temperature. Burrowing
\end{abstract}


effects in Styrofoam floats exhibited a curvilinear relationship with temperature and peaked around $18^{\circ} \mathrm{C}$. These results suggest a $1-2^{\circ} \mathrm{C}$ increase in water temperature could increase boring effects 5-17\% of populations of isopods in Oregon and California bays. To examine the small-scale factors that mediate colonization and boring, I conducted a series of binary choice experiments. I found the presence of conspecifics, biofilm, and shade were important factors influencing colonization. These small scale factors likely explain why isopod attack is focused in some substrata. Finally, to examine the boring effects of tropical isopods in mangroves, I examined the associations between burrowing by $S$. terebrans and mangrove performance and fecundity. I found negative relationships between boring effects and performance and fecundity in two mangrove species in a restored mangrove stand in Taiwan. Together, these studies elucidate the effects of bioerosive isopods on saltmarshes, mangroves, and marine structures. However, the similar mechanisms involved in bioerosion in other boring species suggest that these results can be used to infer similar effects of other borers. In addition, since many species of sphaeromatid isopods have been introduced, this research shows how the effects of a non-native bioeroder can damage marine facilities and degrade and alter marine habitats. Through biological erosion and thus changing the physical structure of a marine habitat these non-native species can have ecosystem-level effects that cascade throughout the local community. 


\section{Acknowledgements}

I am extremely thankful for the support and advice of my adviser, Catherine de Rivera, and committee including Heejun Chang, Elise Granek, Gregory Ruiz, and Mark Sytsma. Yangdong Pan and James Carlton provided helpful advice throughout this project. I appreciate the help of Hwey Lian Hsieh and CP Chen and their lab members; my work in Taiwan would not have been successful without their accommodations and generosity. I am grateful to Steven Rumrill and other members of the South Slough National Estuarine Research Reserve for advice and help in the field. Alan Shanks and Craig Young provided continued mentorship and lab space during my numerous field visits to Coos Bay. John Chapman, Linda Mantel, Sylvia Yamada, Martin Thiel, Chris Parker, Brian Turner, Tara Chestnut, and Leslie Bliss-Ketchum and other members of the de Rivera and Sytsma labs also provided helpful advice and comments on this research. I am very grateful to have worked with numerous volunteers and lab technicians including Anne Phillip, Steve Lesback, Amanda Wilson, Dereck Guba, Justin Ashby, Jason Xing, Holly Keammerer, Stacy Tao, and Ben Grupe. A special thanks goes to the Portland State University library (especially the Interlibrary Loan Department) for finding so many old and difficult to track articles, theses, and books for me.

I am grateful for the funding provided by the Western Regional Panel on Aquatic Nuisance Species (under United States Fish \& Wildlife Service Grant Agreement number 60181-7G256 to C.E. de Rivera) and through the South Slough NERR Fellowship from the Estuarine Reserves Division, Office of Ocean and Coastal Resource Management, National Ocean Service, National Oceanic and Atmospheric Administration. Additional 
funding was provided by the National Science Foundation East Asia and South Pacific Summer Institutes Fellowship and Sigma Xi. The Laurels Tuition Remission Program at Portland State University, Marine Technology Society, and the USA Funds Scholarship program helped defray the high costs of graduate education. Without the financial support provided from the sources above, I would never have been able to attend graduate school. Thank you.

A heartfelt 'thank you' goes to all of my family. But I would especially like to thank my parents Donna and Roger Davidson (for their unwavering support and love), my brother Dan Davidson (who instilled my critical thinking skills at an early age through loving harassment/arguments and fun games), my sister Julie Nogaj (who has always supported my decisions, good and bad), and my grandfather Matt Hatzenbeehler (who helped shape and nurture my scientific mind). I am also fortunate to have such amazing and supportive friends. I would like to thank two friends, in particular, who have supported my academic and personal endeavors throughout my whole life: Gus Erickson and Chris Robinson. If I did not have their support and constant reminders to have fun and enjoy "the now", I probably would have burnt out years ago. Finally, the following people helped me maintain my sanity during this multi-year endeavor including: my fellow sensei's and members of the Ojukan Judo Club, Jigoro Kano, the Aquabats!, Matt Groening and the writers of Futurama, and Stan Sakai. A special thanks to Phillip J Fry, Professor Hubert J Farnsworth, Zapp Brannigan, and Dr. John Zoidberg who all reminded me to laugh at life and myself. 


\section{Table of Contents}

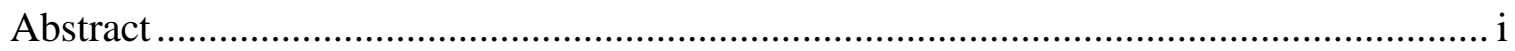

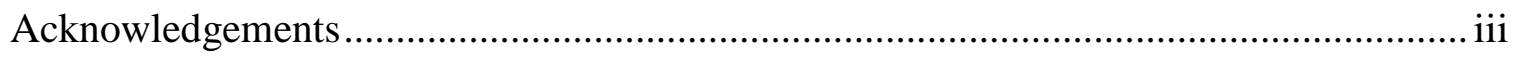

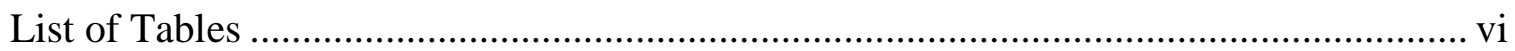

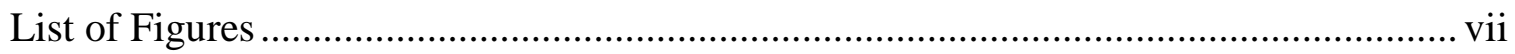

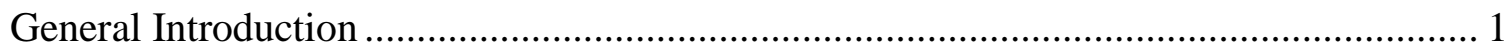

Chapter 1: Per capita effects and burrow morphology of a burrowing isopod (Sphaeroma quoianum) in different estuarine substrata.................................................................. 20

Chapter 2: Accelerated erosion of saltmarshes infested by the non-native burrowing

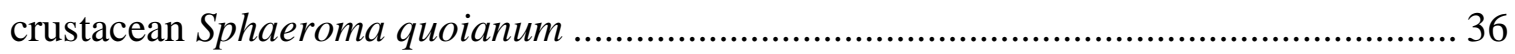

Chapter 3: Boring crustaceans damage polystyrene floats under docks, polluting marine

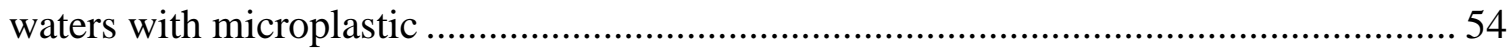

Chapter 4: Seawater temperature mediates the biological erosion by a non-native

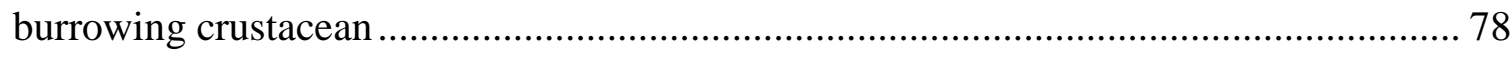

Chapter 5: Factors influencing the colonization of a burrowing isopod (Sphaeroma

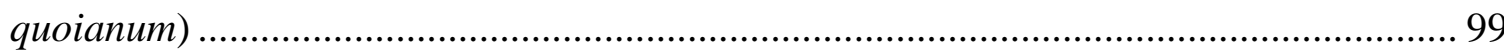

Chapter 6: Damage and alteration of mangroves inhabited by a wood-boring crustacean in a restored mangrove stand in Taiwan ............................................................. 110

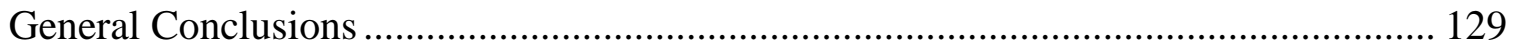

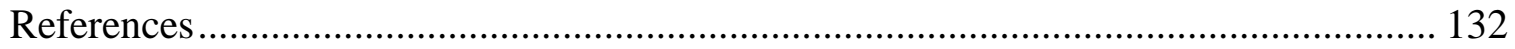




\section{List of Tables}

Table 2.1. Site and sediment characteristics between sites infested and uninfested by populations of Sphaeroma quoianum and burrowed and unburrowed areas within infested sites

Table 3.1. Mean, maximum, and minimum of densities of burrows and isopods (Sphaeroma quoianum) collected from expanded polystyrene floats $(\mathrm{n}=18$; burrow densities) and float mimics ( $n=6$; isopod densities) in Coos Bay, Oregon

Table 3.2. Locations where boring sphaeromatid isopods have attacked expanded polystyrene floats.

Table 4.1. Mean $\pm 95 \%$ confidence intervals of water temperature $\left({ }^{\circ} \mathrm{C}\right)$ in the experimental aquaria. Twelve measurements were taken during the two-month experiment.

Table 4.2. Mean water temperatures (2000-2010) in the Pacific coast National Estuarine Research Reserve system-wide monitoring program stations, predicted water temperatures under B1 (best-case) and A2 scenarios (Meehl et al. 2007), and the predicted change in biological erosion associated with those water temperatures due to temperature-specific boring rates in the lab.....

Table 4.3. Water temperature values for selected Pacific coast National Estuarine Research Reserve System-Wide Monitoring Program (SWMP) stations. .96

Table 5.1. The treatment and control blocks and conditions for colonization experiments 104

Table 5.2. Results from colonization experiments. 106

Table 6.1. Morphological, performance, fecundity, and damage metrics measured for Rhizophora stylosa and Avicennia marina 


\section{List of Figures}

Figure 1.1. The mean burrow length and volume, per capita number of burrows created by individuals of Sphaeroma quoianum, and total volume removed per isopod, for each of four substrata after two months in the lab

Figure 1.2. The mean burrow length and volume of burrows of Sphaeroma quoianum in four substrata collected in the field

Figure 2.1. Methods used to measure lateral erosion and indicators of bank erosion and transformation in marsh sites (side view)

Figure 2.2. Lateral saltmarsh erosion measured by A. erosion pins, B. onshore reference markers (wooden stakes), C. maximum undercutting and D. marsh failure in marshes infested versus uninfested by populations of the burrowing isopod Sphaeroma quoianum

Figure 2.3. Lateral erosion (measured by paired erosion pins) in burrowed and unburrowed areas within marsh banks infested by Sphaeroma quoianum

Figure 3.1. Extensive burrowing by populations of boring isopods damaged the polystyrene floats in the docks used by aquaculture facilities in (A-C) Yaquina Bay, Oregon, USA (Sphaeroma quoianum; 7/15/2007) and (D-F) Tainan, Taiwan (presumably Sphaeroma terebrans; 8/5/2010)

Figure 3.2. Microscope images of the plastic particles created by Sphaeroma quoianum during the burrowing process into expanded polystyrene floats

Figure 3.3. Frequency histograms of the (A) area, (B) perimeter, (C) maximum length, (D) maximum width (orthogonal to the length measurement), (E) equivalent circular diameter (ECD) and (F) perimeter-area ratio of the microplastic particles created during burrowing by Sphaeroma quoianum in expanded polystyrene floats $(n=200)$

Figure 3.4. Global occurrences of boring isopod damage to expanded polystyrene floats. The open circles in North America represent areas with known damage from nonnative sphaeromatid isopods

Figure 4.1. Effect of water temperature on the length and volume of burrows and number of plastic particles created by individuals of Sphaeroma quoianum 86 
Figure 4.2. Effects of temperature on burrow use and the molting frequency (per isopod) of individuals of Sphaeroma quoianum...

Figure 4.3. Effects of temperature on survivorship and the reproduction (\# of juveniles) of individuals of Sphaeroma quoianum $(P>0.05)$.

Figure 6.1. Burrowing isopods (Sphaeroma terebrans) burrowed into multiple parts of mangroves in Haomeiliao Nature Preserve, including (A-B) the free-hanging aerial roots of Rhizophora stylosa (roots used to anchor and support the tree), the (C) pneumatophores (roots used in gaseous exchange) and (D) the trunk, branches, and roots of Avicennia marina.

Figure 6.2. Relationships between the percentage of roots burrowed by Sphaeroma terebrans in Rhizophora stylosa and measures of damage, morphology, performance, and fecundity

Figure 6.3. The association between the number of burrows per Avicennia marina and (A) mean pneumatophore density, (B) mean biomass of pneumatophores per quadrat, (C) mean pneumatophore weight and (D) mean number of lenticels per pneumatophore 


\section{General Introduction}

Marine bioeroders, borers, and burrowers can cause dramatic changes to the physical structure and function of marine habitats and facilities. By altering the nature or physical state of either biotic or abiotic materials via their erosive actions, they change the availability of resources in a habitat for other species (termed allogenic ecosystem engineers, Jones et al. 1994). This process also may damage structures or facilities of human value. Bioerosion is defined by Neumann (1966) as the destruction or removal of consolidated mineral or lithic substrata by the direct action of organisms. For this research, however, I define bioerosion as biologically-induced removal, destruction, or deterioration of lithic and non-lithic substrata including consolidated organic soils (marsh banks composed of compacted mud, clay and/or peat), artificial substrata (Styrofoam floats and docks), and persistent organic substrata such as wood (including debris, mangroves, and man-made structures). I expand the use of the term bioerosion to include consolidated non-lithic substrata since the mechanism and effects of biological erosion on non-lithic substrata is similar to lithic substrata. Bioerosion could be categorized by feeding modes such as: i) consumptive bioerosion, where organisms receive a nutritive benefit from consuming the substratum, ii) incidental consumptive bioerosion, where bioerosion is a byproduct of feeding (e.g. scraping of organic material off a substratum and incidental consumption), and iii) non-consumptive bioerosion, where bioerosion occurs from activities unrelated to feeding (i.e. by creating a burrow for protection). Bioerosion through all of these mechanisms can be substantial in some marine 
environments and exceed the erosion by physical or chemical processes (Warme and Marshall 1969, Warme 1971).

\section{Ecological effects of bioerosion in the marine environment}

Bioerosion is an essential ecosystem process that can affect the structure and function of marine ecosystems and communities. Bioeroders help maintain a mass balance between accretion and erosion and serve as recyclers in marine ecosystems (Hutchings 1986, Cragg 1993, Glynn 1997), making the eroded materials available to other organisms. Bioerosion is important for maintaining some ecosystems including coral and sand beaches (Schneider and Toruski 1983, Hutchings 1986) or perhaps the ecotone between dense mangrove forest and open marine waters (Snedaker and Enright 1974). Furthermore, the degradation of woody debris by wood-borers keeps estuaries from becoming clogged by debris (Cragg 1993). The novel habitats created through bioerosion (burrows, depressions, pits, or excavations) increase heterogeneity and can be inhabited by diverse and abundant species assemblages (Hutchings 1983, Pinn et al. 2008, Davidson et al. 2010, Davidson and Grupe in prep). These habitats may also provide refuges from environmental stressors or predators (Bortolus et al. 2002, Palomo et al. 2003). The community inhabiting these excavations may also enhance nutrient recycling by drawing organic matter into these systems (Hutchings 1986, Levin et al. 1997) and the complex topography of pits, burrows, and excavations may enhance the passive deposition of particles including organic matter (Yager et al. 1993). 
Bioerosion may alter the physical and chemical properties of the substrata with concomitant effects to the community and ecosystem. Bioerosion by grapsid crabs and littorine snails facilitates the development of tidal channels (Escapa et al. 2007) and deepening of tidepools (North 1954), respectively. Burrowing in marshes changes percolation rate, decomposition rate, organic content, redox potential, and porosity (Bertness 1985, Escapa et al. 2007), which can affect primary producers (Bertness 1985, Escapa et al. 2007) and other biota. Wood-boring species alter and mobilize nutrients by metabolizing wood and expelling it as feces (Cragg 1993). Bioeroded and expelled sediments and particles may also increase turbidity, thus affecting survivorship and settlement of marine species (as with resuspended sediment, Rhoads and Young 1970). The removal of substrata through bioerosion may also scour recently settled marine larvae, affecting the settlement and recruitment of other species (Sammarco 1980).

Due to its effects on structure and function of ecosystems and communities, increases in the rates of bioerosion could have a variety of implications for marine ecosystems. For example, the introduction of new bioeroders, increases in the abundances of native bioeroders, or increases in bioerosion rates of individual taxa, among other factors, may increase overall bioerosion rates in a system. One of the most detrimental ecological impacts accelerated bioerosion may have is the destruction or decomposition of important habitats. When bioeroders occur in high densities or erode at high rates, they can deteriorate or decompose important ecosystems including saltmarshes (Talley et al. 2001, Davidson and de Rivera 2010), mangroves (Rehm and Humm 1973, Perry and Brusca 1989), and coral reefs (Glynn et al. 1979, Eakin 1996) into simpler and more 
homogenous habitats. Even minor levels of bioerosion can weaken a substratum, making it vulnerable to acute disturbances such as storms or floods (Harmelin-Vivien 1994).

The destruction of the structural components of these ecosystems, even on a local scale, can lead to alterations in the physical, chemical, and biological characteristics of the area. The loss of important ecosystems (saltmarshes, coral reefs, mangroves) may also affect the essential ecosystem services they provide such as: storm and flood abatement, detoxification of pollutants, groundwater recharge, and support for protected or commercial species (Mitsch and Gosselink 1993). Many marine ecosystems that are threatened (mangroves, saltmarshes, coral reefs, for example) are those that are most prone to damages from bioerosion.

Potential economic effects of bioerosion in marine environments

Bioerosion can also affect places or objects of cultural or economic importance. Many wood bioeroders damage or destroy marine vessels, structures, and facilities such as docks, pilings, and tide gates (Hill and Kofoid 1927, Cragg et al. 1999, pers obs.) and can damage industrial facilities and infrastructure (Mills 1978, Jenner et al. 2003). Despite chemical and physical deterrents, burrowing isopods can severely damage wooden power poles (Mills 1978), and boring bivalves can damage cooling pipes used in power plants (Jenner et al. 2003). Bioerosion can reduce the integrity of sea walls (Chilton 1919), levees, and dikes (Rudnick et al. 2005, Davidson 2008). Clay and compacted mud dikes infested by the non-indigenous isopod Sphaeroma quoianum failed during winter storms, causing tens of thousands of dollars of damage to some residents of 
Coos Bay, Oregon (SS Rumrill per comm, Davidson 2008). Attack by the non-native shipworm Teredo navalis to pilings and docks in San Francisco bay cost an estimated \$615 million in damages over three years (Miller 1926, Neily 1927, Cohen and Carlton 1995). In Australia, damage from marine borers is extensive; timber replacement costs to human-made structures alone cost \$20 million per year (in 1986 AUD dollars; Cookson 1986).

In addition to damaging the infrastructure of fisheries and aquaculture, bioeroders may also affect the fisheries or aquaculture species. Boring sponges (Cliona sp.) bore into and weaken the shells of commercially important mollusks, such as abalone, scallops and oysters (Morris et al. 1980). Historically and culturally important coastal features or artifacts are also be damaged by bioeroders (i.e. Viking shipwreck, Civil War vessel; Kim et al. 1996, Jurgens and Blanchette 2005); the consequences of such damages and loss are hard to quantify. Furthermore, bioeroders may have an economic effect by degrading ecosystems (coral reefs, saltmarshes, mangroves) that also important to ecotourism and recreation.

\section{Factors influencing the effects of bioeroders}

The rate of substratum decomposition, hence bioerosive effect, is a function of the distribution and density of bioeroder populations and their per capita effects. Thus, organisms with small per capita effects may have larger population effects due to wide distributions and high densities (McLean 1967, Andrews and Williams 2000). For example, McLean (1967) estimated the bioerosion rate of the snail Nerita tesselata was 
$0.7 \mathrm{~g} \mathrm{yr}^{-1}$, but total bioerosion from the high densities of this snail $\left(220 \mathrm{~m}^{-2}\right)$ exceeded $9000 \mathrm{~cm}^{3} \mathrm{yr}^{-1}$ of sandstone from a site in Barbados. Per capita rates of bioerosion can be affected by numerous factors such as the frequency of bioerosive action (Bruggemann et al. 1996, Smith 2008), method of bioerosion (i.e. rasping, excavating, boring), and size of the bioeroder (McLean 1967, Bruggemann et al. 1996, Carreiro-Silva and McClanahan 2001, Pinn et al. 2005).

The extent and ultimate effects of bioerosion can be influenced by interactions with the environment (i.e. disturbance, salinity, sunlight, temperature, wave forces; Hill 1996, Kirwan et al. 2008, Smith 2008, Borges et al. 2009) and community (presence of predators, conspecifics; Brooks and Bell 2001, Ellison and Farnsworth 1990, BrownSaracino et al. 2007). Physical features of the substratum also influence bioerosion rates; bioerosion rates decrease with increasing hardness (McLean 1967, Evans 1968), density (Cragg et al. 2007), cementation (Manzello et al. 2008), and rates of recovery (e.g. regrowth or accumulation, Brooks and Bell 2002). Since different substrata exhibit different physical characteristics, substratum composition is another factor that may influence the effects of a bioeroder (McLean 1967, Bruggemann et al. 1996, Davidson et al. 2008a).

Boring sphaeromatid isopods as model organisms for exploring bioerosive effects

Burrowing sphaeromatid isopods are an ideal model to investigate how boring and burrowing animals affect coastal habitats and structures. Burrowing isopods are common in tropical through temperate environments, they are relatively easily 
manipulated, and their effects and presence are conspicuous and readily detectable. They are also a hardy taxa with wide salinity (Riegel 1959), temperature (Jansen 1971), and desiccation tolerances (pers obs). In addition, since many boring isopods have been unintentionally translocated throughout the world by humans, boring isopods can provide opportunities to explore additional questions in invasion ecology and biogeography.

\section{Estuarine distribution}

Populations of Sphaeroma are usually found within the brackish regions of estuaries (Harrison and Holdich 1984, Murata and Wada 2002, Davidson 2008) but are known to tolerate extreme temperatures and a wide range of salinities (Riegel 1959, Jansen 1971). The temperate species S. quoianum is widely distributed throughout the intertidal and most prevalent between salinities of 5-31 PSU in Coos Bay, Oregon, Tamar estuary, Tasmania, and Port Phillip Bay, Australia (Davidson et al. 2008b). Similarly, populations of S. terebrans and S. peruvianum are found in brackish embayments and tidal creeks ranging from nearly freshwater to marine (Rice et al. 1990, pers obs). Boring isopods primarily inhabit the shallow subtidal to the high tide mark (Perry and Brusca 1989, Davidson 2008); however individuals of S. quoianum have been observed in waters as deep as $7 \mathrm{~m}$ (Cohen et al. 2001).

\section{Identification of burrowing Sphaeromatid crustaceans}

Isopod crustaceans of family Sphaeromatidae are small and rotund and can vary in color from a dark gray/black color to very light tan (pers obs). Adults can reach up to 
$16 \mathrm{~mm}$ in length (Hurley and Jansen 1977). Sphaeromatid species can be distinguished from each other and other isopods by examining the patterns of tuberculation on the pleotelson (number, orientation, and size of tubercles) and the morphology of the apex of the pleotelson, uropods, and pleopods (Hurley and Jansen 1977). While the family Sphaeromatidae has a large number of described genera (99) and species (more than 680, Wetzer 2011), Sphaeroma is the only genus that apparently includes species capable of creating their own burrows in consolidated substrata (possible exception: Ptyosphaera alata, Cookson 1986). Even within the genus Sphaeroma, only ten species are recognized as burrowers or borers (unpublished review); others rarely make burrows or merely nestle or modify existing burrows (i.e. Sphaeroma walkeri; Carlton and Iverson 1981).

\section{Natural History}

Sphaeromatid isopods can be found in a diversity of solid substrata. Tropical burrowing isopods primarily bore into mangrove trees and decayed wood while temperate species are recognized from primarily decayed wood, marine structures, and friable rocks (Rice et al. 1990, Cragg et al. 1999, Davidson 2008). Individuals of the temperate species Sphaeroma quoianum, however, are primarily found in marsh banks, wood, and sandstone (Davidson 2008, Davidson et al. 2008, Davidson et al. 2010), they can also inhabit other friable rocks (claystone and mudstone), Styrofoam floats used in floating docks, and the non-decayed wood used in marine structures (Carlton 1979, Davidson 2008). Rarely are they found living amongst surface dwelling biofouling 
organisms or under rocks (Davidson 2008, Davidson et al. 2008b). The complex, anastomizing burrow networks created by boring isopods perforate substrata and appear to affect substratum integrity (Carlton 1979, Talley et al. 2001, Davidson 2008, pers obs) and may exacerbate erosion (Higgins 1956, Carlton 1979, Talley et al. 2001) and the destruction of marine structures (Cragg et al. 1999). Isopods can rapidly colonize substrata and create burrows large enough for them to inhabit in less than 24 hours (Brooks and Bell 2002, Davidson et al. 2008a).

Boring isopods are filter feeders. Using pleopods to generate a current of water, an isopod moves detritus or phytoplankton into the burrow, captures these particles by setal brushes, then cleans them off using their mandibles (Rotramel 1975a, Si et al. 2002). They excavate burrows primarily for living space and do not intentionally consume the material they excavate (Rotramel 1975a, but see Benson 1999). However, Messana (2004) suggests that the filter feeding process may also aid in waste removal, water exchange/ventilation, and reproduction. The filter feeding mechanism is also important during burrow construction. Isopods use their mandibles to break and remove bits of substratum. They release the bits of substrata at their midline and use the current created by the beating of their pleopods to move the particles under their body and out of the burrow (Rotramel 1975a).

By creating dense aggregations of burrows and galleries, boring isopods create a habitat for other species (Estevez 1978, Santhakumari and Nair 1982, Davidson et al. 2010). Davidson et al. (2010) sampled burrowed substrata of marsh bank, sandstone, and decayed wood and found that tens of thousands of animals from at least 58 different 
estuarine and semi-terrestrial taxa (per cubic meter) use these burrows. Several benthic fauna observed in burrows were found at tidal heights higher than they are typically found suggesting that burrows of $S$. quoianum may extend the tidal distribution of some species (Davidson et al. 2010). Some animals even modify existing isopod burrows by expanding the size of the burrow (grapsid crabs; pers obs). Ectocommensal isopods of the genus Iais are also present on many individuals of Sphaeroma; they are often found on the ventral surface of male and female hosts, feeding from and cleaning their setae (Rotramel 1975b, pers obs). A variety of other ectocommensals can be found living on sphaeromatids including protists, hydroids, nematodes, ostracods, harpacticoid copepods and others (Santhakumari and Nair 1982, Clamp 2006).

\section{Life history \& reproductive biology}

Sphaeromatid isopods are gonochoric and direct developers. It is unclear if boring sphaeromatids are monogamous or polygamous. Boring sphaeromatid isopods are found in burrows in pairs occasionally (Barrows 1919, Schneider1976, Messana et al. 1994) and occur in apparent family groups (Messana et al. 1994, Thiel 1999), but most of the time only one individual is found in a burrow (Messana et al. 1994). Messana et al. (1994) also suggested that wandering males of $S$. terebrans could mate more than once and thus may be responsible for the existence of multiple cohorts observed in a substratum (or even in a burrow). Schneider (1976) further suggested that the lifespan of female S. quoianum may allow it to mate with more than one individual. Complex sexual behaviors are possible in Sphaeroma as many other isopods exhibit diverse mating strategies such as polygyny and 
sexual polymorphisms (Shuster 1989) and sequential hermaphroditisim (both protoandry and protogyny; Brook et al. 2004). Females tend to be slightly larger than males in Sphaeroma (Schneider 1976, Messana 2004), but no other indicator of poly- or dimorphism is apparent.

The burrow dwelling lifestyle of Sphaeroma requires special behaviors to ensure reproductive success (Messana 2004). While Messana (2004) described the mating strategy of $S$. terebrans, these results are likely similar to the strategies used by other boring sphaeromatids. Females remain in the burrow (head first) and defend it from intruders (Messana 2004) including males who attempt to mate. Her attempts to defend the burrow eventually diminish as the male undergoes a series of peristaltic movements and then releases a spermatophore. The current from the beating of the female's pleopods brings the spermatophore into her abdomen region, presumably to fertilize her eggs (Messana 2004). The male then leaves and does not return to the burrow; males are not involved in subsequent parental care (Thiel 1999)

The females brood eggs in a marsupium until the eggs hatch into mancas (Schneider 1976, Hurley and Jansen 1977, Thiel 1999, Murata and Wada 2002). The manca stage isopods stay within the marsupium until they crawl out as fully formed juveniles. Sphaeroma also exhibits extended parental care. The juvenile isopods remain at the terminal end of the burrow under the protection of the mother (Messana 2004, Thiel 1999, pers obs). The female can close off the opening of the burrow with her armored pleotelson and thus keep the juveniles safe from predators or unfavorable environmental conditions (Messana 2004). These juvenile isopods may eventually form 
side burrows off the maternal burrow (Thiel 1999, pers obs). They may also disperse from the burrow or are perhaps expelled by the mother when their size interferes with feeding or ventilation (Thiel 1999).

Adults of Sphaeroma quoianum are estimated to grow at a rate of $0.64 \mathrm{~mm}$ per month, live for 1 to 1.5 years, and become reproductive after six months (Schneider 1976). Gravid females and juveniles can be found throughout the year in several species of Sphaeroma, suggesting that adults reproduce continuously (Hill and Kofoid 1927, Schneider 1976, Perry and Brusca 1989, Thiel 1999, Davidson et al. 2010). However, the brood size varies between seasons in the temperate species $S$. quoianum (64 in the spring and 19.5 in the fall; Schneider 1976).

\section{Genetic structure}

Populations of boring isopods appear to be relatively limited in their dispersal and as a consequence, may differentiate relatively rapidly. Baratti et al. (2005) found isopod populations of $S$. terebrans only a couple hundred kilometers exhibited high genetic differentiation. Furthermore, populations in Florida and Brazil, Africa, and the Seychelles Islands were also highly differentiated and appear to be evolving separately; these populations may represent different species (Baratti et al. 2011). Even within the Seychelles Islands, the genetic distance between neighboring populations of S. terebrans is greater than the difference between Florida and African populations (Baratti et al 2011). Thus, the genetic structure of Sphaeroma may vary at relatively small scales. 
Invasion history and vectors

Many sphaeromatids are thought to have been historically translocated throughout the world via wooden-hulled ships (Carlton 1979, Carlton and Iverson 1981, Carlton and Ruckelhaus 1987). Several examples of boring sphaeromatid invasions include: Sphaeroma quoianum on the Pacific coast of North America (Rotramel 1972, Carlton 1979), Sphaeroma terebrans in the Caribbean (Carlton and Ruckelshaus 1987), and Sphaeroma silvai in Brazil (originally misidentified as S. annandalei, Khalaji-Pirbalouty and Wagele 2010). In many other areas, the invasion status of Sphaeroma appears cryptogenic (S. terebrans in South Africa [Robinson et al. 2005], S. quoianum in Hong Kong [Davidson 2008]). Wooden-hulled vessels may have been a significant historical vector due to the propensity of isopods to bore into wood substrata including wooden vessels and marine structures (Carlton 1979, Cragg et al. 1999). Sphaeromatid isopods may also be dispersed through the transport of other bored substrata (such as timber, docks, marsh plants or soil, etc). While these isopods are mostly found boring within a substratum, occasionally they are found nestling among cracks and crevices, in barnacle tests (Hass and Knott 1998), and in the interstices of fouling organisms (Davidson 2008, per obs). Since most hulls of modern vessels are not constructed of wood, they are not likely vulnerable to wood-borer attack. However, these vessels can harbor substantial collections of hull fouling and likely remain an occasional vector for boring sphaeromatids (Cohen and Carlton 1995, Wasson et al. 2001). This hypothesis is supported by the fact that several live individuals of $S$. quoianum were found amongst clumps of Mytilus trossulus mussels attached to a trailered boat traveling from San 
Francisco Bay where the boat had been moored (Oregon State Police, pers. comm.; pers obs). This anecdote demonstrates that hull fouling is even a viable vector for boring isopods outside of marine waters.

Rafting is another possible vector for the translocation of this species between or within adjacent estuaries. Colonies of S. quoianum in Coos Bay, Oregon have been found in Styrofoam; rafting by Styrofoam and other floating debris is thought to have been one of the dispersal mechanisms that contributed to their current distribution throughout the bay (Davidson 2008). Similar patterns have been observed in S. terebrans infesting Styrofoam in Taiwan (pers obs). Baratti et al. (2005) further suggests that boring isopods may raft inside broken mangrove prop roots. Active dispersal via swimming is another possible way isopods may invade new habitats, but dispersal to new regions is likely limited (pers obs).

Invasion history and biology of Sphaeroma quoianum, a case study

The invasion history and biology of the temperate isopod Sphaeroma quoianum is relatively well known on the Pacific coast of North America (Rotramel 1972, Carlton 1979, Davidson 2008), and provides a case study by which we can understand invasions and erosional effects of other boring species. Sphaeroma quoianum is native to New Zealand, Australia, and Tasmania, and these isopods are thought to have been introduced to the Pacific coast, initially to San Francisco Bay, via ship fouling/boring in the mid19th century from ships carrying passengers and cargo for the California Gold Rush (Carlton 1979). Like many organisms, S. quoianum was assumed to be native until work 
by Rotramel (1972) compiled evidence that S. quoianum is a non-native species. Despite having relatively limited active dispersal (presumably), the non-native burrowing isopod (Sphaeroma quoianum) has invaded at least fifteen estuaries on the Pacific coast of North America from northern Baja California to Yaquina Bay, Oregon (Davidson 2008). Sphaeroma quoianum can also rapidly spread within estuaries. This isopod was first discovered in Coos Bay, Oregon, in 1995 and soon after spread to the South Slough National Estuarine Research Reserve (Carlton unpublished). Ten years after the invasion had been noted, this species was found in approximately one-half of the surveyed intertidal sites and was present at densities of tens of thousands of individuals per cubic meter of decayed wood, friable rock (sandstone), or marsh bank substrata (Davidson 2008, Davidson et al. 2010).

Ecology in the native vs. non-native range

In the native range of Australia and New Zealand, S. quoianum is primarily recognized as a wood-borer or occasional rock-borer (Hedley 1901, Chilton 1919, Davidson et al. 2008b). Along the Pacific Coast of North America (non-native range), however, isopods have been found in a diversity of substrata including wood, friable rocks, Styrofoam floats, marsh banks, among others (Davidson 2008, unpublished data). The burrowing effects were especially pronounced within marsh bank substrata in invaded estuaries, where their burrowing promoted shoreline erosion (Carlton 1979, Talley et al. 2001, Davidson and de Rivera 2010). In contrast, individuals of S. quoianum 
were rarely found in marsh banks in two bays within their native range (Tamar estuary, Tasmania and Port Phillip Bay, Australia; Davidson et al. 2008b).

The densities of isopods also varied between bays where the species is native and non-native. In the Tamar estuary and Port Phillip Bay, Australia, S. quoianum is found in much lower densities in all substrata examined (Davidson et al. 2008b) compared to nonnative populations in Coos Bay (and likely San Francisco Bay, Talley et al. 2001). The authors speculate an ecological release from parasites and/or pathogens may be responsible for differences in density observed between the embayments in the native and non-native range of S. quoianum (Davidson et al. 2008b).

\section{Overview}

The physical effects of boring isopods in temperate and tropical coastal ecosystems may have broad ecological and economic implications. Using a combination of lab and field studies, I sought to determine how boring isopods affect coastal habitats (saltmarshes, mangroves) and other estuarine substrata as well as marine structures. In addition to quantifying the effect of boring isopods, I examined how various factors affect the colonization and burrowing by boring isopods. While many of these experiments were small-scale, they are also biologically relevant since these experiments occurred at a scale that the animals experience while exploring substrata in the field. Thus, the biological responses of the species in the lab were likely indicative of what field populations would do. Many of the experiments were also relatively short-term. However, since the effects I measured (creation of a burrow) often occurred rapidly and 
within that time scale ( $<2$ months), these short-term experiments were useful tools for inferring the colonization and initial burrowing effects of boring isopods. Furthermore, I expanded these initial short-term experiments to examine boring effects across a longer time scale and across numerous locations in an estuary. Most of this research focused on the temperate Sphaeroma quoianum, but these results are likely applicable to other boring sphaeromatids and the myriad of burrowing organisms known to affect coastal features since many of the mechanisms and behaviors involved in biological erosion are similar across boring taxa.

Some of the bioerosive effects of $S$. quoianum have already been examined in Californian saltmarsh bank systems (Talley et al. 2001) and the associations between burrows and erosion or damage noted by a variety of authors (Higgins 1956, Carlton 1979, Davidson 2008). However, those studies did not estimate the per capita physical effects of burrowing by S. quoianum to other substrata. The first component of my dissertation quantified the per capita physical effects of burrowing by S. quoianum and examined how burrowing varies in different substrata (Chapter 1: Per capita effects and burrow morphology of a burrowing isopod (Sphaeroma quoianum) in different estuarine substrata). After estimating the per capita effects of S. quoianum, I further elucidated the association of burrows of S. quoianum in the two most heavily affected substrata: marsh banks and Styrofoam.

Previous work by Talley et al. (2001) found isopods excavating sediment in the short-term (4 weeks) removed 240\% more sediment than unpopulated controls. However, isopods and their burrows may affect lateral erosion in the longer term after burrows are 
created. These erosive effects may also be manifested at larger spatial scales as environmental factors (water movement) interact with the aggregations of burrows. The second component of my dissertation research used a mensurative field experiment to examine the association between burrows of $S$. quoianum between infested and uninfested marshes (100's meter scale) and between burrowed and unburrowed patches within infested marshes (cm-meter scale; Chapter 2: Accelerated erosion of saltmarshes infested by the non-native burrowing crustacean Sphaeroma quoianum).

Next, I examined the boring effects of $S$. quoianum in Styrofoam floats. Specifically, the third component of research described the boring effects of sphaeromatids to Styrofoam floats and the creation of microplastic pollution, reviewed where boring isopods damage floats in the world, and examined how different types of Styrofoam used in floats may affect burrowing and colonization by S. quoianum (Chapter 3: Boring crustaceans damage polystyrene floats under docks, polluting marine waters with microplastic). I further examined how those effects may be altered by changes in water temperature associated with climate change using a lab experiment (Chapter 4: Seawater temperature mediates the biological erosion by a non-native crustacean). In addition to temperature effects, a variety of other abiotic and biotic factors likely influence colonization, hence burrowing, by $S$. quoianum. I examined some of the other various factors that may influence colonization by individuals of $S$. quoianum using laboratory choice experiments (Chapter 5: Factors influencing the colonization of a nonnative bioeroding isopod (Sphaeroma quoianum). Finally, to determine how a tropical congener (Sphaeroma terebrans) affects mangrove habitats, I examined the relationship 
between isopod burrowing and mangrove damage, performance, and fecundity in a restored mangrove stand in Taiwan (Chapter 6: The destruction and alteration of mangroves infested by a wood-boring crustacean in a tropical mangrove stand in Taiwan). Together these chapters revealed the substantial ways boring isopods physically alter temperate and tropical wetlands and damage marine structures and elucidated some factors that affect their impacts in marine ecosystems. 


\section{Chapter 1: Per capita effects and burrow morphology of a burrowing isopod (Sphaeroma quoianum) in different estuarine substrata}

\section{Introduction}

Marine borers and burrowers can cause drastic alterations to the physical structure of marine substrata. Some of the most prodigious borers include the limnoriid (gribbles) and sphaeromatid isopods and teredinid bivalves (shipworms). These borers can reduce the integrity of wooden marine substrata (woody debris and marine timber) causing economic damages (Miller 1926, Hill and Kofoid 1927, Ray 1959, Cohen and Carlton 1995). For example, boring by the shipworm Teredo navalis and other wood borers in San Francisco Bay and New York harbor facilitated the collapse of docks (Miller 1926, Hill and Kofoid 1927, Cohen and Carlton 1995) causing millions of dollars of damage and repair costs. Piddocks and burrowing mussels also extensively modify the physical characteristics of friable rocks such as sandstone and chalk. For example, boring clams can remove up to $41 \%$ of the volume of chalk and clay bluffs during their lifespan (12 years; Pinn et al. 2005) or up to $12 \mathrm{~mm}$ of sandstone a year (Evans 1968). Burrowing by numerous species of crabs also can modify marsh and clay embankments. The extensive burrowing by grapsid crabs in saltmarshes of Argentina decreased shear strengths and increased erosion rates (Escapa et al. 2007). While most borers and burrowers inhabit only a single substratum type, burrowing sphaeromatid isopods can inhabit numerous substrata ranging from mangrove roots (Rehm and Humm 1973, Perry and Brusca 1989) 
to rock sea walls (Chilton 1919, Dharmaraj and Balakrishnan Nair 1982) and Styrofoam floats (Carlton 2001).

The burrowing isopod Sphaeroma quoianum (Milne Edwards 1840; native to Australia and New Zealand) is introduced to at least 15 estuaries on the Pacific coast of North America (Davidson 2008). Sphaeroma quoianum can burrow into numerous substrata, but is most often found in firm marsh banks (embankments composed of peat, mud, and clay), wood (decayed and non-decayed; treated and non-treated), friable rock (such as sandstone and mudstone bluffs and stones), and expanded polystyrene plastic floats (hereafter: Styrofoam; Davidson 2008). These isopods are filter feeders and they do not intentionally consume the material they excavate (Rotramel 1975). Dense aggregations of burrows of S. quoianum (many thousands per $\mathrm{m}^{3}$ of material) substantially weaken substrata (Hill and Kofoid 1927, Talley et al. 2001) and greatly increase the surface area exposed to erosion (pers obs) and the area available to other organisms to inhabit (Davidson et al. 2010).

The substrata affected by $S$. quoianum are valued by humans. Saltmarshes provide numerous ecosystem services (Mitsch and Gosselink 2003) and sandstone rock buffers shoreline erosion (Masselink and Hughes 2003). Non-decayed wood and Styrofoam floats are important components of docks and other marine infrastructure. Since these burrowers can cause economic damages and modify estuarine substrata and habitats, estimating the per capita burrowing rates of $S$. quoianum will help quantify their geomorphic effects on different estuarine substrata. My study seeks to determine how substratum type affects the length and volume of burrows created by S. quoianum and to 
quantify this per capita bioerosive effect using a lab experiment. I hypothesize isopods will create the longest and most voluminous burrows in soft marsh bank and Styrofoam substrata because these are softer than non-decayed wood and sandstone. My lab studies are supplemented by measurements of the morphology of burrows created by populations of $S$. quoianum in the field. Together these data will allow me to estimate per capita effects of burrowing and examine how burrows change the physical characteristics of four common estuarine substrata.

\section{Methods}

\section{Lab experiment}

I conducted a laboratory experiment to quantify the rate of bioerosion by $S$. quoianum on four substrata: marsh bank, non-decayed untreated wood, sandstone, and Styrofoam. Using a Latin square design, I placed 24 experimental units (6 replicates of 4 substrata) in a free flowing and aerated seawater table. To mimic field conditions whence populations of $S$. quoianum were collected, salinity was maintained at 28-33 PSU by adding freshwater, water temperature was maintained at $14^{\circ} \mathrm{C}$, and additional phytoplankton were added every two weeks for food. Animals were held in experimental conditions for 24 hours prior to experimentation.

I gathered samples of the four types of substrata from intertidal areas with populations of $S$. quoianum in Coos Bay, Oregon $\left(43^{\circ} 27^{\prime} 2.4^{\prime \prime} \mathrm{N}, 124^{\circ} 13^{\prime} 22.2^{\prime \prime} \mathrm{W}\right)$. The samples were all burrowed by $S$. quoianum, demonstrating the substrata I collected were 
capable of being altered by these isopods. I cut six replicate blocks from the unburrowed portions of each substratum and shaped these to a standard volume $\left(800 \mathrm{~cm}^{3}\right)$. Since marsh bank blocks could possibly harbor infauna, I defaunated them by freezing prior to experimentation (infauna were not detected in any substratum at the end of the experiment). Substrata were then placed into plastic containers and sealed so that only one side of the substratum was exposed $\left(\right.$ surface area $\left.=100 \mathrm{~cm}^{2}\right)$. I cut the marsh bank blocks slightly larger than the container and inserted them snugly into place, thus the blocks remained mostly compacted despite constant submersion. To ensure the containers were properly flushed with aerated water, mesh screens were added on the lids and two sides. Since $S$. quoianum is thigmotactic, ten small divots $(6.35 \times 6.35 \mathrm{~mm})$ were created on the surface of the blocks to prompt isopods to initiate burrowing. These divots greatly decreased the time it took for isopods to begin burrowing in preliminary experiments (Davidson unpublished data). Ten adult isopods (10-13 $\mathrm{mm}$ in length) were added to each enclosure and were left to burrow. I separated isopods into relative size categories (small, medium, large) and dispersed them among replicates so that all replicates received all sides evenly. I did not include the divots in my measurements if isopods did not burrow into them.

I ended the experiment after two months when I observed signs the edges of the marsh bank blocks were beginning to erode and increased mortality of the isopods (15$20 \%)$. The level of mortality did not significantly vary between substrata $(F=1.3, P=0.29)$ and thus is unlikely to have confounded the results. Because I could not determine when isopods died during the experiment, my per capita effects were estimated from 10 
isopods, thus these measurements may be underestimated in some instances. It is unlikely isopods would have created substantially larger or longer burrows after two months since in a 2-week field experiment (Davidson et al. 2008a), isopods had already created burrows half as long as my final measurements in this experiment for all four substrata (unpublished data).

This experiment examined bioerosion in subtidal conditions. While these four substrata can be found in permanently subtidal conditions, some substrata (marsh banks, for example) are found most often in intertidal conditions. Thus, my measurements of burrowing rate may be higher than what occurs in the field since burrowing may cease during low tide. However, individuals of $S$. quoianum are rapid and intermittent burrowers (Barrows 1919, pers obs); thus, it is unlikely that isopods exposed to the subtidal conditions of this two-month experiment would have yielded longer burrows than if they were exposed to intertidal conditions. Most populations of S. quoianum are intertidal, however, so I also measured burrows in the field and compared their substrataspecific lengths and volumes under both field and experimental conditions.

\section{Field sampling}

The morphology of burrows and burrowing effects of populations of S. quoianum were further examined by haphazardly collecting samples of burrowed substrata from the field during February 2011 from Coos Bay, Oregon. I collected six marsh blocks, nine pieces of woody debris, eleven sandstone rocks, and four pieces of Styrofoam float jetsam. Sample sizes of the substrata differed because samples fell apart or were 
unavailable in the field. I measured $14.41 \pm 2.66$ (mean $\pm 95 \% \mathrm{CI}$ ) burrows per substratum (423 burrows total) since some substrata failed to be properly casted or broke during processing (see below). Field burrow samples were collected from the same locations where I collected the substrata used in lab experiments. Since I could not collect samples from wooden marine structures that were lightly burrowed, my estimates of burrow morphology of wood were made from decayed and non-decayed woody debris.

\section{Measurements of burrow morphology}

The burrow morphology of both the experimental blocks and the field-collected samples was processed in the same fashion. I removed the isopods that were accessible without disturbing the burrow and then made wax (wood, sandstone or marsh) or plaster of Paris (Styrofoam) casts of the burrows. I broke apart the substratum carefully by hand or with a chisel and removed the casts. Occasionally the wax and plaster burrow casts were truncated from incomplete filling of the burrows by the casting material or by the presence of isopods that I had been unable to remove. When I observed incomplete casting, I also measured the distance from the incomplete burrow cast to the terminal end of the burrow and added it to the length total. Some irregularly shaped substrata samples were unable to be properly casted; in those circumstances, I measured the burrow length and diameter directly. Likewise, in field-collected samples, some burrows were connected to other burrows forming side chambers or burrow complexes. In these instances, I considered burrows distinct from each other when they split from a central burrow and/or exhibited a change in diameter (suggesting a differently sized isopod 
extended the burrow). I measured the diameter of the burrows at the middle of the burrow or burrow cast. Since the burrows are vermiform in shape, the volume was calculated based on the volume of a cylinder plus the volume of one-half a sphere (to represent the tapered end of the burrow). Surface area was measured by completely covering intact burrow casts in aluminum foil. This foil was then removed and carefully flattened. I photographed the flattened foil covers with known size references and used ImageJ (version1.43u) photoanalysis software to estimate surface area.

\section{Data analysis}

Differences in the mean burrow length, diameter, volume and total volume removed per isopod (per capita) were analyzed using nested ANOVA. When a significant

difference was detected, I used the Tukey HSD test for pairwise contrasts. I examined the association between surface area, diameter, and length using Pearson's correlations. Model assumptions were visually evaluated using boxplots and frequency histograms; as necessary, the data were log-, square-root, or cube-root-transformed to meet model assumptions and to reduce the influence of outliers. I used Kruskal Wallis tests (with Behrens-Fisher nonparametric multiple comparisons tests) when transformations failed to normalize the data. 


\section{Results}

\section{Lab experiment}

Isopods burrowed in all four substrata. I detected significant differences in the mean burrow length $\left(F_{3,20}=30.3, P<0.001\right)$ and burrow volume $\left(F_{3,20}=45.7, P<0.001\right)$ and the per capita total volume removed $\left(F_{3,20}=40.9, P<0.001\right)$ by individuals of $S$. quoianum between the four substrata (Figure 1.1). The mean burrow length and mean volume removed by $S$. quoianum were greatest in marsh bank followed in descending order by Styrofoam, sandstone, and non-decayed wood. Isopods created burrows that averaged between 2.5 to 15 times greater than their mean body volume in marsh (x $15.2 \pm$ 2.3; mean $\pm 95 \%$ CI), Styrofoam (x $8.9 \pm 0.9$ ), sandstone (x $6.2 \pm 2.2$ ), and wood (x $2.5 \pm$ 0.39).

In some replicates, isopods created multiple burrows. The number of burrows created differed between substrata (Figure 1.1, $H=11.9$, df $=3, P=0.008$ ): marsh bank substrata harbored the most burrows at the end of the experiment but was only significantly greater than wood $(P=0.001$; other treatment differences: $P>0.05)$. Individuals made more than one burrow each in five of the six replicate marsh blocks and in one sandstone block. Individual isopods were found outside of burrows in five of the wood blocks (and one marsh bank block) and were found sharing burrows with another isopod in one Styrofoam block. 


\section{Field sampling}

The mean length and volume of burrows in the field-collected marsh bank and Styrofoam samples were greater than sandstone and wood samples (Figure 1.2), but I only detected a significant difference in the mean length of burrows $\left(F_{3,26}=3.06\right.$, $P=0.046$; volume: $\left.F_{3,26}=2.95, P=0.051\right)$. The pairwise contrasts revealed that burrows in marsh bank were significantly longer than sandstone burrows $(P=0.038$, all other contrasts $P>0.05)$. The mean burrow diameter did not differ between substrata $\left(F_{3,26}=0.83, P=0.49\right)$. The mean diameters $( \pm 95 \% \mathrm{CI})$ of marsh bank, Styrofoam, sandstone, and wood burrows were $5.87 \pm 0.63,6.16 \pm 0.86,5.44 \pm 0.48$ and $5.66 \pm 0.47$ mm, respectively. 

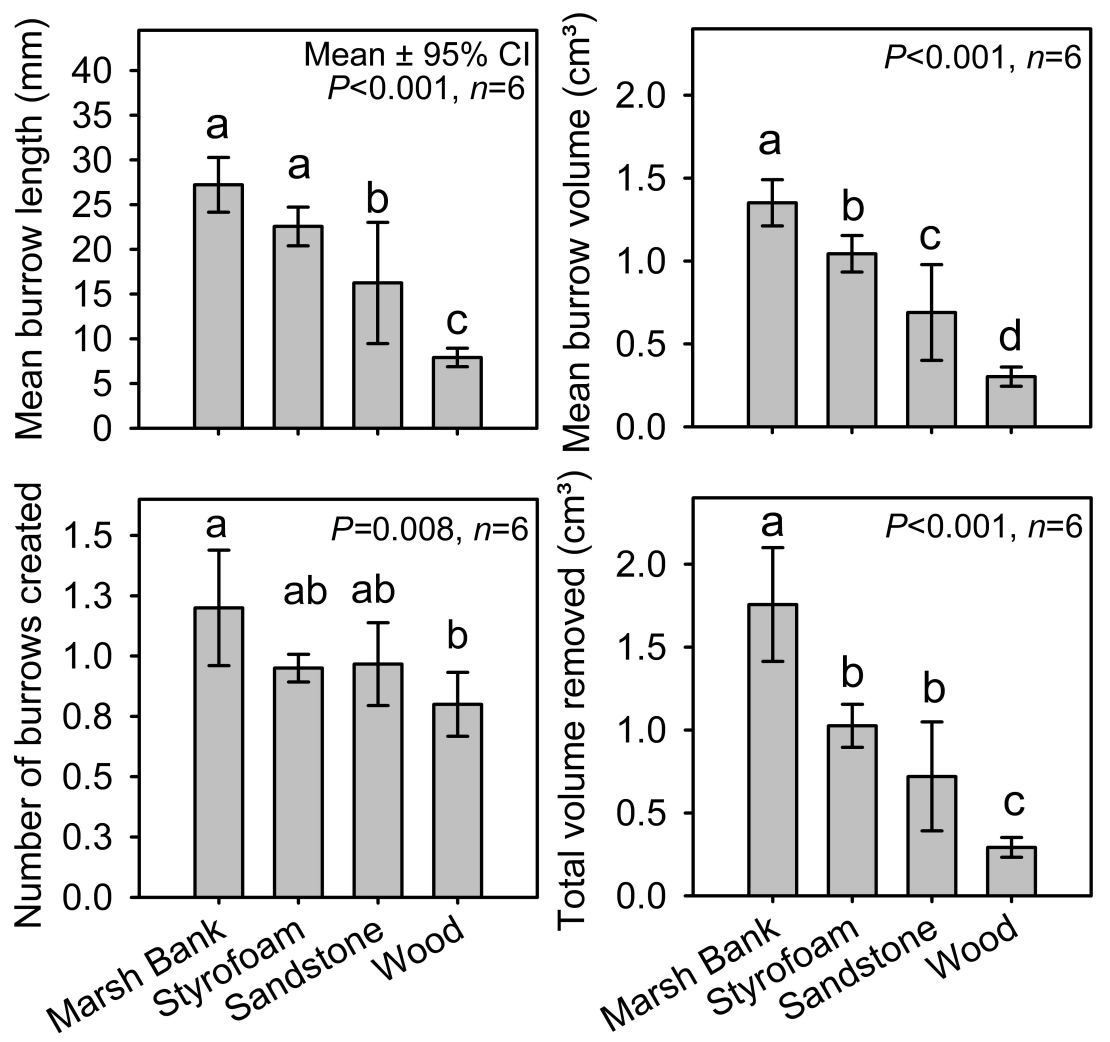

Figure 1.1. The mean burrow length and volume, per capita number of burrows created by individuals of Sphaeroma quoianum, and total volume removed per isopod, for each of four substrata after two months in the lab. Statistically significant differences between treatment levels are denoted by different letters. 

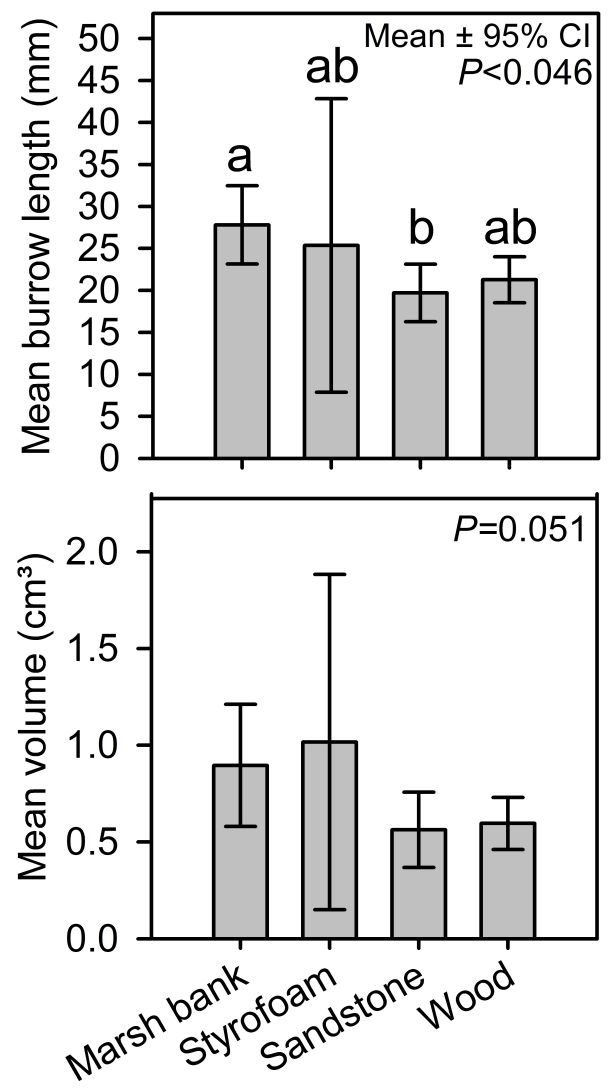

Figure 1.2. The mean burrow length and volume of burrows of Sphaeroma quoianum in four substrata collected in the field. Measurements are from six marsh bank, nine woody debris, eleven sandstone, and four Styrofoam samples. Statistically significant differences between treatment levels are denoted by different letters.

General observations of burrow morphology and associations

All of the individual burrows observed were vermiform in shape. I detected a positive linear relationship between burrow diameter and length $\left(r^{2}=0.36, \mathrm{df}=421, t=15.3\right.$, $P<0.001)$; larger isopods burrowed deeper into the substratum. The burrows ranged between 2.15-77.4 $\mathrm{mm}$ in length and 1.9-10.35 $\mathrm{mm}$ in width. Most burrows went straight into the substratum and did not change directions; however, long burrows created in 
Styrofoam and marsh bank substrata could be sinuous. These longer burrows often connected with other burrows forming interconnected burrow galleries in Styrofoam and marsh bank substrata.

The surface area and length of burrows were also positively correlated $\left(r^{2}=0.90\right.$, $\mathrm{df}=97, t=29.53, P<0.001, y=30.35 x-7.85)$. For each $1 \mathrm{~mm}$ of length added to a burrow, the surface area increased by $22.50 \mathrm{~mm}^{2}$. By comparing the area of the burrow's aperture (which would be the surface area if the burrow were not present) to the surface area of the burrow, I could also calculate the percent increase in surface area of a substratum due to burrows of S. quoianum. The percent change in surface area (through the creation of burrows) increased by $328.46 \%$ for each $1 \mathrm{~mm}$ of length added. The percent change in surface area was also positively correlated to the length of burrows $\left(r^{2}=0.79, \mathrm{df}=97, t=18.89, P<0.001, y=57.95 x-270.5\right)$.

\section{Discussion}

The burrowing effects of $S$. quoianum were greater in the marsh bank and Styrofoam substrata than the harder sandstone and wood substrata in both laboratory and field studies. In the laboratory, S. quoianum created the longest and most voluminous burrows and removed the most material per capita in marsh bank and Styrofoam substrata. Isopods also created multiple burrows in marsh bank blocks, which indicates that isopods will abandon existing burrows to create new ones in that substratum. It is unclear why isopods did not create multiple burrows in the soft Styrofoam substrata; it 
may be due to the greater stability of Styrofoam relative to marsh bank or the lack of microhabitat differences within the block. Marsh bank substratum is dynamic and constantly being altered through tidal action and other factors (Gabet 1998). Abandoned burrows within this substratum are often deformed and showing signs of collapse (pers obs), which suggests isopods must maintain burrows in marsh banks or create new ones. Potentially, microhabitat differences within the marsh bank substratum, such as the presence of infauna, may also cause an isopod to abandon a burrow. Similar to my laboratory results, burrows of $S$. quoianum measured from samples collected in the field were also longer and more voluminous in marsh banks and Styrofoam floats than in sandstone and woody debris; however, I did not detect a statistical difference between substratum type and volume due to high variation. The high variation exhibited in fieldcollected data likely results from the variable environmental conditions under which burrowing occurred, the greater variation in the physical characteristics (hardness, for example) of the substrata collected, and the greater size range of isopod borers. Due to the high per capita effects of burrowing on marsh and Styrofoam substrata, I predict these two substrata will be most affected by $S$. quoianum in other estuaries.

Burrowing by $S$. quoianum physically alters numerous intertidal and subtidal substrata. While burrows are typically shallow (around 2-3 cm long; this study, Talley et al. 2001) and small $\left(<1 \mathrm{~cm}^{3}\right)$, populations of this isopod occur in high densities creating anastomizing burrow networks at the surface of substrata. This burrowing effect reduces the density of the substratum, makes the substratum more prone to shear (Talley et al. 2001) or collapse (pers obs), and increases the surface area exposed to erosion. I found 
even small changes in burrow depth substantially increased the exposed surface area of a substratum. The increase in surface area may concomitantly increase the level of erosion that acts on that substratum (as hypothesized by Davidson and de Rivera 2010) or increase the availability of space for other organisms to inhabit (Davidson et al. 2010). The relative hardness of the substratum likely affects burrowing by S. quoianum and may explain why burrowing effects were greater in the softer marsh bank and Styrofoam substrata. Bioerosion by numerous taxa, including crustaceans, gastropods, and bivalves, is depressed in harder substrata (McLean 1967, Pinn et al. 2005, Cragg et al. 2007). Similarly, the congeneric burrowing isopod S. terebrans prefers to attack areas of hard wood that already exhibit signs of damage or are softer (Estevez and Simon 1975, Santhakumari 1991).

My results, combined with earlier studies, suggest that all four substrata are affected by S. quoianum. While the wood and sandstone substrata support higher densities of burrows and isopods than saltmarsh bank (Davidson et al. 2010), I found these isopods exert much higher per capita effects on the saltmarsh habitat (and Styrofoam floats) under subtidal conditions. The high per capita effects on these soft substrata are concordant with both field experiments examining the erosion by $S$. quoianum in marshes (Talley et al. 2001, Davidson and de Rivera 2010) and observations and measurements of the burrowing impact of S. quoianum on Styrofoam floating docks (Davidson 2008, Chapter 3). In field experiments, marsh banks burrowed by S. quoianum eroded between 240\% (Talley et al. 2001) and 300\% (Davidson and de Rivera 2010) faster than unburrowed controls and reference areas. Similarly, non-decayed wooden 
structures exhibit little burrowing damage and rarely harbor populations of isopods in the field (Hill and Kofoid 1927, pers obs). Scaling up the results from my lab study, I estimate a population of 100,000 adult isopods (density of a heavily infested Styrofoam float or cubic meter of marsh bank) could, in two months, remove approximately 176 liters of marsh bank, 1031 of submerged Styrofoam, 721 of sandstone, and 291 of nondecayed wood.

A variety of marine borers and burrowers can be found in marsh banks, woody debris, and sandstone in the intertidal and shallow subtidal regions of Coos Bay and other temperate estuaries, but $S$. quoianum appears to be the most common bioeroder detected (pers obs). Other bioeroders can excavate a higher per capita volume of substrata across their lifetime or at a higher rate than $S$. quoianum (between $0.15-0.88 \mathrm{~cm}^{3} / \mathrm{month}$, depending on substratum, Figure 1.1). For example, the pholad Penitella penita bores at rate of $1.15 \mathrm{~cm}^{3} /$ month and $10.39 \mathrm{~cm}^{3} /$ lifetime in sandstone (Haderlie 1981) and the shipworm Bankia setacea bores at a rate of $2.7 \mathrm{~cm}^{3} /$ month and $48.6 \mathrm{~cm}^{3} /$ lifetime in wood (Haderlie and Mellor 1973). Additionally, some borers create longer burrows than $S$. quoianum (between 0.40-1.36 cm/month, depending on substratum, Figure 1.1). Estimates of the mean boring rate of the shipworm Teredo navalis vary between 2.11 $\mathrm{cm} / \mathrm{month}$ (calculated from Hill and Kofoid 1927) and $2.71 \mathrm{~cm} / \mathrm{month}$ (calculated from Scheltema and Truitt 1956). While other bioeroders may have greater per capita rates, they do not appear as prevalent or dense as S. quoianum; nor do they appear across the same breadth of intertidal to shallow subtidal habitats (Davidson 2008, Davidson et al. 2010). The breadth of habitats $S$. quoianum can occupy coupled with high densities and 
wide distributions suggest their modest boring activity can have a substantial cumulative effect on numerous marine substrata. 


\section{Chapter 2: Accelerated erosion of saltmarshes infested by the non-native burrowing crustacean Sphaeroma quoianum}

\section{Introduction}

When the rate of erosion outpaces accretion, nearshore habitats can be greatly altered and in extreme cases, even be converted from one habitat to another (Redfield 1972, Semeniuk 1980, Hutchings 1986). In northwest Australia, high rates of erosion converted dense mangrove forest to tidal flats (Semeniuk 1980). Similarly, bioerosion can exceed coral growth and eventually degrade entire reefs into rubble and sand (Hutchings 1986). Grazing by prolific populations of littorine snails combined with climate stressors in the Gulf of Mexico caused an expansive die-off of saltmarshes and consequent conversion to mudflats (Silliman et al. 2005). While erosion and accretion are natural cyclic processes in tidal marshes (reviewed by Singh Chauhan 2009), anthropogenic changes (e.g. hydrology, land use, sediment load, etc) and the translocation of non-native burrowing species may accelerate erosion of saltmarshes (Talley et al. 2001, Masselink and Hughes 2003, Soomere 2005).

Lateral erosion in saltmarshes is influenced by numerous factors. Abiotic processes are typically regarded as primary drivers of erosion in many systems (Grant 1983, Butler 1995, Widdows and Brinsely 2002). Rainfall (Pilditch et al. 2008), sediment characteristics (water, organic and sand content; Meadows and Tait 1989, Feagin et al. 2009), water velocity (Sgro et al. 2005), and size and direction of tidal prism (Redfield 1972), all strongly influence the rate of erosion. Biotic agents, however, can also 
substantially influence erosion rates, particularly burrowers/bioturbators, consumers, or biostabilizers (Belanger and Bedard 1994, Butler 1995, Widdows et al. 2000, Paramor and Hughes 2004, Jefferies et al. 2006, Escapa et al. 2007).

Burrowers/bioturbators and consumers both can greatly increase the rate of erosion of marshes. Fauna directly reduce the stability of the sediment and accelerate erosion through trampling, burrowing, bioturbation, or other forms of physical disturbance (Dionne 1985, Talley et al. 2001, Escapa et al. 2007). Burrowing by the crab Chasmagnathus granulatus decreases sediment shear strength and increases the erosion rate of saltmarshes in Argentina (Escapa et al. 2007). Dionne (1985) observed extensive marsh erosion from trampling and foraging by geese in Quebec. Furthermore, bioturbation by increasing densities of Manila clams resulted in an exponential increase of sediment erosion in flume experiments (Sgro et al. 2005). Herbivores indirectly accelerate erosion by reducing the abundances of sediment biostabilizers. For example, herbivory and bioturbation by the polychaeate Nereis diversicolor reduces the abundance of marsh plants leading to increased erosion in marshes (Paramor and Hughes 2004). The presence of the diatom-grazing amphipod Corophium volutator significantly decreases sediment shear strength (Gerdol and Hughes 1994) and increases erosion rates (Widdows et al. 2009) in marsh sediment.

On the Pacific coast of North America, over 93\% of salt marshes have been lost to human activities (Bromberg Gedan and Silliman 2009). The introduction of the nonnative burrowing isopod (Sphaeroma quoianum) on the Pacific coast adds yet another stressor to the remaining saltmarshes. Sphaeroma quoianum was first introduced to San 
Francisco Bay, California in the Gold Rush era from its native habitat of Australia and New Zealand (Rotramel 1972, Carlton 1979). This temperate wood-boring isopod then spread through ship fouling or boring (Carlton 1979) to at least 14 other estuaries on the Pacific coast of North America from Baja California to Yaquina Bay, Oregon (Davidson 2008). In many marshes, isopods perforate marsh banks with burrows and increased densities may increase rates of erosion (Carlton 1979, Talley et al. 2001); however, in its native range of Australia, Sphaeroma quoianum does not appear to inhabit marsh banks in high densities and its erosive effects are likely limited (Davidson et al. 2008). Lateral erosion rates are high in locations infested by S. quoianum (Carlton 1979, Talley et al. 2001, Davidson 2008), but uninfested locations were not available to isolate the isopod effects from the other factors affecting erosion. Since numerous factors may confound or obscure the effect of burrowing by $S$. quoianum on erosion, it is not surprising that other studies did not detect a relationship between burrows/isopod densities and erosion rate (Bane 2002) or detected relationships only at certain times or locations (Talley et al. 2001). A short-term (4 week) transplantation experiment, however, revealed that the initial excavation of burrows by $S$. quoianum could increase sediment removal by $240 \%$ compared to controls (Talley et al. 2001), but longer-term testing of mechanisms and these associations is still needed.

Populations of isopods have extensively invaded the saltmarshes of Coos Bay, Oregon (USA), but perhaps since it is a relatively new invasion (discovered in 1995, Carlton 1996), isopods occur in patchy distributions both between marshes and within infested marshes. I build on the earlier studies by measuring erosion in and among the 
discrete isopod aggregations in Coos Bay. This natural "experiment" with different levels of infestation within and between marshes helps isolate the effects of burrowing by isopods from the other factors affecting erosion rates. To examine the relationship between the presence of populations of isopods and lateral erosion rates in the field, I conducted a field study at two scales. This research seeks to quantify the erosive impact of burrows between infested and uninfested saltmarshes (10-100's of meter scale) and between burrowed and unburrowed areas within infested marshes (cm-meter scale). Within infested marshes, burrows can completely cover marsh banks (near 100\% cover) but often burrows appear in patchy distributions. I hypothesized that 1) marsh sites infested by populations of Sphaeroma quoianum will experience more erosion than uninfested marsh sites, and 2) within infested marsh sites, areas with patches of burrows will erode faster than areas without burrows. Hence, the results of this research will elucidate the effects of a non-native burrowing crustacean on critical estuarine habitat and, more broadly, will identify whether and to what extent relatively small, yet densely aggregated infauna can influence erosion in marshes.

\section{Materials and Methods}

I examined the relationship between burrows of Sphaeroma quoianum and lateral erosion rate of marsh banks (embankments composed of mud, clay and/or peat) in sites infested with populations of $S$. quoianum (hereafter: infested sites, $n=13$ ) and sites without substantial populations (e.g., percent cover of burrows <5\%) of S. quoianum (hereafter: uninfested sites, $n=12)$ in Coos Bay, Oregon (43.41605, -124.21878). I 
define sites as stretches of marsh banks $50 \mathrm{~m}$ in length and separated from other sites by at least $150 \mathrm{~m}$, but often much more (except two sites were only $85 \mathrm{~m}$ apart from each other). Experimental sites were selected haphazardly based on accessibility and presence (infested) or absence (uninfested) of isopods in a variety of marshes in the Coos Bay estuary (including one uninfested site in the South Slough National Estuarine Research Reserve). Some uninfested sites were visited but not selected because they visibly differed in site attributes from the infested sites (e.g., sloping marshes lacking a vertical bank). Both types of sites spanned the entire Coos Bay estuary, including tidal creeks, bay fronts, and sloughs and ranged across 5 to 32 PSU.

I examined erosion in marsh sites by measuring lateral erosion over one year and by measuring indicators of bank erosion and transformation (Figure 2.1). In each infested site, I inserted 20 erosion pins (wire pins, $53.3 \mathrm{~cm}$ long) into marsh banks perpendicular to the bank. Half of the pins (10) were randomly placed in burrowed areas ('areas' are subsets of infested sites; mean $\pm 95 \%$ CI: $18 \pm 2$ burrows $100 \mathrm{~cm}^{-2}$ ) and half were randomly placed in adjacent unburrowed areas (mean $\pm 95 \%$ CI: $0.40 \pm 0.21$ burrows $100 \mathrm{~cm}^{-2}$ ). Each unburrowed pin was paired with a burrowed pin within approximately one meter and placed at similar tidal heights. Ten erosion pins were planted per uninfested site to compare erosion rates between infested and uninfested sites. After one year, I returned and measured the length of the exposed section of the erosion pin. I also counted the number of burrows within a six $\mathrm{cm}$ radius from the erosion pins to determine burrow density and estimated burrow percent cover at ten randomly placed quadrats $\left(0.25 \mathrm{~m}^{2}\right)$ in each site. 
In both infested and uninfested sites, I also estimated the amount of lateral erosion by placing onshore reference stakes $1.25 \mathrm{~m}$ from the marsh edge in ten random locations per site (thus 10 measurements per site). The change in the distance between the stakes and marsh edge were measured after one year to estimate erosion rate. I also determined the maximum undercutting of the marsh bank in ten random locations in each site at the end of the experiment. Undercutting was measured by holding a pole perpendicular (vertical) to the marsh edge and measuring the maximum horizontal distance between the pole and the bank. In some sites, the banks sloped at the bottom so I measured the distance from the bottom of the slope to the marsh edge (thus representing negative undercutting). In all sites, I counted the number of slumped and calved marsh bank sections following erosion monitoring.

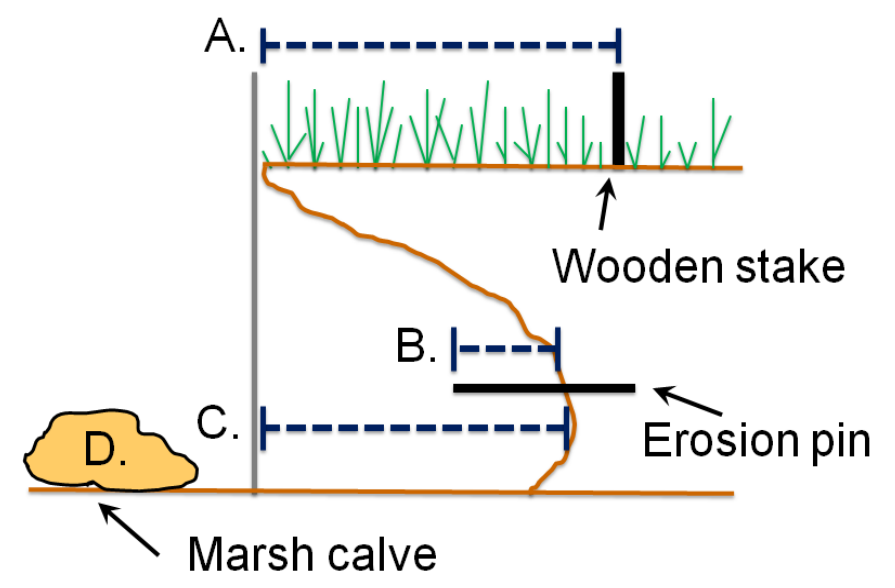

Figure 2.1. Methods used to measure lateral erosion and indicators of bank erosion and transformation in marsh sites (side view). A. Distance (taken initially and at the end) between wooden stake reference markers and the edge of the marsh (denoted by a gray line perpendicular to the marsh) over one year, B. change of distance between the end of an erosion pin and marsh bank over one year, C. maximum distance between the marsh edge and marsh bank, and D. the number of marsh calves and slumped sections present at the end of the experiment. 
I collected sediment cores to compare the percentages of water, sand, and organic matter between infested and uninfested sites and between burrowed and unburrowed areas (where erosion pins were planted). I also recorded characteristics of the site including the relative amount of water movement (by measuring the dissolution of calcium-sulfate clod cards), slope of the marsh bank, and the height of the marsh at each site (from top of the marsh to sediment below the bank). While I was unable to measure the tidal height of each erosion pin, I placed erosion pins in burrowed and unburrowed areas at various heights in the bank so my initial placement of the erosion pins did not exhibit a systematic difference in tidal height across treatments (burrowed vs. unburrowed areas). The overlying vegetation was also identified.

\section{Statistical Analyses}

I tested for a difference in the erosion rate (both pins and stakes), maximum undercutting, and the number of slumped and calved marsh sections between infested and uninfested sites using a two sample t-test, Welch's t-test (heteroscedastic data), or MannWhitney test (when transformations failed to normalize the data) using the mean values from the 10 subsamples measured within site. The sediment (\% water, $\%$ organic, $\%$ sand) and other site characteristics (burrow density, \% cover burrows, relative water movement, slope of the bank, marsh height) between infested and uninfested sites and between burrowed and unburrowed area (within infested sites) were tested in the same fashion. Since my erosion data sometimes included negative values (representing accretion or a sloped bank), I added the minimum values to the respective dataset to 
allow transformation $[\sqrt{ } \mathrm{x}$ or $\log (\mathrm{x})]$. I used a two-way ANOVA to test if the mean erosion rate in burrowed and unburrowed areas differed (Treatment factor, fixed) and if the mean erosion rate differed between infested sites (Site factor, random). Assumptions of all statistical tests were visually evaluated using boxplots, QQ-plots, and frequency histograms. Transformations failed to normalize the data and eliminate heteroscedacity between burrowed and unburrowed erosion rates, so I analyzed the raw data and relied on the robustness of ANOVA to account for the minor violations (Underwood 1981). Relationships between the sediment characteristics and the burrow density, water flow, and erosion rate were examined using Pearson correlations or Spearman's rank correlations. Degrees of freedom for my statistical tests varied due to the loss of erosion pins and stakes during the experiment.

\section{Results}

Erosion in infested versus uninfested marsh sites

Three of four measures of erosion were significantly higher in saltmarsh sites infested by populations of Sphaeroma quoianum than in uninfested marsh sites (Figure 2.2). Infested sites exhibited higher mean erosion rates as measured by erosion pins, higher mean undercutting values, and more evidence of marsh failure/breakage (more slumped and calved areas of marshes) than uninfested marshes. Infested sites had higher, but not significantly higher, erosion rates than uninfested sites when erosion was measured by onshore reference stakes (Figure 2.2B). Estimates of erosion measured from stakes were highly variable and likely require longer-term deployment for effects to be 
detected. Erosion rates may also have been underestimated due to the loss of stakes when large sections of marsh failed. Maximum rates of erosion in infested areas and uninfested areas were 165.37 and $64.52 \mathrm{~mm}$ (erosion pins), 97.5 and $67.0 \mathrm{~cm}$ (stakes), 85 and $56 \mathrm{~cm}$ (undercutting), and 57 and 28 (number of slumps and calves).

Lateral erosion was also positively correlated with burrow densities, whether erosion was measured by erosion pins $\left(r^{2}=0.37, t_{23}=3.7, P=0.001\right)$, undercutting $\left(r^{2}=0.50, t_{23}=4.8, P<0.001\right)$, or the number of slumps and calves $\left(r^{2}=0.23, t_{23}=2.6, P=0.01\right)$ in marshes. However, I did not detect a significant correlation between burrow density and erosion measured through reference stakes $\left(r^{2}=0.12, t_{22}=1.71, P=0.10\right)$. 
A. Erosion measured by pins

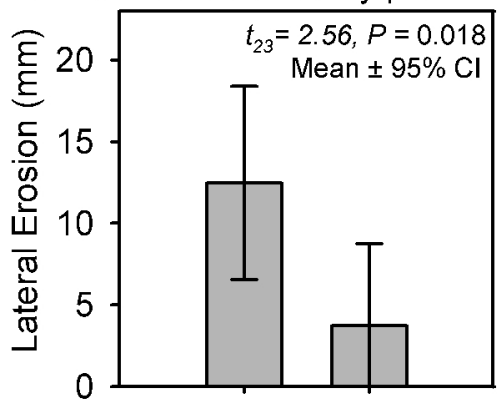

C. Maximum undercutting

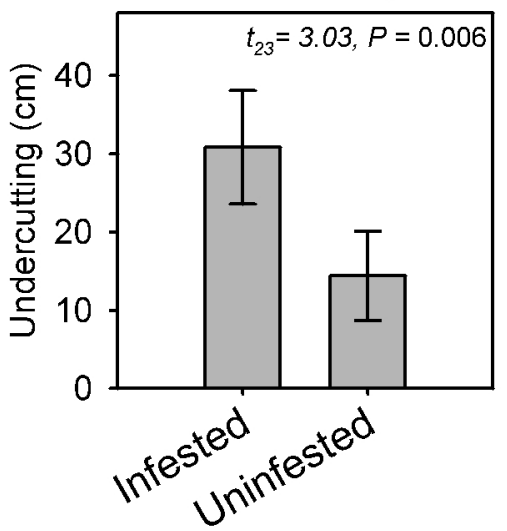

B. Erosion measured by stakes

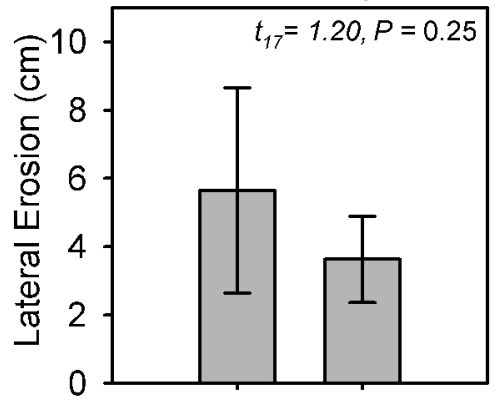

D. Marsh Failure

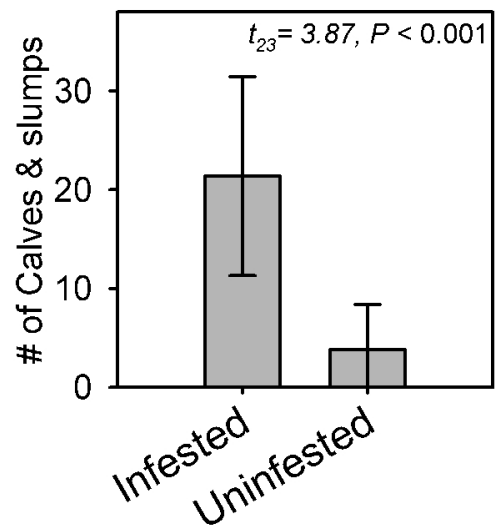

Figure 2.2. Lateral saltmarsh erosion measured by A. erosion pins, B. onshore reference markers (wooden stakes), C. maximum undercutting and D. marsh failure in marshes infested versus uninfested by populations of the burrowing isopod Sphaeroma quoianum. Bars show mean $\pm 95 \% \mathrm{CI} ; \mathrm{n}=13$ for infested sites, 12 for uninfested sites. Degrees of freedom varied due to the use of different analyses: two-sample t-test (A, C, D) or Welch's two-sample t-test (B).

\section{Erosion in burrowed versus adjacent unburrowed areas of infested marshes}

Within infested marshes, the mean lateral erosion rate was three times greater in burrowed areas than adjacent unburrowed areas $\left(F_{1,12}=33.08, P<0.001\right.$, Figure 2.3).

Maximum erosion in burrowed and unburrowed areas was 165.37 and $79.08 \mathrm{~mm}$, respectively. The rate of erosion also varied between sites $\left(F_{1,12}=5.6, P<0.001\right)$ but the 
effect of burrows was consistent across all sites (Treatment*Site interaction, $\left.F_{12,208}=1.0, P=0.45\right)$. Lateral erosion and burrow density were also positively correlated $\left(\mathrm{r}^{2}=0.50, t_{24}=4.9, P<0.001\right)$ within infested sites. The estimates of erosion were likely conservative since some pins were lost in the sites when large sections of marsh bank collapsed. In addition, isopods colonized or increased burrow density in $22.2 \%$ of the unburrowed areas I monitored, which suggests many of the unburrowed habitats examined are suitable for isopods.

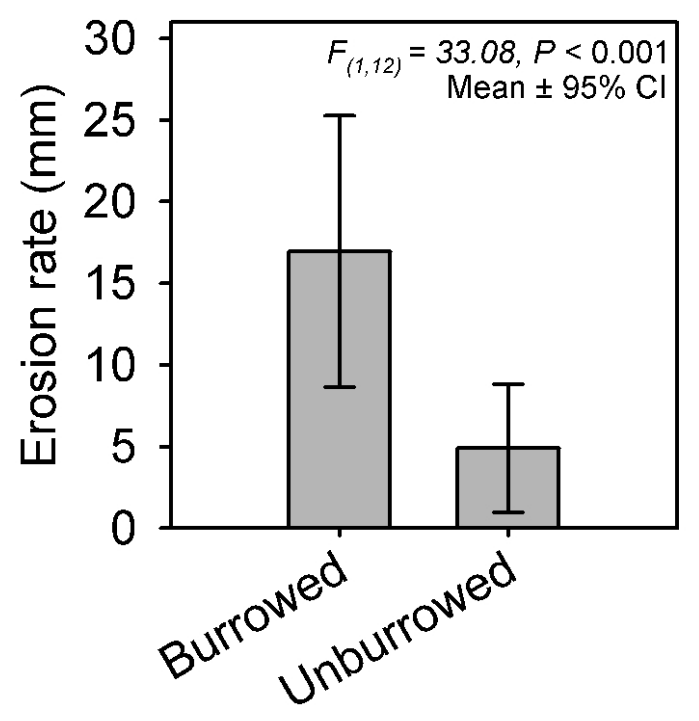

Figure 2.3. Lateral erosion (measured by paired erosion pins) in burrowed and unburrowed areas within marsh banks infested by Sphaeroma quoianum. Bars show means $\pm 95 \% \mathrm{CI} ; \mathrm{n}=13$.

\section{Habitat characteristics}

In addition to erosion rates, infested and uninfested marshes differed significantly in burrow densities and \% cover and in the mean height of the marshes (Table 2.1). The other measured factors (\% water, $\%$ organics, $\%$ sand, slope, and water movement) have 
similar values and I did not detect a significant difference in those factors between infested and uninfested sites. The mean percentage of sand in uninfested marsh sediment was higher than infested marshes but was also highly variable across sites. Similarly, the other sediment characteristics and slope of the marsh bank in burrowed areas did not significantly differ from unburrowed areas (Table 2.1). The vegetation type did not vary consistently between sites; most sites were dominated by Salicornia virginica and Carex lyngbyei. Other marsh plants and algae were present in varying densities including Deschampsia caespitosa, Distichlis spicata, Jaumea carnosa, Scirpus sp., Ulva sp. and Fucus gardneri. 
Table 2.1. Site and sediment characteristics between sites infested and uninfested by populations of Sphaeroma quoianum and burrowed and unburrowed areas within infested sites. Values are presented as means $\pm 95 \%$ confidence intervals. Bolded text denotes statistically significant differences between means.

\begin{tabular}{|c|c|c|c|c|c|c|}
\hline & \multicolumn{2}{|c|}{ Sites } & \multicolumn{4}{|c|}{ Areas within infested sites } \\
\hline & Infested & Uninfested & & Burrowed & Unburrowed & \\
\hline $\begin{array}{l}\text { Burrow } \\
\text { density } \\
\left(\# / 0.25 \mathrm{~m}^{2}\right)\end{array}$ & $194.5 \pm 29.6$ & $5.8 \pm 6.1$ & $\begin{array}{l}W=156 \\
P<0.001\end{array}$ & $365.5 \pm 52.8$ & $27.0 \pm 14.2$ & $\begin{array}{c}W=169 \\
P<0.001\end{array}$ \\
\hline $\begin{array}{l}\text { \% cover } \\
\text { Burrows }\end{array}$ & $43.9 \pm 7.7$ & $1.4 \pm 1.5$ & $\begin{array}{l}W=144 \\
P<0.001\end{array}$ & - & - & - \\
\hline$\%$ water & $53.5 \pm 2.9$ & $52.5 \pm 5.0$ & $\begin{array}{c}t_{23}=0.33 \\
P=0.74\end{array}$ & $53.7 \pm 3.0$ & $53.2 \pm 3.1$ & $\begin{aligned} t_{24} & =0.21 \\
P & =0.84\end{aligned}$ \\
\hline$\%$ organics & $11.0 \pm 1.4$ & $10.4 \pm 1.6$ & $\begin{array}{c}t_{23}=0.61 \\
P=0.55\end{array}$ & $11.4 \pm 1.5$ & $10.7 \pm 1.5$ & $\begin{aligned} t_{24} & =0.66 \\
P & =0.52\end{aligned}$ \\
\hline$\%$ sand & $6.3 \pm 2.5$ & $23.3 \pm 14.9$ & $\begin{aligned} t_{11} & =-1.04^{\mathrm{a}} \\
P & =0.32\end{aligned}$ & $5.5 \pm 2.8$ & $7.0 \pm 3.5$ & $\begin{aligned} t_{2 l} & =-0.71, \\
P & =0.48\end{aligned}$ \\
\hline Slope $\left({ }^{\circ}\right)^{\mathrm{b}}$ & $94.2 \pm 2.4$ & $91.9 \pm 1.8$ & $\begin{array}{l}W=107 \\
P=0.12\end{array}$ & $92.9 \pm 2.1$ & $95.4 \pm 3.4$ & $\begin{array}{c}W=63.5 \\
P=0.29\end{array}$ \\
\hline $\begin{array}{l}\text { Water } \\
\text { movement }\end{array}$ & $4.2 \pm 1.1$ & $3.7 \pm 1.1$ & $\begin{array}{c}t_{23}=1.01 \\
P=0.32\end{array}$ & - & - & - \\
\hline $\begin{array}{l}\text { Marsh } \\
\text { height (m) }\end{array}$ & $1.3 \pm 0.3$ & $0.7 \pm 0.2$ & $\begin{array}{c}t_{23}=3.83 \\
P<0.001\end{array}$ & - & - & - \\
\hline
\end{tabular}

Footnotes:

${ }^{a}$ Results from Welch two-sample t-test

${ }^{\mathrm{b}}$ vertical banks are $90^{\circ}$, banks greater than $90^{\circ}$ represent undercut banks, banks less than $90^{\circ}$ represent sloped banks

${ }^{\mathrm{c}}$ Water movement measured by the dissolution of calcium sulfate blocks (in grams lost per 24 hours) 


\section{Discussion}

The physical modification of substrata by animals can alter the structure and function of many marine habitats. These physical effects are especially acute in habitats where dense aggregations of animals, such as burrowers, erode substrata. In Coos Bay, Oregon, I demonstrated that the saltmarshes infested by populations of the non-native burrowing isopod Sphaeroma quoianum experience higher rates of erosion, are more undercut, and experienced more slumping and calving than uninfested marsh sites. While burrowing animals that create larger burrows have been associated directly with erosion and shoreline loss, for example Chinese mitten crabs (Dutton and Conroy 1998), grapsid crabs (Escapa et al. 2007), and beavers, nutria, and other mammals (Butler 1995, Linscombe and Kinler 1997, Meyer 2006), my study suggests that small burrowing organisms, when in dense aggregations, can also accelerate erosion and have appreciable physical effects to saltmarshes. Studies have also documented the physical effects of dense aggregations of small fauna to other wetland habitats. In simulated tidal flats, increasing densities of small Manila clams (Venerupis philippinarum, $30 \mathrm{~mm}$ ) and mud snails (Hydrobia ulvae, 2-4.5 mm) caused an exponential increase in sediment erosion (Sgro et al. 2005, Orvain et al. 2006). Feeding by swarms of mysids also promote sediment suspension and erosion (Roast et al. 2004). Similarly, prodigious burrowing by aggregations of small sphaeromatid isopods in mangroves destroys the aerial roots used to stabilize the trees and alters their morphology (Rehm and Humm 1973, Brooks and Bell 2002). Thus, aggregations of small burrowers and bioturbators can have substantial 
erosive effects to wetland habitats; the loss of which could negatively affect the many species that depend on wetlands for food and refuge (Boesch and Turner 1984).

While the initial excavation of burrows removes a relatively small volume of the outer areas of marshes (Talley et al. 2001, Davidson and de Rivera, in press), the increase in surface area from the creation of burrows may make infested sites more prone to other erosive forces, such as tidal action. Previous experiments revealed that low densities of isopods ( 1 isopod $10 \mathrm{~cm}^{-2}$ ) removed between $2.7-4.3 \%$ of the outer $5 \mathrm{~cm}$ of marsh sediment in under 2 months (modified from Davidson and de Rivera, in press) and similar to Talley et al. (2001), burrows of Sphaeroma quoianum occupied 3-15\% of the outer $5 \mathrm{~cm}$ of sediment in burrowed areas of San Diego Bay. The creation of burrows, however, also substantially increases the exposed surface area of marsh banks: each burrow increases the mean $( \pm 95 \% \mathrm{CI})$ surface area by $1,579 \pm 149 \%$ (burrow opening: $0.51 \pm 0.03 \mathrm{~cm}$ vs. total burrow surface area: $7.5 \pm 0.82 \mathrm{~cm}$; Davidson, unpublished). This increase in surface area of marsh exposed to additional erosive forces plus the active flushing of the burrows by isopods likely facilitate the removal of additional sediment through tidal action and decreases the shear strength of the bank (Talley et al. 2001). As the infested banks become more perforated by additional recruitment of isopods and as the interior of the preexisting burrows are continuously washed away, the marsh bank is weakened and experiences more lateral erosion and undercutting. Eventually, the bank collapses when the undercut portion succumbs to gravity (Redfield 1972, Gabet 1998) leading to the characteristic slumped and calved sections of marsh present in many sites infested by S. quoianum (Carlton 1979, Talley et al. 2001). 
The positive association between burrows of Sphaeroma quoianum and erosion were also consistent across both spatial scales - between marsh sites (10's-100's meters) and within infested sites (cm's-m scale). This suggests that isopod burrowing may have a direct localized erosive effect ( $\mathrm{cm}-\mathrm{m}$ scale) but also that their erosive effects on a small scale may contribute indirectly to erosion on larger scales by facilitating wave and tidally-induced erosion. Within infested sites, even small patches of burrows experienced lateral erosion rates 300\% higher than adjacent unburrowed areas. My results are consistent with results from Talley et al. (2001) who showed that densely burrowed areas exhibited lower sediment shear strengths and more undercutting. They also found isopods in experimental enclosures could remove up to $240 \%$ more sediment than unpopulated controls. My experiment continues to examine this association between isopod burrows and erosion rate by following the initial erosive effect of excavating burrows in marsh banks and by contrasting these results to unburrowed areas and sites in numerous estuarine locations. These results suggest that the erosive effects continue after the isopod establishes its burrow.

While my study design is mensurative, it is replicated across a variety of locations within the Coos Bay estuary, and my results are consistent with anecdotal observations from other Pacific coast estuaries (Talley et al. 2001, Davidson 2008). I did not detect systematic differences between infested and uninfested sites, except infested marsh sites were typically taller than uninfested marsh sites. This may have two potential confounding effects: taller marshes might have more available space for isopods and harbor more isopods or taller marshes may have more area exposed to erosive forces. I 
recognize additional unmeasured factors may also affect erosion rate. The additional factors that affect erosion likely caused the high observed variability in erosion between the sites. By also examining the effect of burrows on erosion rate with a meter or less scale, I attempted to separate the effect of burrows from the other factors that affect erosion in an estuary. However, even if unmeasured factors affected the results, it is highly unlikely that those factors varied consistently across all measured sites and measured locations within sites. Thus, it appears unlikely an unmeasured factor could consistently confound my results within $\mathrm{cm}$ scales. An alternative hypothesis for my results could be that isopods colonize areas that already exhibit high rates of erosion. That hypothesis seems unlikely because: 1) during the course of the study isopods colonized several of the previously unburrowed areas that served as my reference areas, 2) maintaining a burrow in dynamic areas with high erosion would require constant attention and be energetically expensive, and 3) isopods can suffer mortality when weak, unstable areas erode, collapse, or slump (pers obs). Isopods, like other burrowing crustaceans, appear to prefer burrowing in more solid sediments (Jones and Simon 1982, Wang et al. 2009, pers obs). In addition, the perceived benefits of settling in high erosional environments (increased flushing of wastes, food) are likely not as important for a filter feeder that constantly exchanges the water that enters and leaves the burrow (Rotramel 1975). Thus, I hypothesize that isopods will preferentially colonize substrata that are stable and not prone to collapse. Future studies should examine the factors that affect colonization by this non-native species. 
Saltmarshes are dynamic habitats prone to cyclic patterns of erosion and accretion (Redfield 1972, Gabet 1998, Singh Chauhan 2009). However, anthropogenic changes in hydrology, land use, sediment load, and other factors can accelerate erosion rates and alter the physical characteristics of these habitats. My study adds to previous studies on the biotic sources of erosion, further suggesting that small burrowing or bioturbating species can also be substantial agents of change in saltmarsh habitats. While human actions that alter wetlands are now closely regulated, the potential erosive impacts of bioeroding and bioturbating species, such as Sphaeroma quoianum, remain unmeasured and largely ignored. The widespread invasion of S. quoianum in Pacific coast estuaries and lack of effective management for this non-native species suggests that the small percentage of intact saltmarshes on the Pacific coast remain prone to erosion. 


\section{Chapter 3: Boring crustaceans damage polystyrene floats under docks, polluting marine waters with microplastic}

\section{Introduction}

Marine borers can cause substantial damage to marine structures. The most extensive and costly damage occurs in wooden structures by teredinid bivalves (shipworms) and isopod crustaceans (Neily 1927, Cragg et al. 1999). For example, the non-native shipworm Teredo navalis destroyed the timber pilings and supports causing nearly 50 structures to collapse into San Francisco Bay and causing $\$ 615$ million in damages (Miller 1926, Neily 1927, Cohen and Carlton 1995). Crustacean borers are also very destructive (Hill and Kofoid 1927, Cookson 1986, Cragg et al. 1999), especially in Australia where timber replacement costs from marine borers are around \$20 million per year (presumably in 1986 AUD dollars; Cookson 1986). Moreover, borers can attack non-wooden structures as well, such as rock sea walls (Chilton 1919), concrete structures (Kofoid and Miller 1927), and even steel support beams (Irwin 1953).

Burrowing sphaeromatid isopods (native to the Indo and West Pacific; Carlton and Iverson 1981, Harrison and Holdich 1984, Carlton and Ruckelshaus 1997) bore into numerous substrata used in marine structures and facilities in temperate and tropical regions (Chilton 1919, Kofoid and Miller 1927, Carlton 1979). These borers are especially destructive to expanded polystyrene floats (commonly known as Styrofoam) used in many docks. Densely clustered colonies of isopods perforate the submerged surface of the float and appear to reduce its functionality. While burrows are initially 
often shallow (less than $30 \mathrm{~mm}$ deep, and rarely exceeding $60 \mathrm{~mm}$; Perry and Brusca 1989, Talley et al. 2001, Davidson and de Rivera, in press), subsequent generations and colonizers may extend and/or build from old burrows, creating an interconnected burrow network (as described by Thiel 1999, Talley et al. 2001). This extensive network substantially reduces the density of the outer $60 \mathrm{~mm}$ of the float, making the foam noticeably weaker and more susceptible to breakage. As the outer surface is removed, additional area of the float becomes vulnerable to attack. Boring sphaeromatid isopods are filter feeders that excavate burrows for habitat (Rotramel 1975, Si et al. 2002); therefore, any consumption of excavated material is likely incidental (Rotramel 1975, Messana et al. 1994, Si et al. 2002).

Minute plastic particles are created through the boring process of polystyrene floats by S. quoianum (Carlton, Chang, and Wells, unpublished, as cited in Carlton and Ruiz 2005), S. terebrans, and S. peruvianum (pers obs). Like other microplastics (defined as $<5 \mathrm{~mm}$ in diameter, Arthur et al. 2009) in the marine environment, these particles may have detrimental effects to marine organisms (Carpenter et al. 1972, Gregory 1996, Thompson et al. 2004). Plastics persist for hundreds to thousands of years in normal oceanic conditions (Barnes et al. 2009). Also, polystyrene fragments and other minute plastics in the marine environment are readily colonized by biofilm and other organisms causing them to sink (Ye and Andrady 1991, Barnes 2002, Gregory 2009). Thus, these particles may interact with benthic (Thompson et al. 2004, Graham and Thompson 2009) and pelagic organisms (Carpenter et al. 1972, Boerger et al. 2010, Davison and Asch 2011). Ingested microplastics may cause both toxicological effects by transmitting 
bioaccumulating toxins such as persistent organic pollutants (Mato et al. 2001, Teuton et al. 2009) and physical effects by occluding feeding structures or inducing a false indication of satiation.

The damage caused by boring isopods to polystyrene floats under floating docks can result in economic costs and contribute to microplastic pollution. In this paper, I report observations of the destructive effects of boring isopods on foam floats, quantify the density of burrows and individuals in floats, and discuss the morphology and ecological implications of the plastic particles created through the boring process. Furthermore, I present results of an experiment examining how different polystyrene float types may prevent damage by borers. Together these observations, surveys, and experimental results reveal (a) damaging effects of non-native and native borers on the floatation in docks, (b) how a non-native species contributes to microplastic pollution, and (c) approaches to reduce these effects in the many bays that harbor populations of boring isopods.

\section{Methods}

Observations of isopods attacking floats

I conducted shoreline surveys in Yaquina Bay, Oregon, USA, and in Budai Township and Tainan, Taiwan. I examined: (a) the high tide lines for polystyrene flotsam and (b) docks and marinas in intertidal and shallow subtidal areas for damaged polystyrene floats, noting also populations of Sphaeroma sp. occurring in adjacent substrata. I focused on areas with salinity between 5-31 PSU, where boring isopod 
populations are most often found (Davidson 2008, Davidson et al. 2008, unpublished data). Polystyrene floats and flotsam were considered burrowed by sphaeromatids if they harbored living or dead individuals in their burrows or exhibited burrows consistent with the burrow morphology exhibited by sphaeromatid isopods: i) vermiform burrows with smooth walls, ii) circular diameters between $2-10 \mathrm{~mm}$, and iii) up to $77 \mathrm{~mm}$ deep, and iv) mostly straight without abrupt changes in direction (Barrows 1919, Talley et al. 2001, Davidson and de Rivera, in press). To my knowledge, no other boring organism creates burrows consistent with this morphology. The closest organisms with a similar morphology are some shipworms; however, their burrows often exhibit ribbed patterns on the burrow walls and often have small remnants of calcareous shell (Turner 1966).

Mean density of individuals and burrows of S. quoianum in expanded polystyrene flotsam

Between February 2005 and May 2006, I collected samples of the burrowed expanded polystyrene floating dock flotsam encountered during surveys of Coos Bay ( $n=18$ pieces). For each piece, I haphazardly placed a $10 \times 10 \mathrm{~cm}$ quadrat in the burrowed area of the float and photographed it. The number of quadrats photographed varied concomitantly with the size of the expanded polystyrene flotsam found. I used one quadrat to estimate the burrow density of small pieces (30-60 cm long) and between 6-50 quadrats for larger pieces (entire floats $>60-100 \mathrm{~cm}$ long). I used digital analysis software, ImageJ version $1.49 \mathrm{u}$, to count the total numbers of burrows per quadrat. I deployed burrowed, expanded polystyrene float mimics in Coos Bay, Oregon for one year (2005-2006) to provide an estimate for how many isopods inhabit expanded 
polystyrene floats. The float mimics were constructed of a burrowed expanded polystyrene float found in the field (devoid of isopods). Blocks were cut to $10 \times 10 \times 8$ cm (length, width, depth). Each block was surrounded in polyethylene tape exposing only the burrowed $100 \mathrm{~cm}^{2}$ face. Burrow densities in these mimics were $64.2 \pm 2.3$ burrows per $100 \mathrm{~cm}^{2}$ (mean $\pm 95 \% \mathrm{CI}$ ). The blocks were affixed facing downwards to weighted PVC tubing and placed around a length of rebar planted into the ground. The weighted PVC tube kept the orientation of the blocks pointing downward while allowing the floats to move up and down with the tide. I deployed these expanded polystyrene dock mimics in six different locations with salinity between 10-31 PSU in Coos Bay, Oregon.

Quantity and morphology of the plastic particles created during boring by S. quoianum I conducted a lab experiment to quantify the numbers of particles created by $S$. quoianum during the boring process (methodology described in detail in Chapter 4). I placed a small colony of 20 adult isopods (7-12 mm in length) from Coos Bay, Oregon inside a cage with an expanded polystyrene foam block $\left(800 \mathrm{~cm}^{3}\right)$ with one exposed surface $\left(100 \mathrm{~cm}^{2}\right)$. I then submerged the cage in a closed aerated aquarium at a temperature $\left(12.3^{\circ} \mathrm{C}\right)$ similar to the mean temperature of Coos Bay $\left(12.77^{\circ} \mathrm{C}\right.$, NOAA 2011) and allowed them to burrow for two months. At the end of the experiment, I measured the burrow characteristics (mean length, volume) and collected the plastic particles by discharging the aquarium water through a $63 \mu \mathrm{m}$ sieve. The particles were placed on a gridded paper filter $\left(1 \mathrm{~cm}^{2}\right.$ grid $)$ and agitated to help homogenize the distribution of particles on the grid. I counted the total number of grid squares occupied 
by plastic particles and then randomly selected five subsamples $\left(1 \mathrm{~cm}^{2}\right.$ squares $)$ to be photographed using a digital camera. The numbers of particles in each square subsample were counted using digital analysis software. I calculated the total number of particles created by 20 isopods by multiplying the mean number of particles per subsample $\left(1 \mathrm{~cm}^{2}\right)$ by the total number of squares occupied by plastic particles.

To examine the morphology of the particles, I collected particles from aquaria where adult individuals of S. quoianum (7-12 $\mathrm{mm}$ long) had burrowed into a block of expanded polystyrene. The plastic particles and surrounding water were haphazardly collected from aquarium water and placed on a microscope slide. Then I photographed the particles using a digital camera attached to a light microscope (with a calibrated scale bar). Image analysis and preprocessing were completed using ImageJ. Images were preprocessed using the Sharpen and Find Edges functions to make the main body of the particle more conspicuous. I measured the area (as measured by ImageJ), perimeter, longest axis (length), and the widest axis (orthogonal to the longest axis, width) of each of 200 particles and calculated the equivalent circular diameter $\left(\mathrm{ECD}=\sqrt{\frac{4}{\pi} \cdot \text { Area }}\right.$; Spurles et al. 1998, Russ 2007). The ECD standardizes irregular objects to a standard circle to allow comparisons of objects of variable shape and orientation (Russ 2007). All measurements were recorded from the areas of the particles that were solid and opaque; the many light, short, diaphanous plastic threads exuding from most sides were not included in measurements. 
The effects of polystyrene float type on colonization by a non-native boring isopod

Using a Latin square design, I tested how three different types of polystyrene floats were affected by $S$. quoianum. I affixed one block of polystyrene $(5 \times 6 \times 12 \mathrm{~cm})$ vertically per cylindrical microcosm $(946 \mathrm{ml})$. The treatments were: a) expanded polystyrene (EPS; $n=23)$, b) extruded polystyrene (XPS; $n=22$ ), or c) expanded polystyrene encapsulated with a damaged polyethylene cover (encapsulated EPS; four $\mathrm{cm}$ single tear at the bottom, mimicking wear and tear of encapsulation material exposed to boats and floating debris, $n=23$ ). Thin polyethylene encapsulation sheeting was often used to encapsulate floats in floating docks in Coos Bay and other Pacific coast estuaries (pers obs). While the use of encapsulation material over foam is mandatory in Oregon for new installations (Oregon Administrative Rule 250-014-0030), many docks do not use it or the material is degraded and torn (pers obs). I filled each microcosm with saltwater (25 PSU) and periodically added phytoplankton, their primary food source in nature (Rotramel 1975), for sustenance. Since S. quoianum exhibits thigmotaxis, I created a small divot in the bottom of each block to prompt isopods to start burrowing. One adult isopod between 7-12 $\mathrm{mm}$ in length was then added to each microcosm and allowed to burrow for 24 days. I recorded if the isopod was burrowing, not burrowing, moribund, or dead each day for 15 days. I also recorded the status on days 19 and 24 (the last day of the experiment).

I tested if total number of isopods that burrowed in a block differed among treatments using a chi-square test (with 10,000 randomizations). The differences in total burrow length and burrow use (the percent of the time isopods were present in burrows 
they created) between EPS and encapsulated EPS treatments were analyzed using MannWhitney tests since transformations failed to normalize the data. Statistical analysis of the XPS treatment data was unnecessary as no burrowing was observed.

\section{Results}

Damage to the dock floats of aquaculture facilities and marinas by sphaeromatid isopods

I observed damage from dense colonies of boring isopods to aquaculture facilities in Yaquina Bay, Oregon, USA and Tainan, Taiwan. In Yaquina Bay, Oregon, colonies of the non-native isopod $S$. quoianum damaged the expanded polystyrene floats used by an aquaculture facility to raise oysters. Repair of the docks required removing around 60 heavily riddled floats (each $~ 1 \mathrm{~m}$ long; Figure 3.1A-C). Some floats still harbored dead isopods. The outer surface of many of the floats had become eroded, vacuous, and easily ablated by touching the surface. The attack was so intense in some floats that it reduced the normally rectangular shaped float to a t-shaped cross-section (Figure 3.1B).

I observed similar patterns in Tainan, Taiwan; fifteen floats removed from an adjacent aquaculture facility were found onshore and heavily riddled with isopod burrows (Figure 3.1D-F). In Taiwan, the native isopod S. terebrans was likely responsible for the damage since this species was abundant in the mangroves lining the pond. 

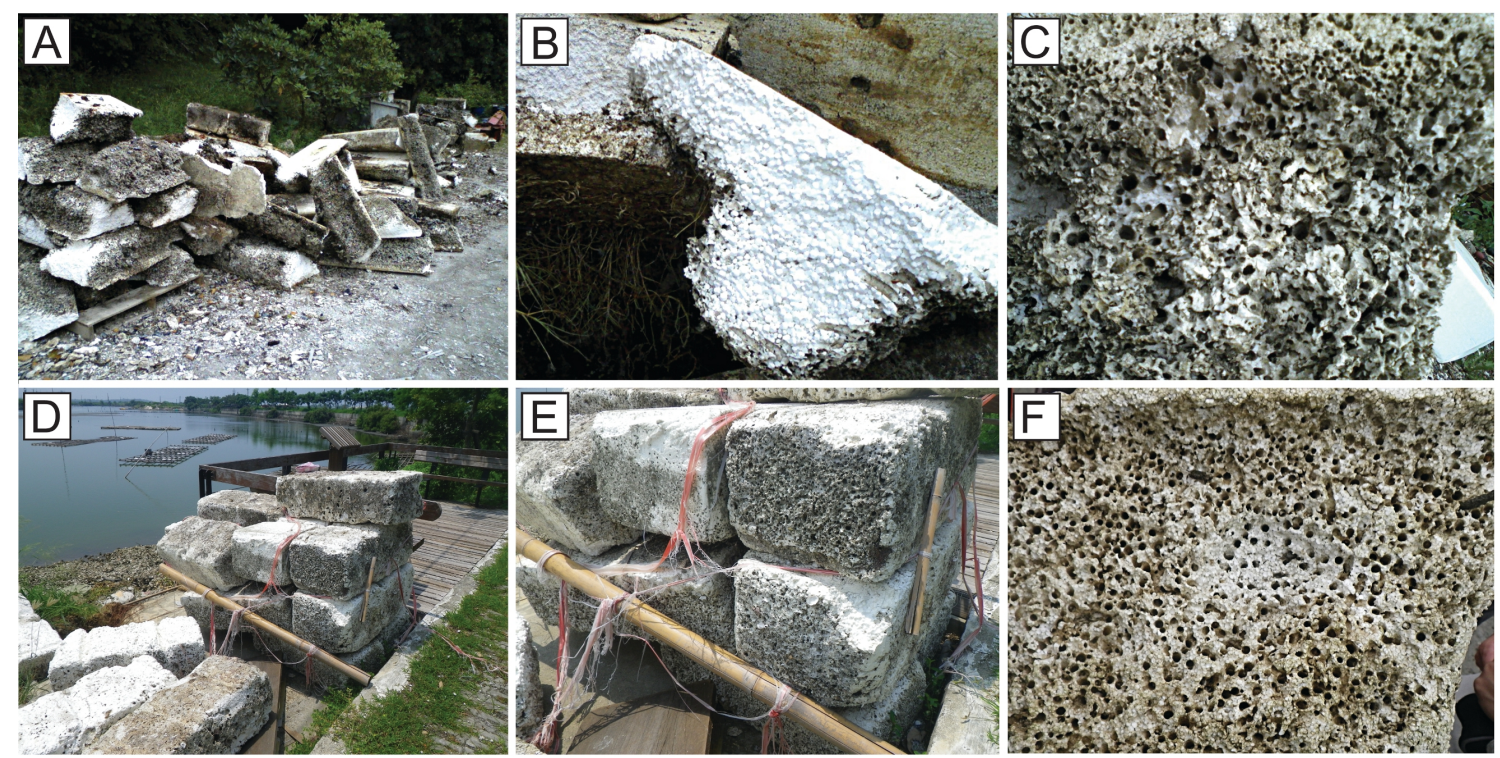

Figure 3.1. Extensive burrowing by populations of boring isopods damaged the polystyrene floats in the docks used by aquaculture facilities in (A-C) Yaquina Bay, Oregon, USA (Sphaeroma quoianum; 7/15/2007) and (D-F) Tainan, Taiwan (presumably Sphaeroma terebrans; $8 / 5 / 2010$ ). The floats in A and D were approximately $1 \mathrm{~m}$ and $2 \mathrm{~m}$ in length, respectively. Images in $\mathrm{C}$ and $\mathrm{F}$ are at differing scales, but the burrows pictured in these images are similar in size $(8-10 \mathrm{~mm})$.

In addition to the above observations of isopods impacting these aquaculture facilities, field surveys revealed the presence of heavily burrowed foam flotsam or floats in Yaquina Bay and several sites in Taiwan. Five out of six sites in Yaquina Bay with foam flotsam or exposed floats accessible for examination were damaged by isopods. Burrowed floats were also observed in Taiwanese sites including flotsam in Kinmen Island (presumably washed ashore from neighboring Xiamen, mainland China), and two burrowed floats each in Budai Township and Tainan.

Burrows and isopods were also found in high densities in expanded polystyrene 
foam flotsam and in float mimics. The foam collected from Coos Bay harbored thousands of burrows of S. quoianum per square meter (Table 3.1). Similarly, isopods were found in high densities in the experimental float mimics.

Table 3.1. Mean, maximum, and minimum of densities of burrows and isopods (Sphaeroma quoianum) collected from expanded polystyrene floats $(n=18$; burrow densities) and float mimics ( $\mathrm{n}=6$; isopod densities) in Coos Bay, Oregon.

\begin{tabular}{lccc}
\hline Density & Mean $( \pm 95 \%$ Cl) & Max & Min \\
\hline Burrows per $\mathrm{m}^{2}$ & $7,875( \pm 1,687)$ & 25,000 & 2,400 \\
Burrows per float $^{\mathrm{a}}$ & $23,413( \pm 5,016)$ & 74,322 & 7,134 \\
Isopods $^{\mathrm{b}}$ per $\mathrm{m}^{2}$ & $14,900( \pm 7,576)$ & 32,000 & 2,400 \\
Isopods per float & $44,296( \pm 22,523)$ & 95,133 & 7,135 \\
\hline
\end{tabular}

Footnotes:

${ }^{\text {a }}$ Calculations were based on a float with the following dimensions: $244 \times 122 \times 46 \mathrm{~cm}$; surface area $\sim 3 \mathrm{~m}^{2}$ assuming the outer $6 \mathrm{~cm}$ was vulnerable to burrowing damage.

${ }^{\mathrm{b}}$ Isopod densities are based on the colonization of the outer $6 \mathrm{~cm}$ of expanded polystyrene float mimics $(n$ =6) deployed for one year.

Quantity and morphology of the microplastic created by S. quoianum

Twenty individuals of $S$. quoianum created over 45,505 plastic particles when excavating 16 burrows (total length of all burrows $=241.2 \mathrm{~mm}$ ). This equates to over 2,844 plastic particles from a burrow an average of $15.1 \mathrm{~mm}$ long. The plastic particles created by S. quoianum were variable and irregular in shape (Figure 3.2). Most of the plastic particles were roughly globular or rectangular in shape and lined with fine strands; others were highly irregular. The mean maximum length of the particles was $464.6 \mu \mathrm{m}$ and mean maximum width (orthogonal to the maximum length) was $283.0 \mu \mathrm{m}$ (Figure 3.3). The mean ECD was $255.1 \mu \mathrm{m}$. The mean perimeter-area ratio was 0.033 , which 
was $\sim 200 \%$ higher than a similar-sized circle (diameter $=255 \mu \mathrm{m}$, perimeter-area ratio= 0.016). While the histograms of the morphological characteristics were centered around the means described above, they were skewed to the right due to a few high values (Figure 3.3).
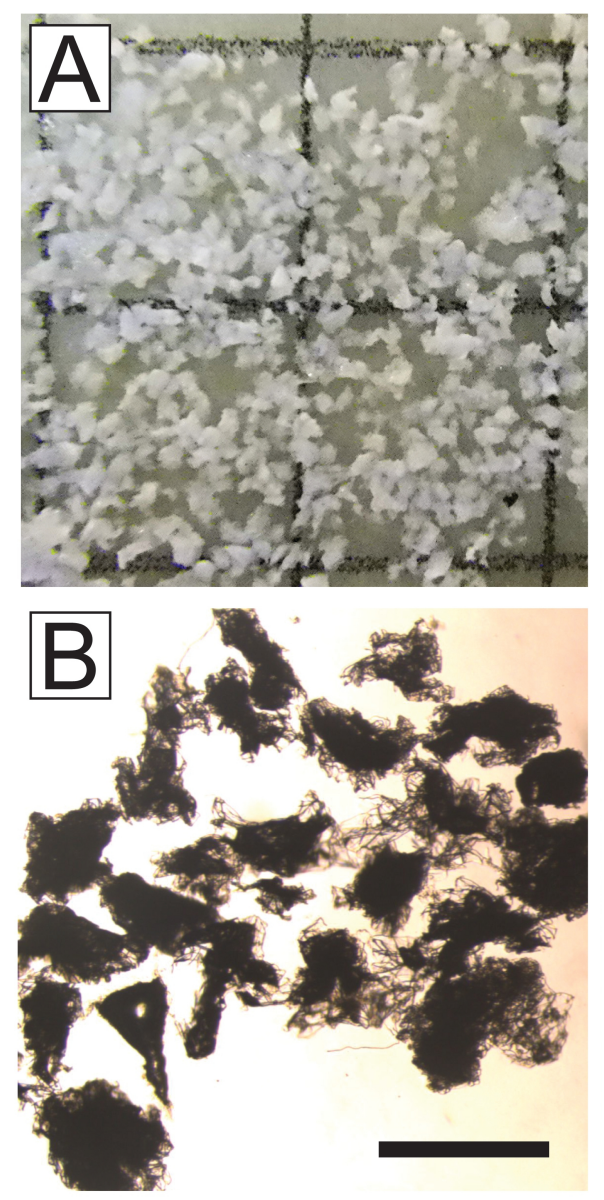

Figure 3.2. Microscope images of the plastic particles created by Sphaeroma quoianum during the burrowing process into expanded polystyrene floats. The images are shown at two magnifications: (A) Each square in the image is $0.25 \mathrm{~cm}^{2}$. (B) The scale bar in this image is 500 microns. 

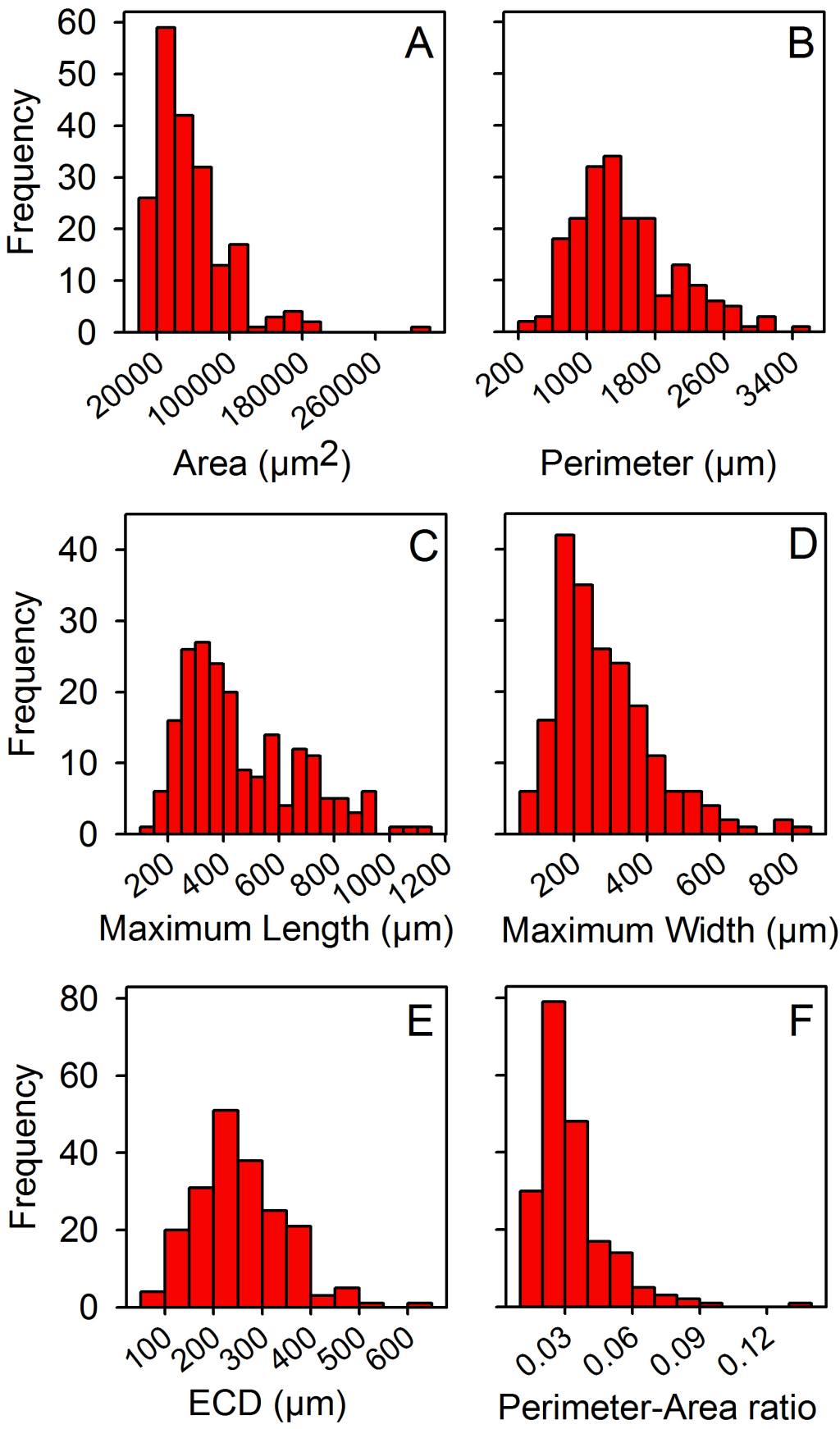

Figure 3.3. Frequency histograms of the (A) area, (B) perimeter, (C) maximum length, (D) maximum width (orthogonal to the length measurement), (E) equivalent circular diameter (ECD) and (F) perimeter-area ratio of the microplastic particles created during burrowing by Sphaeroma quoianum in expanded polystyrene floats $(n=200)$. 
The effects of polystyrene float type on colonization by a non-native boring isopod

The type of polystyrene float affected the frequency of burrowing, burrow length, and burrow use by S. quoianum. Isopods burrowed more often in expanded polystyrene (10 of 23 floats were burrowed, 43.5\%) than damaged encapsulated expanded

polystyrene $(7 / 23,30.4 \%)$ and extruded polystyrene $\left(0 / 22,0 \% ; \chi^{2}=10.3, \mathrm{df}=2, P=0.006\right)$. There was no difference in the frequency of burrowing between EPS and damaged encapsulated EPS $\left(\chi^{2}=0.89, \mathrm{df}=1, P=0.35\right.$ ). Isopods did not burrow into (hence did not use burrows) in the extruded foam treatment. While the expanded polystyrene had greater values in all measures than the encapsulated treatment, mean burrow length $( \pm \mathrm{SE})$ was not significantly greater in the EPS (3.23 \pm 0.76$)$ than in the damaged encapsulated EPS (2.21 $\pm 0.76 ; U=311, P=0.26$ ). Likewise, isopods did not use burrows significantly more in the EPS (13.52 \pm 4.13$)$ than the encapsulated EPS $(9.14 \pm 3.57 ; U=318, P=0.19)$.

\section{Discussion}

Damage to foam floats in aquaculture facilities and marinas by boring isopods

Expanded polystyrene flotsam damaged by boring isopod was encountered during field surveys and by numerous other authors implying many locations are suffering damage from burrowing sphaeromatids (Figure 3.4, Table 3.2). Dense colonies of boring isopods attacked the floats used in aquaculture facilities in Yaquina Bay, Oregon, USA and Tainan, Taiwan, forcing the replacement of floats and incurring economic costs. The damage made the floats noticeably weaker and vacuous; the outermost surface was easily removed by hand. Given such a weakened surface, additional damage may occur to 
heavily burrowed floats when they are scoured by water movement or abraded with debris. Similar patterns have been reported from Coos Bay and San Francisco, California (Davidson 2008, Carlton, per comm, Cohen and Carlton 1995) with non-native populations of S. quoianum. During surveys of Coos Bay, I discovered a ten-meter section of an abandoned dock riddled with burrows (Davidson 2008) and another dock in a state of disrepair with the exposed floats burrowed by isopods (pers obs). Likewise, a tugboat terminal in Coos Bay was abandoned when severe burrowing by isopods rendered it virtually inoperable (Carlton, per comm). While my previous study reported polystyrene foam (Styrofoam) was rarely inhabited compared to other substrata (Davidson 2008), few docks accessible to examination were available and thus may reflect low sampling effort. Four out of five surveyed docks with exposed floats exhibited burrowing damage consistent with S. quoianum (unpublished data from Davidson 2008). Furthermore, Cohen and Carlton (1995) report the dock floats in marinas of San Francisco Bay were frequently riddled by $S$. quoianum. This report is consistent with accounts by Rotramel (1971, per comm) who first observed extensive damage by $S$. quoianum in floating docks at Berkeley Marina (San Francisco, CA) in 1966. Damage to floats under docks was also noted in Moss Landing Harbor in 1998 (Elkhorn Slough, CA; Wasson, per comm). 


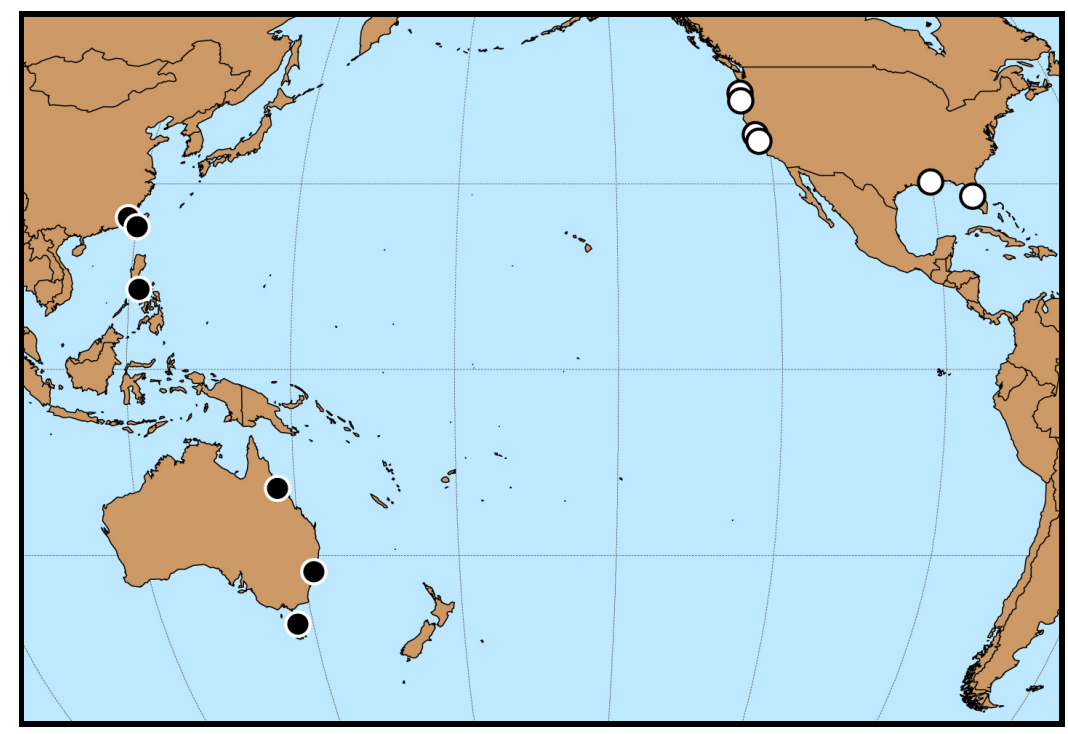

Figure 3.4. Global occurrences of boring isopod damage to expanded polystyrene floats. The open circles in North America represent areas with known damage from non-native sphaeromatid isopods. The closed circles in Asia and Australia denote areas damaged by native populations. See Table 3.2 for details.

The boring damage on polystyrene floats was so extensive due to the very high densities of burrows in the floats. The burrow densities in float flotsam and float mimics exceeded many thousands per exposed square meter of foam. These values were greater than the densities observed in intertidal marsh banks, decayed wood, and sandstone (Davidson et al. 2010) but appear similar to the burrow densities observed in burrowed foam floats from sites in Taiwan (pers obs). I hypothesize foam floats harbor higher burrow and isopod densities than intertidal substrata: data suggest polystyrene foam, when submerged, are relatively easy for isopods to burrow into (Davidson and de Rivera in press) and likely maintains the burrow networks better than softer, more dynamic substratum such as marsh banks. However, the boring effects appear to be condition dependent. I previously found: (a) the colonization rate of isopods was lower in intertidal 
polystyrene blocks compared to intertidal marsh banks and decayed wood (Davidson et al. 2008) but (b) per capita burrowing rates were greater in marsh banks and polystyrene foam than friable rock and wood when exposed to constant subtidal conditions (Chapter $1)$.

Furthermore, the presence of large pieces of foam floats found throughout Coos Bay suggests rafting may be an important dispersal mechanism for S. quoianum. Since isopod boring may facilitate the breakage of floats, potentially large floating colonies may be dispersed to new areas within a bay or possibly between bays. Certainly the movement of large aggregated colonies of hundreds or thousands of individuals of $S$. quoianum may enhance invasion success in new locations. 
Table 3.2. Locations where boring sphaeromatid isopods have attacked expanded polystyrene floats. The species included: Sphaeroma quoianum (SQ) Sphaeroma terebrans (ST), Ptyosphaera alata (PA), and Sphaeroma triste (STT).

\begin{tabular}{|c|c|c|c|c|c|}
\hline Location & Year & Species & $\begin{array}{l}\text { Invasion } \\
\text { status }\end{array}$ & Substratum & Reference \\
\hline Yaquina Bay, Oregon & 2007 & $S Q$ & Non-native & $\begin{array}{l}\text { Floats, } \\
\text { flotsam }\end{array}$ & this paper \\
\hline Coos Bay, Oregon & 1995 & $S Q$ & Non-native & $\begin{array}{l}\text { Floats, } \\
\text { flotsam }\end{array}$ & $\begin{array}{l}\text { Cohen and } \\
\text { Carlton 1995, }\end{array}$ \\
\hline $\begin{array}{l}\text { San Francisco Bay, } \\
\text { California }\end{array}$ & 1966 & $S Q$ & Non-native & $\begin{array}{l}\text { Floats, } \\
\text { flotsam }\end{array}$ & $\begin{array}{l}\text { Rotramel } 1975 \text {, } \\
\text { per comm. }\end{array}$ \\
\hline Elkhorn Slough, California & 1998 & $S Q$ & Non-native & $\begin{array}{l}\text { Floats, } \\
\text { flotsam }\end{array}$ & $\begin{array}{l}\text { Wasson, per } \\
\text { comm. }\end{array}$ \\
\hline $\begin{array}{l}\text { Throughout southwest } \\
\text { Florida }\end{array}$ & 1978 & $S T$ & Non-native & $\begin{array}{l}\text { Floats, } \\
\text { flotsam }\end{array}$ & $\begin{array}{l}\text { Estevez 1978, } \\
\text { per comm. }\end{array}$ \\
\hline $\begin{array}{l}\text { Lake Pontchartrain, } \\
\text { Louisiana }\end{array}$ & 2004 & $S T$ & Non-native & Flotsam & Wilkinson 2004 \\
\hline Kinmen Island, Taiwan & 2010 & $S T$ & Native & Flotsam & this paper \\
\hline Budai township, Taiwan & 2010 & $S T$ & Native & Flotsam & this paper \\
\hline Tainan, Taiwan & 2010 & $S T$ & Native & $\begin{array}{l}\text { Floats, } \\
\text { flotsam }\end{array}$ & this paper \\
\hline Tamar river, Tasmania & 2006 & $S Q$ & Native & Flotsam & $\begin{array}{l}\text { Davidson et al. } \\
2008\end{array}$ \\
\hline Port Stephens, Australia & 1986 & $\begin{array}{l}S Q, S T \\
P A\end{array}$ & Native & Floats & Cookson 1986 \\
\hline Townsville, Australia ${ }^{1}$ & 1973 & STT & Native & Flotsam & $\begin{array}{l}\text { Harrison and } \\
\text { Holdich } 1984\end{array}$ \\
\hline Philippines $^{2}$ & 1986 & $S T, S T T$ & Native & Floats & Angell 1986 \\
\hline
\end{tabular}

Footnotes:

${ }^{1}$ Harrison and Holdich (1984) noted Sphaeroma triste in polystyrene blocks (in 1973) affixed beside a dock in Townsville, Australia.

${ }^{2}$ Angell (1986) reports the necessity of protecting expanded polystyrene floats used in oyster culture facilities in the Philippines from borers, likely S. terebrans or S. triste. 


\section{Microplastic pollution created by boring isopods}

Boring by sphaeromatid isopods in expanded polystyrene floats created millions of microplastic particles and may have negative effects to marine organisms. I found a burrow (15.1 mm long) created by an isopod in two months can result in 2,844 plastic particles when exposed to water temperatures similar to what populations experience in Coos Bay. Extrapolating that estimate to a population of 100,000 (a density observed in a cubic meter of substrata, Davidson et al. [2010]; or a heavily infested float, Table 3.1), the total number of particles created by 100,000 isopods each creating a burrow is 228.4 million. However, the mean burrow length observed in this experiment $(15.1 \mathrm{~mm})$ is shorter than the mean burrow length created by S. quoianum in the lab $(22.6 \mathrm{~mm}$ in the lab at $\left.14^{\circ} \mathrm{C}\right)$ and from field measurements $(25.3 \mathrm{~mm}$; Davidson and de Rivera, in press). If I estimate the number of plastic particles created using these average values and the correlations presented in Chapter 4 (\# of plastic particles $=254.9 *[$ burrow length, $\mathrm{mm}]$ 1263.6, $r^{2}=0.82$ ), I estimate an adult S. quoianum (in two months) would create between 4,497 and 5,198 particles during the boring process (449.7-519.8 million per 100,000 isopods). While there is some variation in the specific number of particles created in the boring process, these estimates reveal the extremely high magnitude of microplastic that is created through the boring process by this non-native isopod and likely other boring isopods. 


\section{Potential implications of microplastic pollution}

Microplastics, similar in size to those created by this bioeroder, persist in the marine environment (Barnes et al. 2009) and may be consumed or colonized by numerous species (Gregory 2009). These particles were similar in size to numerous species of zooplankton and some phytoplankton (Spurles et al. 1988, Hansen et al. 1994) and thus may be confused for planktonic food. Microplastics are ingested by species in a variety of trophic levels, habitats, and feeding modes. They have been ingested by detritivorous amphipods (Thompson et al. 2004); deposit feeding echinoderms (Graham and Thompson 2009) and polychaetes (Thompson et al. 2004); filter feeding mussels (Browne et al. 2008), crustaceans (Thompson et al. 2004), and echinoderms (Graham and Thompson 2009); omnivorous lobsters (Murray and Cowie 2011); and small planktivorous fish (Boerger et al. 2010, Davison and Asch 2011). Larger predators such as birds (Laist 1997), turtles (Laist 1997), numerous species of fish (Carpenter et al. 1972, Kartar et al. 1976, Laist 1997) and mammals (Eriksson and Burton 2003) were also found with microplastics inside their guts; although some of these plastics may be the result of the breakdown of larger particles. Since isopods damage the floats used in aquaculture facilities, the microplastic pollution created may even become ingested by the cultured species (for example, oysters) and thus may be transferred to humans.

There are three primary effects of microplastics to marine life including facilitating the spread of non-native species, physical effects, and toxicological effects when ingested. Microplastics may facilitate the spread of non-native species (Barnes 2002, Gregory 2009) by providing a surface to which those organisms can attach and 
subsequently floating to a new area. Numerous non-native taxa have been found on plastics including sponges, hydroids, bryozoans, mollusks, isopods, barnacles, polychaetes (Barnes 2002, Gregory 2009), and toxic microalgae (Masó et al. 2003). Even microplastics may be a viable vector; plastics similar in size to the current study have been found transporting non-native bryozoans (Barnes 2002, Gregory 2009). The high surface area of these microplastics and high abundances created through burrowing may provide additional opportunities for small non-native taxa to colonize and disperse to new areas.

When ingested, microplastics can also accumulate in some organisms (Browne et al. 2008, Murray and Cowie 2011), which may lead to physical effects. Plastic accumulation may lead to intestinal obstructions (Carpenter et al. 1972) and stomach ulcers (as with birds, Pettit et al. 1981). It also may cause false indication of satiation, hence reduced growth and perhaps fitness (Connors and Smith 1982, Ryan 1988). Researchers have found negative correlations between plastic load and body mass (Ryan 1987, Spear et al. 1995) and possibly the amount of fatty deposits in seabirds (Connors and Smith 1982). Browne et al. (2008) did not find a significant short-term biological effect of the ingestion of microplastic in the mussel Mytilus edulis; however, they caution additional longer-term studies with an array of different polymers and organisms is necessary.

Microplastics are chemically inert (Teuton et al. 2009), yet may become toxic when they degrade or through the accumulation of toxins from the ambient environment. When the plastics degrade, they release toxic additives including phthalates, organotin, 
and nonylphenol (Zitko 1993, Mato et al. 2001, Teuton et al. 2009). Other toxins, such as persistent organic pollutants, have a higher affinity for plastics than ambient seawater and accumulate in very high concentrations (Mato et al. 2001, Teuton et al. 2007) and may be absorbed into marine fauna (Ryan et al. 1988, Teuton et al. 2007, Thompson, unpublished, as cited in Teuton et al. 2009). These persistent organic pollutants including polychlorinated biphenyls (PCB's), polycyclic aromatic hydrocarbons (PAH's), chlorinated phenols, organochlorine pesticides (DDT, and DDE) and Bisphenol-A (BPA) are of particular concern since they are endocrine disruptors and carcinogenic (Walker et al. 2006). Furthermore, heavy metals (cadmium and lead) can also accumulate in microplastics (Ashton et al. 2010). Since the microplastics created by isopods are small, irregular, and have a high perimeter to area ratio (and likely a high surface area to volume ratio), it seems likely they would accumulate toxins more rapidly than larger spherical plastic particles and pellets.

\section{Polystyrene float type prevents colonization by a non-native boring isopod}

Isopods did not burrow into the XPS foam treatments during the lab experiment, which suggests this foam type may prevent isopod colonization and burrowing in the field. These lab results are consistent with observations from the field. The XPS floats or flotsam I have encountered during surveys were never burrowed by isopods. The XPS foam is noticeably harder than EPS foam and it is likely this substratum is too hard for boring. In contrast, EPS foam, such as the type used in many floating docks, was burrowed more frequently and burrowed deeper than the other treatments. The damaged 
encapsulation EPS float mimics also experienced lower colonization rates, burrow use, and shorter burrows than the EPS floats, although the results were not statistically different. The laboratory experiment, combined with field and lab observations, suggests that XPS is resistant to isopod damage and thus may be a viable option to reduce the impacts of burrowing by S. quoianum and other boring isopods.

As of 1992, dock owners installing new polystyrene floats in Oregon waters must encapsulate their floats, at a minimum, with a $7 \mathrm{mil}(0.178 \mathrm{~mm})$ layer of plastic sheeting (Oregon Administrative Rule 250-014-0030) or another material (wood, rigid plastics, concrete, etc). In Coos Bay, I have observed many floats encapsulated with thin covers of polyethylene (around 1-2 mm thick); however, the material on many floats appeared torn, brittle, and discolored (pers obs) presumably from interactions with UV light, seawater, and floating debris. Some floats exhibited isopod damage under the damaged encapsulation material. Since isopods are thigmotactic and negatively phototactic (Chapter 5), they may actively seek the damaged and shaded areas under the opaque plastic encapsulation material. Hard encapsulation materials, such as a high density polyethylene plastic shell (thick rigid plastic), concrete, and wood appear to prevent isopod burrowing (pers obs). However, wood encapsulation material also degrades in marine waters, and may, itself, harbor burrows of isopods (pers obs); the seams between some planks are often large enough for the small thigmotactic isopods to slip between (pers obs). Thus, encapsulation material can be effective to prevent isopod damage, but only if it remains intact and sealed entirely. I recommend using extruded polystyrene 
covered in a hard encapsulation material to prevent damage by S. quoianum and floating debris.

Using a thick and resilient encapsulation material and extruded foam clearly will decrease burrowing and the subsequent degradation and plastic pollution. Polyethylene plastic shells prevent damage from muskrats in North Carolina (Deaton 2010) and are highly likely to be as effective in preventing damages from smaller borers. A change away from expanded polystyrene, however, would likely require legislation or an education campaign about the economic and ecological benefits of this change. Oregon already has taken a legislative approach by adopting rules requiring encapsulation around floats (Oregon Administrative Rule 250-014-0030). An economic model has not been calculated but would include the additional output costs for the material itself (float and encapsulation type), installation costs, information on the longevity of the float (hence reduced frequency of installation), lost opportunity costs associated with an inoperable dock, and the effectiveness of the float (buoyancy per unit volume). Quantifying these values will be essential for determining the most cost-effective strategy to prevent isopod boring damage to docks.

\section{Conclusions}

The destruction of expanded polystyrene floats used in floating docks and aquaculture facilities by boring isopods can be extensive and widespread. Burrowing by dense colonies of isopods can degrade floats, reducing their longevity and function. Burrowing also releases millions of microplastic particles into the marine environment. 
These particles are similar in morphology to other plastic particles (Carpenter et al. 1972, Gregory 1996) found to have detrimental effects on marine organisms. These effects, however, may be prevented or reduced by using extruded polystyrene floats and/or a thick rigid encapsulation material. 


\section{Chapter 4: Seawater temperature mediates the biological erosion by a non-native burrowing crustacean}

\section{Introduction}

Increasing ocean temperatures associated with global climate change has the potential to greatly alter the marine environment (Nicholls et al. 2007). These effects are diverse, including shifting species distributions (Perry et al. 2005, Hays et al. 2005, Sorte et al. 2010a), increasing coral bleaching and death (Hoegh-Goldberg et al. 2007), facilitating the invasion of non-indigenous species (Stachowicz et al. 2002, Sorte et al. 2010b), and threatening stenothermal taxa (Hughes et al. 2003, Peck et al. 2004). Changing ocean water temperatures can also have more subtle effects by altering the rate of biological activities, such as feeding, reproduction, and growth (Cossins and Bowler 1987, Sanford 1999, Fabry et al. 2008, Widdocombe and Spicer 2008, Gooding et al. 2009). Altering water temperatures, hence the rate of many biological activities, only a few degrees may elicit substantial community and ecosystem changes (Sanford 1999, Hoegh-Goldberg et al. 2007, Gooding et al. 2009, Kordas et al. 2011). Small changes in temperature $\left(3^{\circ} \mathrm{C}\right)$ can affect the predation rate of keystone predators (sea stars and gastropods; Sanford 1999, 2002) and thus may alter trophic dynamics. Water temperature also affects the predation rate of shore crabs on bivalves (Sanchez-Salazar et al. 1986) and grazing by gastropods (Petraitis 1992). The development of sea urchins was also depressed by small increases in water temperature (4-6 ${ }^{\circ}$; Byrne et al. 2009). 
The biological erosion, boring, or burrowing of substrata (hereafter: bioerosion) is a less often considered, yet important biological activity that is likely to be influenced by changing ocean temperatures. Since bioerosion can be substantial in some marine environments and exceed the erosion by physical or chemical processes (Warme and Marshall 1969, Warme 1971), increases in the rates of bioerosion may fundamentally alter the physical structure of marine ecosystems and damage marine facilities. When bioeroders occur in high densities or erode at high rates, they can alter the heterogeneity of important ecosystems, including saltmarshes (Talley et al. 2001, Escapa et al. 2007, Davidson and de Rivera 2010), mangroves (Rehm and Humm 1973, Perry and Brusca 1989), and coral reefs (Glynn et al. 1979, Eakin 1996). Bioerosion by grapsid crabs and littorine snails facilitate the development of tidal channels (Escapa et al. 2007) and the deepening of tidepools (McLean 1967), respectively. Bioerosion by herbivorous fish, urchins, and mollusks can also reduce coral reef growth (Glynn et al. 1979, Hutchings 1986) and the survivorship of coral spat (Sammarco 1980). Higher seawater temperatures has been shown to accelerate the boring and bioerosion rates of limnoriid isopods in the lab (Eltringham 1965, Borges et al. 2008), shipworms (Ibrahim 1981), clionid sponges (Rutzler 2002), and parrotfish (Smith 2008). However, overall, empirical evidence of the effects of temperature on the rates of these important erosive activities is limited.

Burrowing sphaeromatid isopods are estuarine bioeroders distributed throughout tropical and temperate regions. These crustaceans use their mandibles to physically remove small bits of substrata, but they do not intentionally consume the material they excavate (Barrows 1919, Rotramel 1975). Sphaeroma quoianum, a non-native burrowing 
isopod from Australia and New Zealand, has invaded at least 15 estuaries on the Pacific coast of North America (Davidson 2008). Dense colonies of this burrower inhabit and damage marsh banks, wood, friable rock, and expanded polystyrene plastic floats (hereafter: Styrofoam) used in floating docks (Higgins 1956, Talley et al 2001, Davidson 2008, Davidson and de Rivera, in press). Burrowing in Styrofoam floats and their subsequent breakage may also have an economic effect. Moreover, by degrading floats into a fine plastic dust, these burrowers exacerbate plastic pollution in oceans (Carlton, Chang, and Wells, unpublished, as cited in Carlton and Ruiz 2005, Chapter 3).

Because empirical evidence of the effect of temperature on bioerosion is limited, my objective was to quantify how bioerosion may be affected by changing ocean temperatures. I used S. quoianum as a model bioeroder to infer how changing ocean temperature may affect bioerosion in marine environments. Given the center of a species' range is considered to be the physiological optimum (Hutchinson 1957, Brown 1984, Hengeveld 1993), and the midpoint of the present non-native distribution of S. quoianum in the northeast Pacific is near San Francisco Bay (Davidson 2008; mean water temperature: $16.4^{\circ} \mathrm{C}$, NOAA $\left.2011 \mathrm{a}\right)$, I hypothesized isopods subjected to the temperatures near $16.4^{\circ} \mathrm{C}$ will exhibit maximum boring rates (longer, more voluminous burrows). While their range may still be expanding in the eastern Pacific, it is not yet certain whether or in which direction the range center will shift with continued expansion. Given the physiological optimum may not be right at the current center of the recipient range, the peak may occur at a slightly higher or lower temperature. I predicted this relationship will be inverse parabolic in shape following general $\mathrm{Q}_{10}$ predictions; 
additional warming or cooling will cause bioerosion to decrease. Since the rate at which S. quoianum creates plastic particles is dependent on the bioerosion process, I also predicted the number of plastic particles created by $S$. quoianum will be similarly related to water temperature.

\section{Methods}

I examined the effect of water temperature on bioerosion rates and plastic pollution by exposing isopods to thirteen water temperatures in the laboratory. Closed aerated saltwater aquaria (10 gallon) were maintained at one of thirteen temperatures, ranging from $7.5^{\circ} \mathrm{C}-25.2^{\circ} \mathrm{C}$, using aquarium chillers and heaters (Table 4.1). These temperatures were selected to exceed the mean water temperatures experienced by nonnative populations near or at their published southernmost distribution (San Diego Bay, CA: $20.6^{\circ} \mathrm{C}$, NOAA 2011a; San Quintin Bay, Baja California: $17.3^{\circ} \mathrm{C}$, Alvarez-Borrego and Alvarez-Borrego 1982) and northernmost distribution (Yaquina Bay, Oregon: $11.4^{\circ} \mathrm{C}$, NOAA 2011 b, Davidson 2008). Temperatures in the tank varied slightly over the two-month experiment (Table 4.1). The water temperatures in the aquaria were changed to the experimental levels slowly over four hours to help the organisms acclimate. Air pumps were added to ensure an adequate supply of dissolved oxygen in each tank, and salinity was maintained at 30 PSU. Water conditioner (Kordon AmQuel+ instant water detoxifier) was added prior to the experiment and after one month in response to regular monitoring for nitrates, nitrites, ammonium, and ammonia. The water conditioner was 
added to eliminate potentially toxic nitrogen compounds, chlorines and other chemicals that might otherwise have affected the health of experimental organisms.

Table 4.1. Mean $\pm 95 \%$ confidence intervals of water temperature $\left({ }^{\circ} \mathrm{C}\right)$ in the experimental aquaria. Twelve measurements were taken during the two-month experiment.

\begin{tabular}{cc}
\hline Mean $\left({ }^{\circ} \mathrm{C}\right)$ & $\mathbf{\pm 9 5 \%} \mathbf{~ C l}$ \\
\hline 7.50 & 0.16 \\
10.00 & 0.16 \\
10.84 & 0.24 \\
12.34 & 0.39 \\
13.83 & 0.19 \\
14.24 & 0.12 \\
15.78 & 0.30 \\
16.36 & 0.40 \\
18.27 & 0.39 \\
23.38 & 0.81 \\
23.43 & 0.74 \\
24.22 & 0.75 \\
25.19 & 0.36 \\
\hline
\end{tabular}

In each aquarium, twenty isopods were encaged with a Styrofoam block (800 $\left.\mathrm{cm}^{3}\right)$ with one exposed side $\left(100 \mathrm{~cm}^{2}\right)$. The isopods used in the experiment were collected from Coos Bay, Oregon (in late January 2010) and ranged between 7-12 mm in length. I divided isopods into four relative size categories to ensure all treatments received isopods of similar size. Ovigerous isopods were excluded from the experiment. I created fifteen small divots (4 mm deep) on the surface of the Styrofoam block to prompt isopod burrowing and left the isopods to burrow for 62 days. Previous experiments (Davidson and de Rivera 2011) reveal these small divots greatly decreased the time it took for 
isopods to initiate burrowing. I did not include the divots in my measurements if isopods did not burrow into them. Animals were fed spray-dried phytoplankton every two days. Experimental blocks were examined twice during the experiment (after 1 month, 1.5 months, and 2 months) to remove any dead isopods (without replacement) or molts. At the end of the experiment, I removed all isopods, measured the total length of burrows created by isopods and calculated the total volume excavated per block. Burrow length and width measurements were used to estimate the volume of a burrow. To correct for the vermiform shape of a burrow, I calculated the volume of a cylinder plus the volume of one-half a sphere (to represent the tapered end of a vermiform burrow; Davidson and de Rivera, in press). I also recorded survivorship, growth (\# of molts), reproduction (\# of juvenile isopods), and the number of isopods that were outside of burrows at the end of the experiment. Juveniles were not included in my measurements of survivorship. The per capita estimates of bioerosion were based on the original twenty isopods because I could not determine when each of the isopods died.

Plastic particles were collected by discharging aquarium water through a $63 \mu \mathrm{m}$ sieve. I could not detect, using dissecting and light microscopes, smaller plastic particles in the water discharged through the sieve. I collected all plastic particles from each aquarium, soaked them in $2 \%$ hydrogen peroxide to remove organic material (isopod feces), and then poured the solution onto a gridded paper filter $\left(1 \mathrm{~cm}^{2}\right.$ grid $)$. Hydrogen peroxide did not appear to affect the plastic particles in preliminary tests. I agitated the plastic particle solution to help distribute the particles evenly across the gridded filter and then counted the number of squares with plastic particles. I estimated the number of 
particles per paper filter by photographing, with a digital microscope camera, five random subsamples $\left(1 \mathrm{~cm}^{2}\right.$ squares $)$ per filter, then counting the number of particles in each square using ImageJ 1.43u image analysis software. The total number of particles per filter (treatment level) was estimated by multiplying the mean number of particles per $1 \mathrm{~cm}^{2}$ by the total number of squares on the filter that were occupied by plastic particles. Expanded polystyrene foam is resistant to temperature changes; the maximum permissible operating temperature of foam is $75^{\circ} \mathrm{C}$ and it degrades at temperatures exceeding $90^{\circ} \mathrm{C}$ (Goodier 1961), thus it seems unlikely the experimental temperatures would have substantially altered the morphology or properties of the experimental substrata or particles.

I used quadratic regressions, in $\mathrm{R}$ (version 2.7.2), to examine the relationships between water temperature and each dependent variable (total burrow length, total burrow volume, and the number of plastic particles created per 20 isopods). The relationships between temperature and burrow use (\% of isopods inside burrows), molting frequency (\# of molts found), survivorship, and reproduction (\# of juveniles) at the end of the experiment were also examined. I selected the quadratic model based on the best fit of different models (linear, asymptotic, quadratic) through visual evaluation of scatterplots and by the comparison of Akaike information criterion values. All data were square-root transformed, except molt data, which were cube-root transformed, to meet the assumptions of normality and equal variances of residuals. 


\section{Results}

After two months, isopods created the longest and most voluminous burrows and the most plastic particles in the moderate seawater temperatures $\left(13.8^{\circ} \mathrm{C}-18.3^{\circ} \mathrm{C}\right.$, Figure 4.1). Lower burrow lengths and volumes and fewer plastic particles were observed for the coldest and warmest seawater treatments. The burrow length $(\mathrm{mm})$ and number of plastic particles were also positively correlated $\left(r^{2}=0.82, t=7.16, P<0.001 ; y=254.9 x-1263.6\right)$. The mean number of plastic particles created in the two months by an adult isopod varied from a minimum of $67\left(7.5^{\circ} \mathrm{C}\right)$ to maximum of $4,167\left(13.8^{\circ} \mathrm{C}\right)$. 

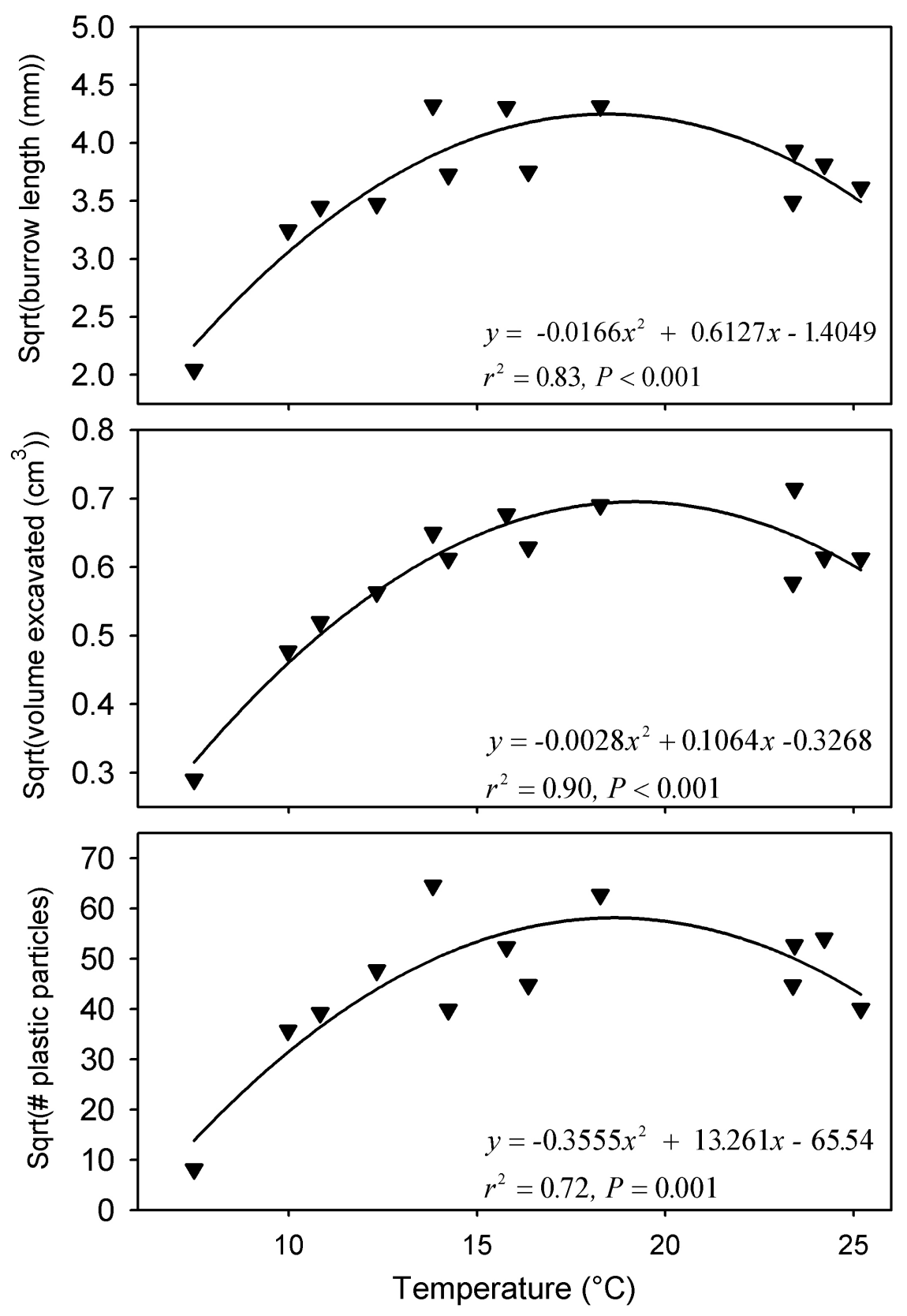

Figure 4.1. Effect of water temperature on the length and volume of burrows and number of plastic particles created by individuals of Sphaeroma quoianum. Values presented are per isopod. 
Similar relationships between water temperature and burrow use and molting frequency were also found (Figure 4.2). A large proportion (63\%) were found outside of their burrows in the coldest water temperature while few (0-10.5\%) of the isopods were present outside of burrows in the moderate water temperatures $\left(13.8-18.3^{\circ} \mathrm{C}\right)$. Molting occurred less often in the colder $\left(<15^{\circ} \mathrm{C}\right)$ than higher $\left(>15^{\circ} \mathrm{C}\right)$ temperatures. I did not detect a significant relationship between survivorship or reproduction and water temperature $(P>0.05$, Figure 4.3). However, survivorship appeared to decrease slightly with increasing temperature and three of the highest water temperatures harbored juveniles of $S$. quoianum. 


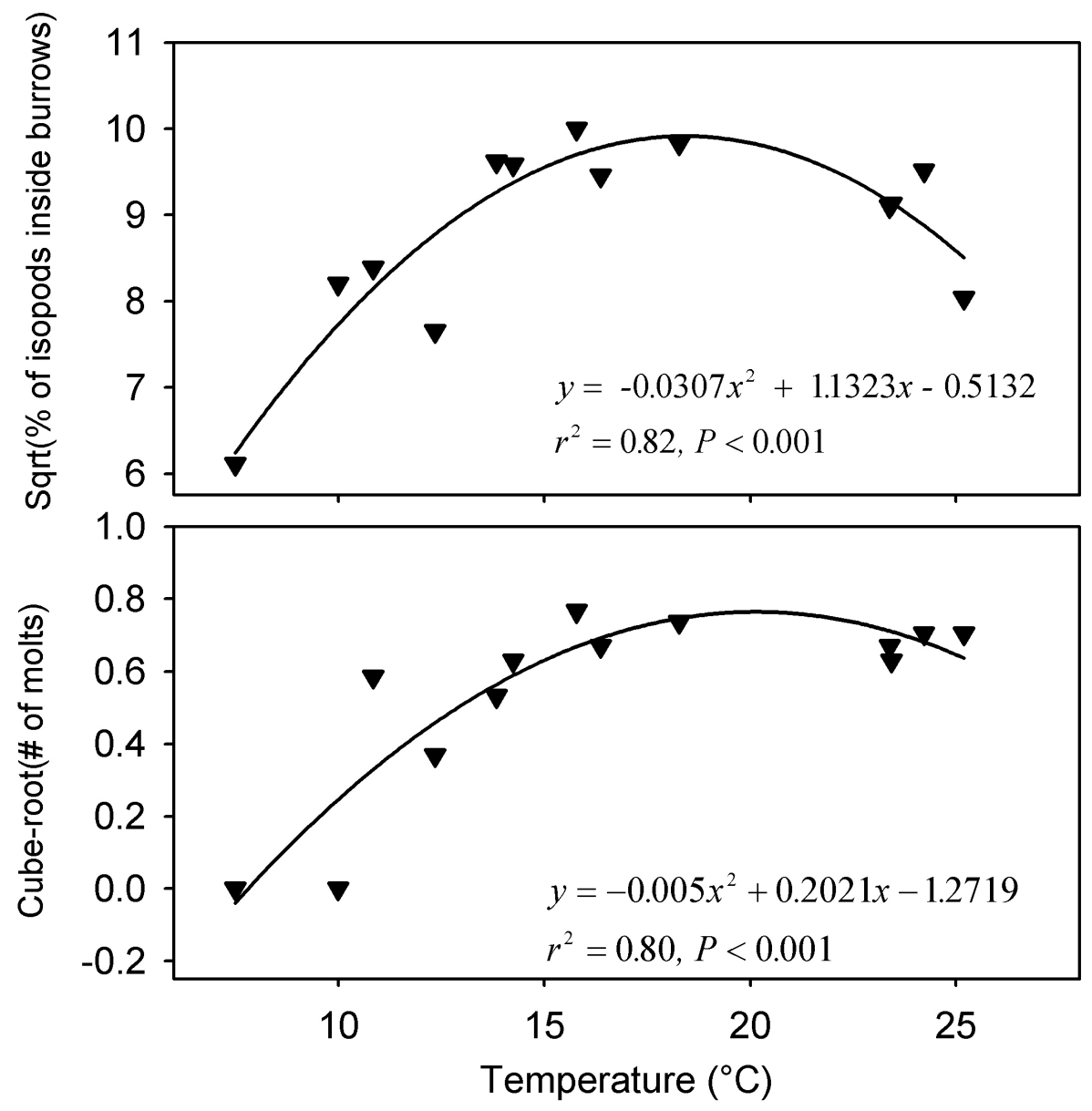

Figure 4.2. Effects of temperature on burrow use and the molting frequency (per isopod) of individuals of Sphaeroma quoianum. 


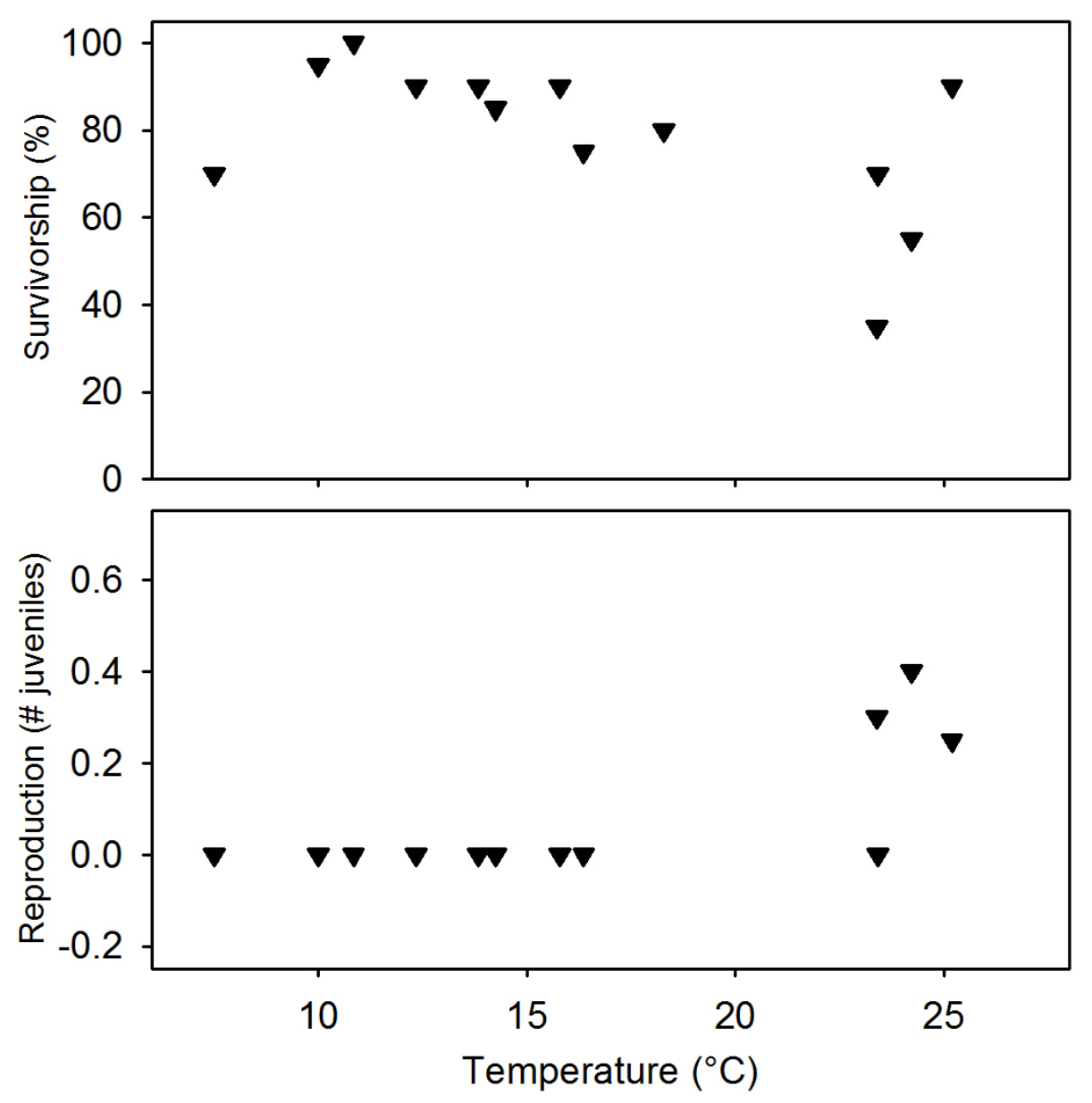

Figure 4.3. Effects of temperature on survivorship and the reproduction (\# of juveniles) of individuals of Sphaeroma quoianum $(P>0.05)$.

\section{Discussion}

Effects of temperature on bioerosion and the creation of plastic particles

Seawater temperature had a strong effect on the rate of bioerosion and other biological activities of the non-native isopod S. quoianum. Generally, isopods in tanks with higher seawater temperatures exhibited higher rates of bioerosion, including longer and more voluminous burrows. As hypothesized, these relationships were inverse 
parabolic in shape, although the specific threshold value (inflection point) differed from the value hypothesized. The effects of water temperature on bioerosion rate peaked at $18.3^{\circ} \mathrm{C}$ and decreased when exposed to either warmer or colder temperatures. These results were consistent with both laboratory and field experiments examining the effects of temperature on bioerosion by numerous taxa. Bioeroders, borers, and burrowers exhibited changes in biological erosion when exposed to changing temperatures, including wood-boring gribbles (Eltringham 1965, Borges et al. 2008), boring mollusks (Roch 1932 as cited in Paalvast and van der Vedle 2011, Norman 1977, Ibrahim 1981), bioeroding sponges (Siegrist et al. 1992, Rutzler 2002), parrotfish (Smith 2008), and sipunculans and polychaetes (Siegrist et al. 1992).

Changes in bioerosion rates associated with changing ocean temperature may have myriad ecological and economic implications in the marine environment because high rates of bioerosion and boring can fundamentally change the nature of a habitat and damage marine structures. For example, littorine snails facilitated the creation of tidepools in the rocky intertidal (McLean 1967). Burrowing by Sphaeroma quoianum accelerated lateral erosion in saltmarsh habitats and converted vertical saltmarshes into undercut ledges and slumps (Talley et al. 2001, Davidson and de Rivera 2010). Initial burrowing by crabs helped develop tidal channels in saltmarshes (Escapa et al. 2007). Coral reefs in many areas of the Eastern Pacific were degraded by bioeroding urchins (Glynn 1988 as cited in Glynn 1993); these effects are especially detrimental in these coral reef habitats where thermal stressors may interact with coral bioeroders to facilitate degradation of the reef structure (Rutzler 2002, Hutchings 2007, Fabricus 2007). 
Conversely, reducing the rates of bioerosion may also have implications for habitats including coral and sand beaches that require regular bioerosion for maintenance (Schneider and Torunki 1982, Hutchings 1986) or for coral reefs where urchin herbivory and bioerosion inhibits algal overgrowth and promotes the colonization of coral (Sammarco 1982). Furthermore, the destruction of pilings by shipworms and isopod wood-borers were responsible for the collapse of docks leading to millions of dollars in damage (Miller 1926, Kofoid and Miller 1927). Thus, bioerosion can be a strong factor influencing the physical structure of marine habitats and facilities.

In addition to affecting rates of bioerosion, changing water temperatures also affected the amount of plastic pollution that was created by this non-native burrower. The boring process of S. quoianum produced thousands of minute plastic particles during the two-month experiment. If I extrapolate those estimates to a colony of 44,296 isopods, the estimated colony size living in a Styrofoam float under a typical dock section (244 x 122 cm; Chapter 3), between 3 and 185 million particles could be created in two months by these borers, depending on water temperature. These estimates may also be underestimating the amount of plastic pollution created since the values presented were per 20 isopods and fewer than 20 isopods created burrows in some experimental treatments. Numerous taxa and trophic levels consume microplastic similar in size to these particles (Thompson et al. 2004, Graham and Thompson 2009, Davison and Asch 2011); thus there could be a variety of ecological implications for the pollution of these minute plastic particles by S. quoianum (Gregory 2009, Chapter 3). 
Other biological activities such as burrow use and molting frequency exhibited a similar relationship to temperature. Differences in burrow use and molting frequency between temperature treatments are likely responsible for the differences in the amount of bioerosion. Low burrow usage implies isopods are not burrowing often and perhaps experiencing stressful conditions. Isopods may also be abandoning their burrows in an attempt to seek less stressful conditions. Since not all isopods in an experimental temperature treatment responded the same way, these data also reveal that the individual response to changes in water temperature varies. Future studies should investigate what factors may influence the use and abandonment of burrows and what drives this individual variation in response. Molting frequency (e.g. growth rate) was also affected by temperature. Higher temperatures caused more molting. Thus, as the isopods grow in size, they would also have to conduct more burrow maintenance (their burrow widths closely match their body widths) and hence would burrow more. Increases in individual growth rates may also lead to demographic changes if isopods exposed to higher temperatures matured faster and experienced shorter generation times. Changes in demography may lead to additional bioerosion effects as higher population growth rates would lead to more bioerosion per unit time. Additional studies investigating how the demography of bioeroders is affected by temperature would also help reveal how a changing climate may affect the process of bioerosion. 


\section{Predictions}

This experiment characterizes the quantitative relationship between increasing seawater temperatures and bioerosion rate in a non-native bioeroder. These results are relevant to populations of boring isopods in Coos Bay, Oregon, but also several other invaded areas on the Pacific coast that appear to be susceptible to increases in bioerosion intensity with changing seawater temperatures. Thus, the implications of these results for the ecosystems $S$. quoianum has invaded depends on the local environmental conditions. In some locales on the Pacific coast, I predict the bioerosion rates and impact will increase with increasing ocean temperatures, while in already warm locations, impacts may decrease as populations are subjected to more stressful environmental conditions.

I used several estuaries with excellent records of temperature to explore the extent of changes to biological erosion due to predicted ocean temperature increases. Using mean ocean temperatures obtained from the National Estuarine Research Reserve (NERR) System-Wide Monitoring Program (SWMP; NOAA 2011a) and predicted increases in ocean temperature by the end of the $21^{\text {st }}$ century from Meehl et al. (2007), I predict that ocean temperature conditions will increase the bioerosive impact of nonnative $S$. quoianum in three of the four estuaries in the NERR system that this isopod has already invaded (Tables 4.2, 4.3). Populations of S. quoianum currently in Elkhorn Slough, San Francisco Bay, and South Slough/Coos Bay (and other invaded estuaries experiencing similar ocean conditions) will likely increase their bioerosive impact with increasing ocean temperatures (assuming those populations would exhibit a similar response to temperature as Coos Bay populations). In those three estuaries, I predict 
bioerosion by $S$. quoianum will increase 5.1 to $17.1 \%$ under the IPCC B1 (best case scenario) for warming and 6.5 to $27.5 \%$ under the A2 scenario (Meehl et al. 2007, Tables 4.2, 4.3). Since burrowing by isopods facilitates erosion of saltmarsh banks (Talley et al. 2001, Davidson and de Rivera 2010) and damages marine structures and facilities (Chilton 1919, Cragg et al. 1999, Chapter 3), increases in bioerosion with increasing seawater temperatures may result in increased erosion of saltmarshes and damage to marine habitats and structures. Similarly, the plastic pollution associated with this bioerosion will also increase. Also, as water temperatures warm and become more hospitable, subsequent invasion may occur of estuaries that do not yet harbor populations of S. quoianum (e.g., Padilla Bay, WA). Similar findings were found by Stachowicz et al. (2002) who determined that increasing winter ocean temperatures facilitated the invasion of non-native tunicates on the east coast of the US. Conversely, estuaries on the southern (warm) edge of the thermal envelope of S. quoianum may experience a decrease in bioerosive impacts (i.e. San Diego Bay, Table 4.2) or may be less susceptible to future invasion by this animal (i.e. Tijuana Estuary, CA). 
Table 4.2. Mean water temperatures (2000-2010) in the Pacific coast National Estuarine Research Reserve System-Wide Monitoring Program stations, predicted water temperatures under B1 (best-case) and A2 scenarios (Meehl et al. 2007), and the predicted change in biological erosion associated with those water temperatures due to temperature-specific boring rates in the lab.

\begin{tabular}{|c|c|c|c|c|c|}
\hline Estuary & $\begin{array}{c}\text { Mean water } \\
\text { temperature } \\
\text { ('C) }^{1}\end{array}$ & $\begin{array}{c}\text { B1 } \\
\text { Scenario } \\
\left(+1.5^{\circ} \mathrm{C}\right)^{2}\end{array}$ & $\begin{array}{c}\text { Predicted } \\
\text { change in } \\
\text { biological } \\
\text { erosion } \\
(\%)^{3}\end{array}$ & $\begin{array}{c}\text { A2 } \\
\text { Scenario } \\
\left(+2.6^{\circ}\right)^{2}\end{array}$ & $\begin{array}{c}\text { Predicted } \\
\text { change in } \\
\text { biological } \\
\text { erosion } \\
(\%)\end{array}$ \\
\hline Padilla Bay, WA ${ }^{4}$ & 11.52 & 13.02 & +22.9 & 14.12 & +37.6 \\
\hline South Slough, OR & 12.72 & 14.22 & +17.1 & 15.32 & +27.5 \\
\hline San Francisco Bay, CA & 16.41 & 17.91 & +5.1 & 19.01 & +6.5 \\
\hline Elkhorn Slough, CA & 15.75 & 17.25 & +6.9 & 18.35 & +9.6 \\
\hline San Diego Bay, $C A^{5}$ & 20.56 & 22.06 & -5.0 & 23.16 & -10.8 \\
\hline Tijuana Estuary, $\mathrm{CA}^{4}$ & 18.92 & 20.42 & -1.1 & 21.52 & -4.2 \\
\hline
\end{tabular}

Footnotes:

\footnotetext{
${ }^{1}$ Mean water temperatures are calculated from the mean temperature of all system-wide monitoring stations between 2000 and 2010. See Table 4.3 for details.

${ }^{2}$ The B1 scenario depicts climate change under a shift towards global sustainability, clean and resource efficient technology, and a service and information economy. The A2 scenario depicts climate change under a continuously increasing population, regionalism, slow economic growth and slow technological change (Meehl et al. 2007). These predictions of upper sea surface temperature increase by year 2100 are based on consensus expert opinion of the Intergovernmental Panel on Climate Change.

${ }^{3}$ Predicted changes in biological erosion were calculated from the relationships between burrow volume and temperature as presented in Figure 4.1.

${ }^{4}$ Populations of S. quoianum do not appear to be have been found in Tijuana Estuary (J. Crooks, pers comm) or Padilla Bay (unpublished survey), but the proximity of these bays to highly invaded bays suggests that invasions may occur in the future.

${ }^{5}$ The stations in San Diego Bay are a part of the Tijuana Estuary NERR SWMP, but are distinct bodies of water.
} 
Table 4.3. Water temperature values for selected Pacific coast National Estuarine Research Reserve System-Wide Monitoring Program (SWMP) stations. The means, 95\% confidence intervals (95\% CI), mean maximum (Max), and mean minimum (Min) temperatures for each NERR site were calculated based on means from each SWMP station. Means from each SWMP station were calculated based on means from the available years (\# years).

\begin{tabular}{|c|c|c|c|c|c|c|c|c|}
\hline SWMP Station & Mean & $\begin{array}{c}95 \% \\
\mathrm{Cl}\end{array}$ & Max & Min & $\begin{array}{l}\text { Sampling } \\
\text { years }\end{array}$ & $\begin{array}{c}\# \\
\text { years }\end{array}$ & Lat & Long \\
\hline adilla Bay, WA & 1.52 & 1.16 & 23.43 & 1.47 & & & & \\
\hline Gong Surface & 0.73 & 0.42 & 18.66 & 4.90 & $2003-10$ & 5 & 48.558 & 122.57 \\
\hline Ploeg Channel & 1.35 & 0.35 & 25.54 & -0.52 & $2001-10$ & 10 & 48.557 & 122.530 \\
\hline Joe Leary Estuary & 2.82 & 15.10 & 27.45 & -1.40 & $2009-10$ & 2 & 48.519 & 122.475 \\
\hline Joe Leary Slough & 12.08 & 0.56 & 23.53 & 2.70 & $2000-09$ & 10 & 48.518 & 122.473 \\
\hline Bayvi & 0.60 & 0.17 & 21.97 & 1.67 & & 11 & 48.496 & 122.501 \\
\hline , OR & 12.72 & 1.30 & 22.54 & 4.26 & & & & \\
\hline Bridge & 1.77 & 0.33 & 19.32 & 6.83 & $2002-10$ & 9 & 43.338 & 124.321 \\
\hline Valino Island & 2.43 & 0.27 & 20.63 & 5.81 & $2000-10$ & 11 & 43.317 & 124.322 \\
\hline en Arm & 3.68 & 0.29 & 26.65 & 1.66 & 200 & 11 & 43.290 & 124.303 \\
\hline Winch & 3.00 & 0.23 & 23.57 & 2.73 & 200 & 11 & 43.282 & 320 \\
\hline an Francisco, CA & 6.41 & 0.81 & 27.11 & 6.10 & & & & \\
\hline & 6.73 & 2.40 & 26.47 & 6.13 & 20 & 3 & 38.195 & 122.033 \\
\hline llard & 6.75 & 2.61 & 25.83 & 6.60 & 20 & 3 & 38.184 & 122.014 \\
\hline Galli & 6.51 & - & 29.70 & 5.50 & & 1 & 38.016 & 122.509 \\
\hline China Camp & 5.66 & 0.24 & 26.42 & 6.18 & $2006-10$ & 5 & 38.001 & 122.460 \\
\hline Ikhorn Slough & .75 & 2.16 & 27.72 & 6.25 & & & & \\
\hline Azevedo Pond & 6.56 & 0.32 & 34.22 & 2.28 & & 1 & & \\
\hline arsh & 6.87 & 0.28 & 31.27 & 5.15 & & 11 & 36 & 121.738 \\
\hline South Marsh & 5.69 & 0.23 & 23.77 & 8.57 & & 11 & 36.818 & 121.739 \\
\hline Vierra Mouth & 13.85 & 0.27 & 21.61 & 9.01 & $2001-10$ & 10 & 36.811 & 121.779 \\
\hline (a) & & 3.19 & 29.38 & 10.02 & & & & \\
\hline Pol & & 1.54 & & 11.07 & & 3 & & 117.116 \\
\hline South Bay & 0.31 & 0.87 & 29.67 & 10.57 & $2008-10$ & 3 & 32.600 & 117.116 \\
\hline \multicolumn{9}{|l|}{ Tijuana Estuary, CA } \\
\hline Tidal Linkage & 1.79 & - & 32.60 & 7.20 & & 1 & 32.574 & 117.127 \\
\hline One & 8.17 & 0.24 & 29.32 & 8.24 & 200 & 11 & 32.568 & 117.131 \\
\hline Boca Rio & 17.13 & 0.35 & 27.18 & 9.50 & $2005-10$ & 6 & 32.560 & 117.129 \\
\hline River Char & 18.94 & 2.57 & 31.53 & 9.33 & $2002-04$ & 3 & 32.558 & 117.106 \\
\hline Model Marsh & 18.56 & 0.33 & 32.94 & 6.16 & 2001-07 & 9 & 32.548 & 117.123 \\
\hline
\end{tabular}

Footnotes:

${ }^{1}$ I excluded temperature data that were outside the high or low sensor range or otherwise rejected by the NERR SWMP. I also excluded incomplete yearly data sets; I only used data sets that spanned the year. 
In addition, warming is expected to be greater in high latitude areas in the northern hemisphere and not as extreme in lower latitude waters (Meehl et al. 2007). Hence, already warm bays may not experience substantial decreases in bioerosion even as high latitude bays experience large increases in bioerosion due to warming. This spatial variability in warming (and other interacting factors) makes predicting the specific responses of populations to increasing ocean temperatures difficult. These challenges are further accentuated by temporal and fine-scale spatial variability as well as differing physiological responses of individuals within populations. Furthermore, extreme values may be more important than means in determining the effects of ocean temperature on biota (Gaines and Denny 1993, Stachowicz et al. 2002). Future studies should examine how bioerosion and other biological activities are affected by increasing variation and extremes of ocean temperatures.

This experiment and my corresponding approximate predictions reveal the general response that incremental differences in water temperature have on the biological erosion rates of a non-native boring crustacean. Thus, the relative change in biological erosion occurring from changes in temperature, while here predicted for specific places, are ecologically relevant to a broader geography and suite of species. Since many other bioeroders and borers exhibit similar responses to increases in water temperature (see previous examples), I predict other bioeroders will increase bioerosion rates when subjected to warm temperatures associated with climate change. Consequently, warming, via its influence on rates of boring, burrowing, and bioerosion, may lead to alteration of 
the physical structure of marine habitats and exacerbate damage to human-made structures. 


\section{Chapter 5: Factors influencing the colonization of a burrowing isopod (Sphaeroma quoianum)}

\section{Introduction}

Colonization in marine invertebrates is affected by factors that operate at numerous scales. While large-scale abiotic factors, such as water temperature, are largely responsible for determining species ranges, small-scale factors (cm-m scale) are important determinants of where a species will colonize within those ranges. Invertebrate colonization is affected by the local features of a habitat such as substratum type (Keough and Downes 1981, Davidson et al. 2008a) and habitat complexity (Heck and Wetstone 1977) but also local abiotic factors such as water velocity (Crisp 1955). Biotic factors that vary at small scales, such as the presence of adult or juvenile conspecifics (Highsmith 1982), competitors (Grosberg 1981), and predators (Keough and Downes 1981, Fernandez et al. 1) may also influence colonization. Examining the influence of these factors on colonization may help explain species distribution patterns, habitat preferences, and the suitability of a local habitat.

Additional factors may be important in determining where and what substratum boring and burrowing animals colonize. Because burrowers and boring species must excavate substrata to create a burrow, the properties of the substrata themselves are particularly important. For example, the hardness of a substratum can reduce burrowing in friable rocks and wood (Pinn et al. 2005, Cragg et al. 2007). Other borers seek areas of 
a substratum that have a textural or surface irregularity or are damaged (Estevez and Simon 1975, Estevez 1978, Santhakumari 1991), thus minor initial damage may promote additional attack by borers. Other boring invertebrates may exhibit negative phototaxis by preferentially colonizing shaded areas of a substratum (Cookson 1994). This response may be relevant to human structures such as docks that are submerged and shaded. The presence of other species such as microorganisms (including biofilm) can also affect where burrowers colonize (reviewed in Cragg et al. 1999). The fungi and bacteria present in decayed wood are an attractant for wood-boring isopods of the genus Limnoria (Cragg et al. 1999) and may also attract other borers. In gregarious organisms, such as Limnoria and Sphaeroma, the presence of conspecifics was a major factor determining where individuals settled (Cragg et al. 1999). Chemical cues from conspecifics in many species also may signal relative mortality risk (reviewed by Wisenden 2000, Dicke and Grostal 2001) or signal reproductive status (reviewed by McClintock and Baker 2001); these factors may also influence where a borer colonizes. Small-scale factors like these may be especially important for direct developing species since the dispersal distance is typically low in comparison to planktonically dispersing species (Underwood and Keough 2001). Such limited dispersal may allow direct developers to become more locally adapted (Stanhope et al. 1992, Behrens Yamada 1989) and conceivably more affected by local changes.

Sphaeroma quoianum is a boring isopod native to Australia and New Zealand that has been introduced throughout the Pacific Coast of North America (Davidson 2008). The isopod attacks numerous substrata including marsh banks, decayed wood, friable 
rock, and Styrofoam floats used in floating docks (Carlton 1979). Thus, burrowing in estuaries may facilitate erosion (Talley et al. 2001, Davidson and de Rivera 2010) and damage marine facilities (Chapter 3). In invaded estuaries, isopods exhibit patchy distributions at the 100's of meter scale and at smaller scales (cm-m's; Davidson and de Rivera 2010). These patchy distributions may be the consequence of their limited dispersal as direct developers (Johnson et al. 2001) and suggest that local, fine scale (cmm) factors may be important determinants of where and what substratum S. quoianum will colonize.

Since the colonization process causes damage to the substratum, understanding the factors affecting colonization will help determine what areas may be vulnerable to attack and how those effects may be reduced. I examined how several abiotic and biotic factors affected the colonization of adult and juvenile individuals of $S$. quoianum. Based on findings for other burrowing isopods and other invertebrates (see above), I hypothesized that individual isopods will colonize substrata harboring a) conspecifics and their burrows, b) artificially drilled burrows, c) conspecifics of the opposite sex, and d) biofilm in greater frequency than control substrata. I also hypothesized that individual isopods will avoid substrata harboring moribund conspecifics and the illuminated regions of microcosms. In addition to determining what fine-scale factors affect the colonization of direct developers, this research may help reveal what management options may be effective in mitigating bioerosion by $S$. quoianum in estuaries. 


\section{Methods}

To evaluate how different factors affect colonization by S. quoianum, I conducted eleven colonization experiments (Table 5.1). All experiments were conducted in replicated closed microcosms (5.7 liters) in a Latin square design. The specific treatments and controls, replication level, and experimental conditions are summarized in Table 5.1. The treatments included: 1) conspecifics \& burrows versus unburrowed blocks; 2) drilled burrows (10 mm deep) versus blank substratum (for juveniles and adults); 3) illuminated half of the microcosm (with natural sunlight) versus shaded half; 4) presence of biofilm versus blank substratum; and 5-7) moribund conspecifics versus drilled burrows (3 experiments with varying numbers of moribund conspecifics), and 8) conspecifics of the opposite and same sex (using males and then females as subjects).

To investigate how biofilm may affect colonization of isopods, I deployed 48 (13 $\mathrm{cm} \times 10 \mathrm{~cm}$ x $6 \mathrm{~cm}$ ) wooden blocks (green Douglas fir with 4 drilled burrows, $20 \mathrm{~mm}$ deep) in the field for 50 days to allow blocks to be colonized by biofilm. I cleaned and sanded one-half of the blocks to provide control blocks for the experiment. I examined the effect of moribund conspecifics on colonization by offering isopod subjects blocks containing recently crushed conspecifics and a control block with drilled burrows. I repeated this experiment three times using variable numbers of crushed isopods: a) 2 moribund conspecifics per block, b) 5 moribund conspecifics per block, and c) a variable number (between 1 and 10) of moribund conspecifics per block. In the latter experiment, 22 replicate microcosms were stocked with 1-10 moribund conspecifics per block; each density level was replicated twice except 1 and 2 moribund conspecific levels, which 
were replicated three times each. Crushed isopods were distributed throughout the drilled burrows so no burrow received more than one crushed isopod. The mass of the crushed isopod was small in comparison of the drilled burrow and likely did not physically interfere with the burrow use by the live isopod colonizer. In trials testing whether the presence of the opposite or same sex affects colonization, each block was stocked with all males or all females.

In each experiment, individual isopods (marked with nail polish) were placed in the middle of a 5.7 liter plastic microcosm and offered a choice between 1) an intact treatment block of substratum (as described above, Table 5.1) or 2) an intact control block. The faces of both blocks were oriented towards the middle. Isopod subjects were all gathered from intertidal populations in Coos Bay, Oregon. Since the sex ratio in this area and in San Francisco Bay was approximately 1.4-1.6 to 1 in favor of females (Schneider 1976, unpublished data), I assumed the subjects were composed of slightly more females than males. Individual isopods were used only once per experiment and after approximately 24 hours, I recorded which block the isopod colonized. Blocks were considered colonized if isopods inhabited a burrow in a block, created a burrow, or if they were crawling or nestled on the block at the experiment end (since this is a common behavior prior to creating a burrow). In the case of the illuminated versus shaded experiment, I recorded which side of the microcosm the isopod was found. Microcosms were scrubbed with soap, rinsed, and dried and then cleaned with alcohol and rinsed twice more with seawater before each experiment. Salinity and water temperature varied between 18-23 PSU and 9.7-13.8 ${ }^{\circ} \mathrm{C}$ for most experiments, typical conditions from the 
estuary whence they came. I used Styrofoam and wood substrata for some experiments due to the difficulty of finding juvenile isopods $(<5 \mathrm{~mm})$ in marsh blocks or when marsh bank substrata were not available. I conducted chi-square tests, using $\mathrm{R}$, to compare the numbers of isopod subjects that colonized in each treatment group with the numbers in the corresponding control group. I used a logistic regression to examine the colonization preferences of isopods in varying densities of moribund conspecifics.

Table 5.1. The treatment and control blocks and conditions for colonization experiments.

\begin{tabular}{|c|c|c|c|c|c|c|}
\hline Treatment & Control & Subject & Substratum & $\mathbf{n}$ & $\begin{array}{l}\text { Salinity } \\
\text { PSU }\end{array}$ & $\begin{array}{l}\text { Water temperature } \\
\left({ }^{\circ} \mathrm{C}\right)\end{array}$ \\
\hline $\begin{array}{l}\text { Conspecifics \& } \\
\text { burrows }\end{array}$ & Unburrowed & Adults & Marsh bank & 14 & $20-22$ & 9.7 \\
\hline Drilled burrows & Unburrowed & Adults & Marsh bank & 13 & 18 & 12 \\
\hline Drilled burrows & Unburrowed & Juveniles & Styrofoam $^{\mathrm{a}}$ & 19 & 18 & 12 \\
\hline Biofilm & Drilled burrows & Adults & Wood $^{b}$ & 20 & 19 & 13.8 \\
\hline Biofilm & Drilled burrows & Juveniles & Wood $^{b}$ & 4 & 19 & 13.8 \\
\hline Illuminated & Shaded & Adults & $N / A^{c}$ & 10 & 23 & 17 \\
\hline $\begin{array}{l}2 \text { Moribund } \\
\text { conspecifics }\end{array}$ & Drilled burrows & Adults & Marsh bank & 14 & $18-21$ & 11.9 \\
\hline $\begin{array}{l}5 \text { Moribund } \\
\text { conspecifics }\end{array}$ & Drilled burrows & Adults & Marsh bank & 12 & $29-30$ & 13.8 \\
\hline $\begin{array}{l}\text { 1-10 Moribund } \\
\text { conspecifics }\end{array}$ & Drilled burrows & Adults & Styrofoam & 22 & 18 & 12 \\
\hline Males & Females & Male & Marsh bank $^{b}$ & 17 & $18-21$ & 12 \\
\hline Males & Females & Female & Marsh bank ${ }^{b}$ & 18 & $18-21$ & 12 \\
\hline
\end{tabular}

Footnotes:

${ }^{a}$ I used different substrata because juveniles were too small and difficult to find in marsh blocks

${ }^{\mathrm{b}}$ Drilled burrows were created in both treatment and control blocks

${ }^{c}$ Colonization was evaluated based on which side of the microcosm the isopod was found at the experiment end. A substratum was not used since it was not possible to illuminate the bottom of a substratum in the container without also interfering with the shaded control. 


\section{Results}

Several factors influenced which block or area individuals of S. quoianum colonized, especially the presence of conspecifics, presence of biofilm, and shade from direct light (Table 5.2). Isopods colonized blocks with conspecifics in burrows significantly more often than unoccupied substrata. This pattern seems attributable to presence of conspecifics rather than presence of burrows because adults and juveniles colonized blocks initially lacking burrows almost as often as those with pre-drilled burrows in unoccupied substrata. Biofilm attracted both adult and juvenile colonizers in wood substrata in nearly all replicates. Isopods selected the shaded side more often than the illuminated side of the microcosm in all replicate trials.

While isopods colonized blocks with moribund conspecifics less frequently than the control block (without isopods) in the trials, the difference was not statistically significant. Similarly, colonization was not affected by the presence of varying numbers of moribund conspecifics. Male and female subjects responded differently to the presence of the opposite sex. When offered a choice between either blocks inhabited by all male isopods or by all female isopods, male isopods selected the block with all males in 16 out of 17 replicates. While there was some transfer of individuals between blocks, the blocks originally stocked with males still harbored a greater number of males than the female block at the end of the experiment. Conversely, female subjects did not exhibit a colonization preference when offered blocks with all males or all females. 
Table 5.2. Results from colonization experiments. Values in parentheses represent the number of replicates where individual subjects colonized treatment or control blocks. Bold text denotes statistical significance.

\begin{tabular}{llllll}
\hline Treatment & Control $^{\mathbf{a}}$ & Subject & $\boldsymbol{n}$ & $\chi^{\mathbf{2}}$ & $\boldsymbol{P}$ \\
\hline Conspecifics \& burrows (14) & Unburrowed (0) & Adults & 14 & 14.0 & $<\mathbf{0 . 0 0 1}$ \\
\hline Drilled burrows (8) & Unburrowed (5) & Adults & 13 & 0.7 & 0.405 \\
\hline Drilled burrows (10) & Unburrowed (9) & Juveniles & 19 & 0.1 & 0.819 \\
\hline Biofilm (19) & Drilled burrows (1) & Adults & 20 & 16.2 & $<\mathbf{0 . 0 0 1}$ \\
\hline Biofilm (4) & Drilled burrows (0) & Juveniles & 4 & 4.0 & $\mathbf{0 . 0 4 6}$ \\
\hline Light (0) & Dark (10) & Adults & 10 & 10.0 & $\mathbf{0 . 0 0 2}$ \\
\hline Two Moribund conspecifics (5) & Drilled burrows (9) & Adults & 14 & 1.14 & 0.285 \\
\hline Five Moribund conspecifics (3) & Drilled burrows (9) & Adults & 12 & 3.0 & 0.083 \\
\hline 1-10 Moribund conspecifics (13) & Drilled burrows (9) & Adults & 22 & $1.18^{\mathrm{b}}$ & 0.240 \\
\hline Males (16) & Females (1) & Male & 17 & 13.2 & $<\mathbf{0 . 0 0 1}$ \\
\hline Males (8) & Females (10) & Female & 18 & 0.2 & 0.637 \\
\hline
\end{tabular}

Footnotes:

${ }^{a}$ Replication level varied due to logistical constraints or from failure of subjects to colonize either block

${ }^{\mathrm{b}}$ Results from a Logistic regression

\section{Discussion}

Several small-scale factors affected the colonization of substrata by $S$. quoianum in lab experiments. Isopods colonized blocks with conspecifics over unoccupied substrata, suggesting aggregation was preferred to colonizing a vacant unburrowed substratum. In addition, since isopods did not exhibit a preference for either unburrowed marsh blocks or marsh blocks with drilled burrows, they appear to be attracted to the biological aspect of the substratum (presence of conspecifics) over the habitat/physical aspect of the substratum (presence of burrows). These results have several important implications. Since the data suggest isopods are gregarious, the presence of existing populations will likely attract dispersing isopods. Colonization by these burrowing 
isopods is damaging to substrata, especially when density is higher (Davidson \& de Rivera 2010), thus areas that are already populated by isopods will likely face substantial local damage or erosion from additional colonizers.

The presence of biofilm attracted both adult and juvenile colonizers in wood substrata implying that substratum conditioning by microorganisms may be important in affecting colonization by $S$. quoianum. The cues exuded by fungal metabolites in decaying wood are an attractant to wood-boring Limnoria (Guyer 1981) and it is possible that S. quoianum responds similarly. Unlike Limnoria, S. quoianum does not consume wood for sustenance, but the presence of fungal metabolites may reveal wood has achieved a certain level of decay (hence reduced hardness) that may indicate the presence of a suitable substratum for burrowing. These results may help explain the long history of attack to wooden structures and vessels throughout the isopod's native range in Australia (Cookson 1986, Cragg et al. 1999) and why decayed wood was a preferred substratum to marsh bank, Styrofoam, and sandstone in field choice experiments in the intertidal (Davidson et al. 2008a). While physical exploration of a surface is likely an important way isopods evaluate suitability for colonization, the data suggest areas colonized by biofilm attract isopods. Thus, both physical exploration and chemoreception may be important during colonization.

Isopods also aggregated in the shaded areas of the microcosms, which suggests $S$. quoianum is negatively phototactic. These results are congruent with field observations of congeneric S. terebrans in Australia (Cookson 1994) and S. terebrans in Taiwan (pers obs) inhabiting shaded regions of woody substrata. In addition, S. quoianum in burrows 
move away from light when burrows are breached or when light is introduced into the burrow opening (pers obs). The avoidance of light may be related to detrimental factors associated with sunlight outside a darkened burrow (desiccation or predators, for example). This preference also may explain why isopods are found in such large densities in Styrofoam floats (Chapter 3). Since floats are under docks and receive minimal light even during the day, isopods may preferentially colonize (hence damage) floats.

Although male isopods of the congener S. terebrans actively seek out females for reproduction (Messana et al. 1994), I found male isopods were attracted to other male isopods substantially more than to female isopods. These results do not appear to be an experimental artifact since the placement of all treatments and controls were alternated and every replicate was treated identically. It is unclear why male isopods would be attracted to other males. I have not observed agonistic interactions between males and females (pers obs) and females of the congener S. terebrans only appear to actively push males out of the burrow following mating (Thiel 1999). Furthermore, since females of $S$. terebrans rarely leave their burrows (Messana et al. 1994, Thiel 1999), it seems unlikely females of $S$. quoianum would actively leave their burrow to prevent colonization of the experimental blocks by males. Other explanations for these results are that males aggregate with other males to enhance individual reproductive success or males are more capable of detecting other males. While isopods exhibit other complex reproductive and social behaviors (Thiel 1999, Shuster 1989), additional experimentation is needed to clarify the meaning of these results. 
On centimeter scales, colonization is influenced by a variety of factors such as the presence of other conspecifics, biofilm, and light. These microscale features may help explain why some populations of $S$. quoianum exhibit patchiness at small scales (centimeters-meters) in the field and why some substrata and marine structures experience acute attack by this borer. If these microscale features promote isopods to attack specific points on a substratum then these factors may concentrate the destructive effects of burrowing. Burrows tend to be quite shallow (Talley et al. 2001, Davidson and de Rivera, in press), but if enough burrows are clustered in a specific area (and also perhaps already damaged by fungal attack) the damaging effects of boring would be enhanced. Thus small scale heterogeneity in various factors may explain why extensive damage is observed in localized patches of substrata. The localized damage to substrata can have several implications, particularly to marine structures and some marine habitats. Focused attacks to certain areas of pilings by borers caused docks to collapse in San Francisco Bay (Kofoid and Miller 1927) while focused damage to marine habitats such as kelp holdfasts by limnoriid isopods caused the loss of entire plants (Barrales and Lobban 1975). Therefore, the consequences of local colonization, prompted by small scale factors, can manifest themselves at greater scales and may have ecosystem level effects. 


\section{Chapter 6: Damage and alteration of mangroves inhabited by a wood-boring crustacean in a restored mangrove stand in Taiwan}

\section{Introduction}

Mangrove forests are important transition zones between terrestrial and marine ecosystems in the tropics and sub-tropics (Odum and Heald 1975, Nagelkerken et al. 2008). Since these habitats link both marine and terrestrial ecosystems, they can be affected by a suite of marine and terrestrial fauna (reviewed by Cannicci et al. 2008). Animals can alter mangrove structure and processes through herbivory (Beever et al. 1979), root and stem-boring (Perry and Brusca 1989, Ellison and Farnsworth 1990, Brooks and Bell 2002, Feller 2002), root-fouling (Perry 1988, Li and Chan 2008), and trampling (Ross 2006). Fauna can also have indirect effects by modulating soil conditions (Smith et al. 1991, Kristensen and Alongi 2006), enhancing the availability of nutrients (Ellison et al. 1996, Lee 1997), or by mediating the effects of other organisms (Ellison and Farnsworth 1990, Offenberg et al. 2005).

While herbivory is an important top-down process regulating mangrove ecosystems, studies by Feller (2002) demonstrated that terrestrial wood-borers can have substantially larger effects on mangroves than herbivores. In Belize, Feller (2002) found insect stem-borers destroyed over $50 \%$ of the mangal canopy while insect herbivores only affected $6 \%$ of the canopy. Marine root-boring and root-fouling species are also important structuring agents in mangrove ecosystems. Prodigious wood-boring by high densities of isopod crustaceans have been implicated in the degradation of mangrove 
ecosystems in Florida (Rehm and Humm 1973), Kenya and Tanzania (Svavarsson et al. 2002), and India (Santhakumari 1991).

Wood-boring isopods attack submerged aerial roots, causing necrosis and breakage. The destruction of aerial roots, which normally grow into the sediment and provide stability, may increase the susceptibility of mangroves to damage from storms (Rehm and Humm 1973, Santhakumari 1991). While burrowing by sphaeromatid isopods initiates root branching (Simberloff et al. 1978, Perry 1988), burrowing causes a net reduction in root growth and productivity (Perry 1988, Brooks and Bell 2002). Many studies have examined the association between wood-boring isopods and the freehanging roots of red mangroves (Rhizophora mangle; Ellison and Farnsworth 1990, Perry 1988, Perry and Brusca 1989), but these studies have not examined the relationship between boring and tree-level characteristics of morphology and performance. I hypothesized that burrow density of wood-boring isopods will be positively associated with (1) evidence of mangrove root damage (root breakage and necrosis); and (2) lower fecundity and performance of the whole tree.

Numerous wood-boring and fouling crustaceans and mollusks are found in mangroves in Taiwan and adjacent areas (Morton 1991, Huang et al. 1996, ValentichScott 2003). The negative effects of barnacles (Fistulobalanus albicostatus) to mangroves have been examined in Taiwan ( $\mathrm{Li}$ and Chan 2008), but the present status and effects of populations of wood-borers in Taiwan mangroves remains unknown. The wood-boring isopod Sphaeroma terebrans appears to be a very prevalent wood-borer in the mangrove trees of southern central Taiwan (pers obs) where it is presumed to be 
native. Pilot surveys revealed approximately $89 \%$ of Avicennia marina and $97 \%$ of Rhizophora stylosa trees harbored burrows of isopods (unpublished data). These animals bore into the free-hanging aerial roots of red mangroves and also appear to attack the trunk, branches, and pneumatophores of Avicennia marina (pers obs). Therefore, I tested if the density of $S$. terebrans burrows in the roots and trees of A. marina and R. stylosa was positively associated with root damage (root breakage and necrosis) but negatively associated with tree fecundity and performance in a mangrove restoration site in Taiwan.

\section{Methods}

Study Site

To examine the relationships between boring damage of $S$. terebrans and the morphology and performance of mangrove trees, I conducted a mensurative experiment in Haomeiliao Nature Preserve (Chiayi County, Taiwan; N2321.661 E12007.826) between July 22 and 27, 2010. Haomeiliao Nature Preserve is a restored intertidal mangrove stand in a semi-enclosed lagoon in southern-central Taiwan largely composed of Avicennia marina ( 2m tall) and Rhizophora stylosa ( 2-3m tall). Several thousand propagules of $R$. stylosa were planted in 1993-1994 (Peng 1993, Chen et al. 1995). Since this site was restored in 1993-94, I assumed the $R$. stylosa trees were similar in age. The records were less clear for $A$. marina but an unknown number of $A$. marina was planted in 1975. Avicennia marina trees may have naturally occurred at the site before restoration began, so their ages may vary. 


\section{Tree Sampling}

I sampled thirteen A. marina trees and ten $R$. stylosa trees accessible along a 600 meter transect that followed the edge of the mangrove stand. Due to the inaccessibility of mangroves, sampling occurred within $40 \mathrm{~m}$ from the edge of the mangrove stand. I used random numbers to select the locations along the transect to sample. At each of those locations, I sampled the nearest mangrove tree orthogonal and shoreward to the transect. Since the mangrove edge was sinuous, some trees were sampled at varying distances from the transect (but within $40 \mathrm{~m}$ and at similar tidal heights).

At each tree, I measured various characteristics of tree morphology, performance, fecundity, and isopod damage (Table 6.1). Because of differences in morphology between the two species, I sampled slightly different aspects and numbers of roots of each species. I haphazardly sampled five free-hanging unbranched aerial root tips from each of ten $R$. stylosa trees and sampled and collected ten pneumatophores from each of thirteen A. marina trees. I cut the aerial root tips off at their initiation point (when it was accessible) or approximately five $\mathrm{cm}$ above the burrowed area of the root and cut pneumatophores off at the surface of the sediment. These roots were dissected in the lab to determine the number of isopods in each root and patterns of damage. The weight and length of sampled pneumatophores were measured and the number of lenticels on each pneumatophore counted. In addition, to measure the density of unburrowed, burrowed, or broken pneumatophores, I randomly placed three quadrats $\left(0.125 \mathrm{~m}^{2}\right)$ within $1 \mathrm{~m}$ of each A. marina tree; I used random numbers between 0-360 (degrees) to indicate the direction around the tree to sample and a random number between 0-100 (cm's) to indicate the 
distance to sample from each tree. I characterized pneumatophores as broken if they were missing their tips or if the outer tissue around the tips was removed. The mean biomass of pneumatophores per quadrat was estimated by multiplying pneumatophore density by the mean pneumatophore weight (from above). Salinity, air temperature, sediment temperature, and relative tidal height were also measured. I estimated tidal inundation time of the sampled trees based on a tidal inundation contour map (Hsieh et al., unpublished data).

I tested the association between the tree morphological characteristics and isopod damage through simple linear regressions. Transformations (square-root or logtransformations) were used to meet the statistical assumptions (i.e. normality and equal variances of residuals) of linear regressions, to reduce the influence of outliers, and improve linearity between variables. Visual examination of scatterplots and Akaike information criterion values were used to evaluate the fit of different models. I examined Cook's distance to reveal potentially influential data points. I present values as means \pm 95\% confidence intervals throughout. 
Table 6.1. Morphological, performance, fecundity, and damage metrics measured for Rhizophora stylosa and Avicennia marina.

$\begin{array}{lr}\text { Mangrove Characteristics } & \text { Rhizophora } \\ \text { Morphological \& Performance Metrics } & \\ \text { Height } & \times \\ \text { Circumference }^{1} & \times \\ \# \text { of Grounded Roots } & \times \\ \# \text { free hanging aerial roots } & \times \\ \% \text { of roots that are grounded } & \\ \text { \# of first-order branches with leaves } & \\ \text { pneumatophore density }\left(\# / 0.125 \mathrm{~m}^{2}\right) & \\ \text { pneumatophore length } & \\ \text { pneumatophore weight } & \\ \text { \# Lenticels/pneumatophore }\end{array}$

$\begin{array}{ll}x & x \\ x & x \\ x & x \\ x & - \\ x & - \\ x & - \\ - & x \\ - & x \\ - & x \\ - & x\end{array}$

\section{Fecundity Metric}

\# of propagules

$X$

\section{Damage Metrics}

\# of burrows per tree

$\%$ of roots burrowed ${ }^{2}$

$\%$ of roots broken ${ }^{2}$

mean \# burrows per root ${ }^{2}$

mean \# isopods per root ${ }^{2}$

mean \% cover of necrotic tissue on

pneumatophore

$\begin{array}{cc}- & x \\ x & x \\ x & x \\ x & x \\ x & x \\ - & x\end{array}$

Footnotes:

${ }^{1}$ Since many of the trees were small (1-2 $\mathrm{m}$ tall), the circumference was measured $\sim 5-10 \mathrm{~cm}$ from the sediment surface, where the trunk first tapers in from the roots.

${ }^{2}$ Roots for $R$. stylosa are free-hanging aerial roots; roots for A. marina are pneumatophores 


\section{Results}

Extent of burrowing in mangroves

Both R. stylosa and A. marina trees exhibited extensive burrowing damage from Sphaeroma terebrans (Figure 6.1). In R. stylosa, the mean percentage of roots burrowed by isopods was $44.6 \pm 22.6 \%$ and the mean percentage of broken roots was $30.4 \pm 23.0 \%$. However, when pooling the data for all roots of $R$. stylosa, $86.0 \%$ of all sampled aerial roots were burrowed and $79.1 \%$ of roots harbored isopods. Nearly $88.4 \%$ of the roots that were burrowed were free hanging aerial roots and $11.6 \%$ were grounded roots. Only three branches of the sampled $R$. stylosa trees had ever been burrowed by isopods. The mean number of burrows in the sampled A. marina trees was $194 \pm 90$. More burrows were in the trunk $(53.1 \%)$ and branches $(30.1 \%)$ than grounded roots $(16.8 \%)$. The trees with the most visible damage by burrows had truncated, broken, or necrotic roots, discolored leaves, and in A. marina, perforated sections or hollowed out trunks (Figure 6.1). No other burrowing organisms (insects or shipworms) were found in the roots of $R$. stylosa or in A. marina. 

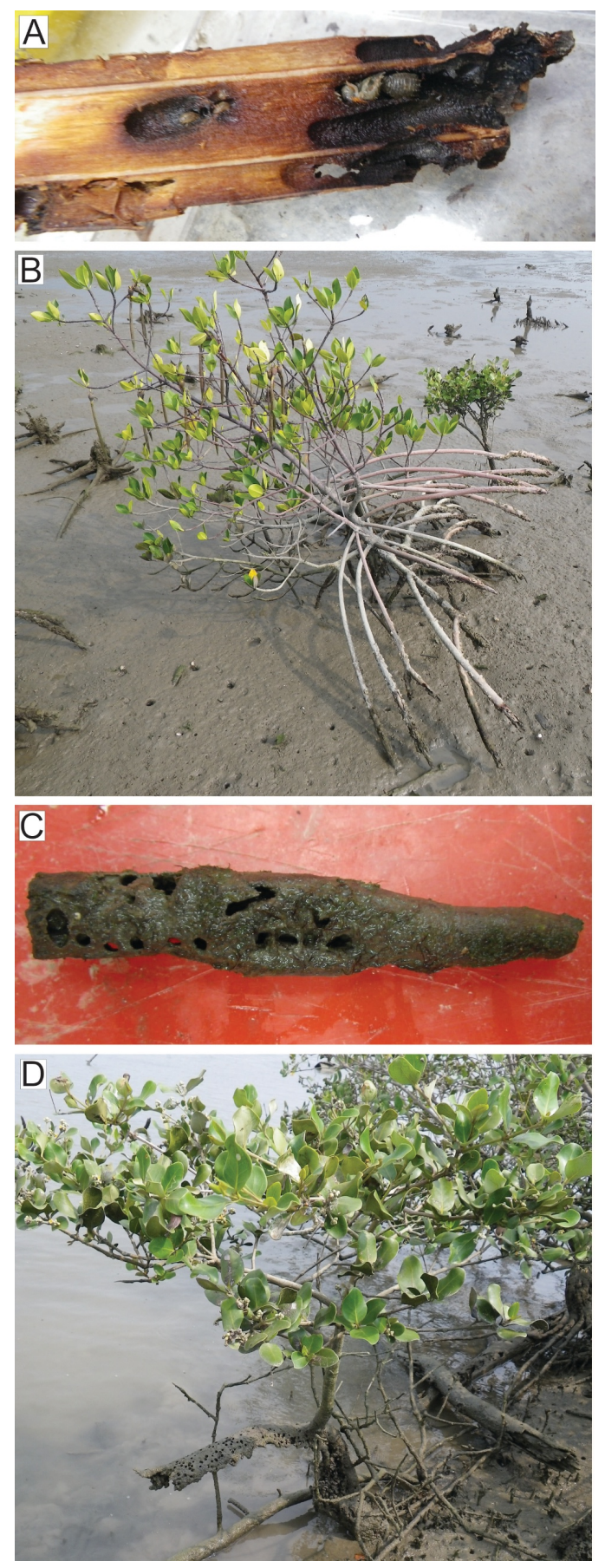

Figure 6.1. Burrowing isopods (Sphaeroma terebrans) burrowed into multiple parts of mangroves in Haomeiliao Nature Preserve, including (A-B) the free-hanging aerial roots of Rhizophora stylosa (roots used to anchor and support the tree), the (C) pneumatophores (roots used in gaseous exchange) and (D) the trunk, branches, and roots of Avicennia marina. 


\section{Relationship between burrows and isopods in mangrove roots and root damage}

In $R$. stylosa, the free-hanging aerial roots harbored mean burrow densities of $10.33 \pm 5.54$ and isopod densities of $17.36 \pm 10.21$ per root. Approximately $41 \%$ of the isopods in these roots were adults ( $>5 \mathrm{~mm}$ ). The mean density of burrows in roots was related to the mean number of isopods in roots $\left(r^{2}=0.89, P<0.001, t=7.92, \mathrm{df}=8\right)$. The mean burrow density in the aerial roots was negatively related to the number of ground roots $\left(r^{2}=0.46, t=2.49, P=0.031, \mathrm{df}=8\right)$. Similarly, burrow density was positively related to the percentage of aerial roots $\left(r^{2}=0.54, P=0.015, t=3.07, \mathrm{df}=8\right)$ and ground roots $\left(r^{2}=0.44, P=0.037, t=2.49, \mathrm{df}=8\right)$ that were burrowed. $\mathrm{I}$ did not detect significant relationships between the mean burrow densities in roots and other measured variables $(P>0.05)$.

In the sampled pneumatophores of A. marina, mean burrow and isopod densities were $1.81 \pm 0.52$ and $0.53 \pm 0.19$, respectively. However, within burrowed pneumatophores, mean burrow and isopod densities were $2.70 \pm 0.56$ and $1.59 \pm 0.33$. Burrows were present in pneumatophores of all sampled trees and in $65.8 \%$ of all sampled pneumatophores. Isopods were present in pneumatophores of 12 out of 13 sampled trees and in only $32.5 \%$ of all sampled pneumatophores. Juvenile isopods $(<5 \mathrm{~mm})$ were the primary inhabitants of pneumatophores $(61 / 62 ; 98.4 \%)$; only one larger isopod was observed in a relatively large pneumatophore.

Approximately $78.3 \%$ of sampled pneumatophores exhibited discolored, necrotic tissue. The arenchyma tissue had been completely removed in the most heavily burrowed and discolored pneumatophores, leaving only a thin outer sheath. The mean burrow 
density in pneumatophores was positively related to the percentage of pneumatophore surface that was damaged, discolored, and necrotic $\left(r^{2}=0.50, P=0.007, t=3.3, \mathrm{df}=11\right)$.

\section{Relationship between isopod burrowing and mangrove damage, morphology,} performance, and fecundity

The percentage of roots burrowed was positively related with the percentages of roots that were broken (Figure 6.2A) and negatively related with the number of ground roots present and anchoring the tree into the ground (Figure 6.2B) in R. stylosa. Some heavily burrowed individuals of $R$. stylosa, had few supportive ground roots remaining, and had fallen over or were tipping over. The total percentage of roots burrowed by isopods was also positively associated with the percentage of primary branches lacking leaves in $R$. stylosa (Figure 6.2C) and negatively associated with the number of propagules (Figure 6.2D). The total numbers of burrows in A. marina was negatively related to the mean density of pneumatophores (Figure 6.3A). While one value was highly influential (Cook's distance = 1.69; other values ranged between 0.002 and 0.438 ) during this analysis, the relationship between the variables remained the same even after the data point was excluded from the analysis $\left(r^{2}=0.52, P=0.009, t=-3.26, \mathrm{df}=10\right)$. This influential data point was the most heavily burrowed tree in the data set. The total numbers of burrows in A. marina was also negatively related to the mean mass of pneumatophores per quadrat (Figure 6.3B). The total number of burrows in A. marina was also negatively associated with the mean pneumatophore weight (Figure 6.3C) and numbers of lenticels per pneumatophore (Figure 6.3D) although these relationships were 
not statistically significant. No other measures of tree morphology or performance (height, \# of ground roots, etc, see Table 6.1) were significantly related to burrow numbers in A. marina or the percentage of roots burrowed in $R$. stylosa $(P>0.05)$.
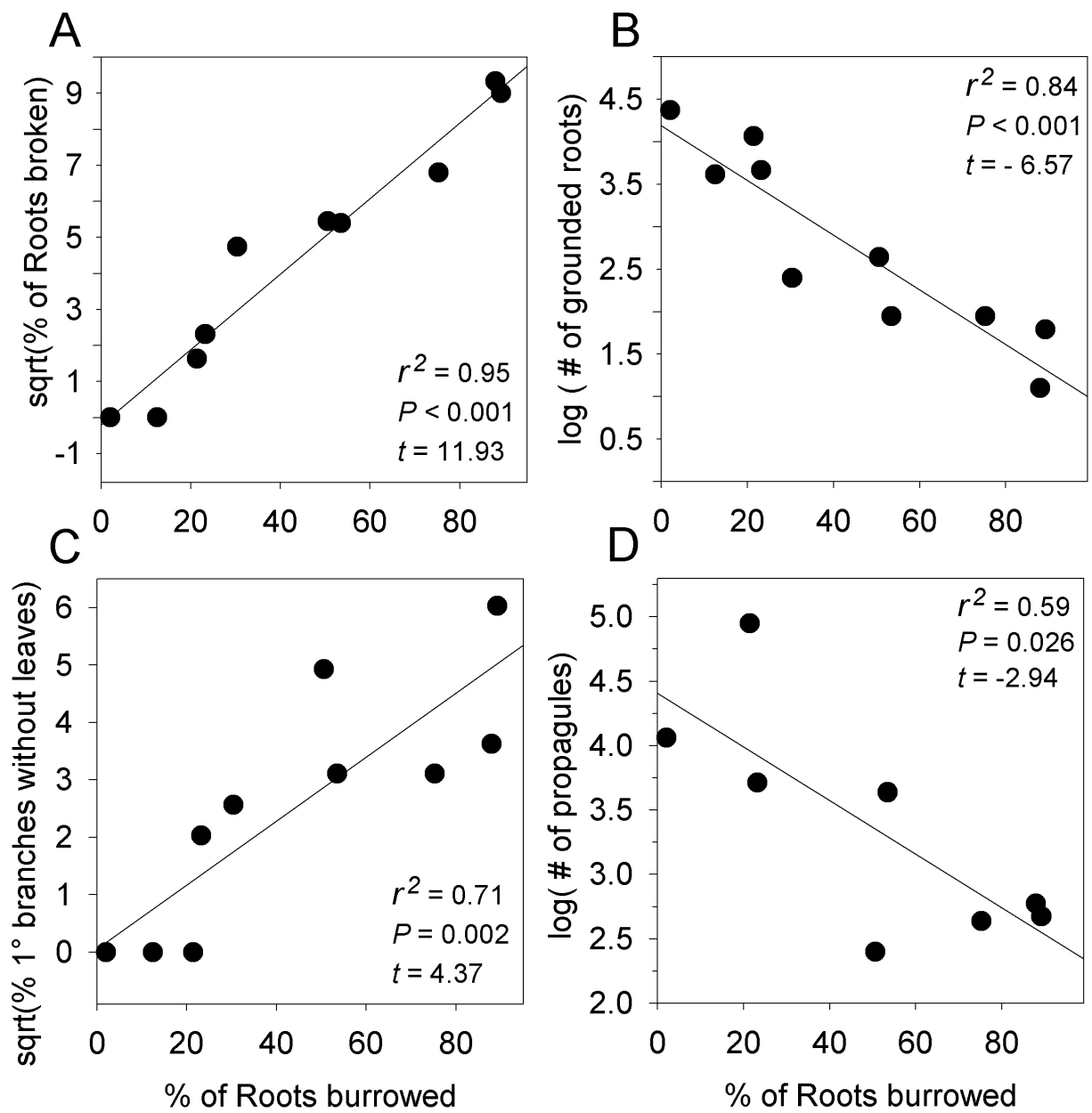

Figure 6.2. Relationships between the percentage of roots burrowed by Sphaeroma terebrans in Rhizophora stylosa and measures of damage, morphology, performance, and fecundity. Sample size differed due to missing data on propagules for one tree.

Environmental factors 
No strong associations $(P>0.05)$ emerged between any of the environmental factors (salinity, air temperature, sediment temperature, tidal inundation time) and the numbers of burrows per tree, percentage of burrowed roots/pneumatophores or mean density of burrows or isopods. However, higher percentages of burrowed roots in $R$. stylos $a$ were found in trees closer to the mangrove edge transect $\left(r^{2}=0.52, P=0.018, t=-\right.$ 2.97, $\mathrm{df}=8$ ). A significant relationship was not found between the distance from the transect and burrowing in A. marina $(P>0.05)$. 

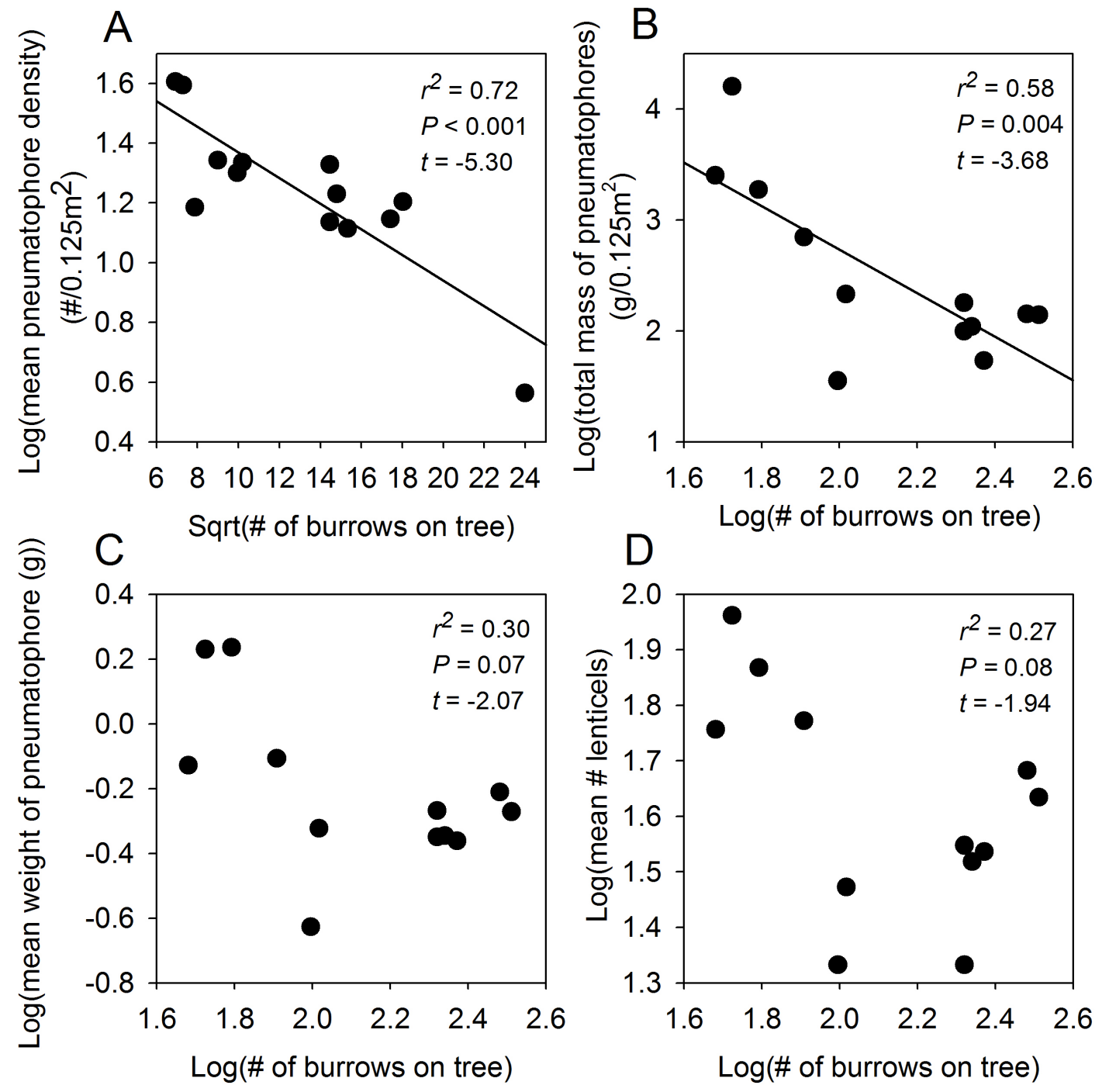

Figure 6.3. The association between the number of burrows per Avicennia marina and (A) mean pneumatophore density, (B) mean biomass of pneumatophores per quadrat, (C) mean pneumatophore weight and (D) mean number of lenticels per pneumatophore. Sample size varied due to missing samples of pneumatophores for one tree. 


\section{Discussion}

Marine wood-borers can have numerous sublethal effects on mangroves by boring into mangrove roots. Isopod boring can reduce root growth rates 50-55\% (Ellison and Farnsworth 1990, Perry 1988) and root productivity 62\% (Perry and Brusca 1989) and stimulate the creation of new root tips or cause atrophy and root breakage (Perry and Brusca 1989). While boring may stimulate root production (Simberloff et al. 1978, Perry 1988, Perry and Brusca 1989), boring damage causes a net reduction in productivity in red mangroves (Perry and Brusca 1989). Thus, the boring effects that occur at the rootlevel may result in effects that alter the tree itself. Furthermore, repair of the root damage, not the stimulation of new plant material, is the most frequent result of boring damage to the root (Brooks and Bell 2002). Brooks and Bell (2002) found 98\% of marked roots underwent repair while only $32 \%$ created new root tips. Since isopods can create burrows in mangrove roots in as little as 24 hours (Brooks and Bell 2001, unpublished data), abundant or frequent isopod boring may exceed the ability of plant to repair the damage and reduce the allocation of resources towards production thus resulting in tree-level effects. I hypothesize the cumulative effect of high levels of isopod boring reduces productivity and diverts energy to root regeneration that would otherwise be devoted to the generation of propagules and leaves.

In the current study, I found mangroves that were more burrowed by the woodboring isopod Sphaeroma terebrans exhibited more damage, an altered morphology, lower performance, and lower fecundity. These associations suggest that boring damage can negatively affect $R$. stylosa and A. marina at the level of the whole tree. Rhizophora 
stylosa trees that were more heavily burrowed by isopods had fewer propagules and fewer of their primary branches had leaves. Thus, more damaged trees may have experienced depressed fecundity and a reduced photosynthetic capacity. In Belize, terrestrial wood-boring insects similarly reduced the numbers of flowers and leaves on mangroves (Feller 2002). Avicennia marina was also affected by isopod boring; trees that were more heavily burrowed had fewer pneumatophores. These burrowed trees also had smaller pneumatophores with fewer lenticels (pores used for oxygen exchange), although these relationships were not statistically significant. Likewise, the pneumatophores that were more burrowed also had more necrotic and discolored tissue. These results suggest burrowing in the tree and its pneumatophores reduces the number of functional pneumatophores and increases root necrosis. A reduction in the number and size of pneumatophores and the lenticels may make the tree less capable of tolerating the anoxic conditions and could affect performance and survivorship (Kathiresan and Bingham 2001). In addition, estimates of the numbers of lenticels that function on heavily burrowed pneumatophores is likely overestimated since I was unable to evaluate functionality while conducting counts of lenticels. Furthermore, since pneumatophores are photosynthetic (Kataya et al. 2001), a reduction in their number and size reduces a tree's photosynthetic capacity. Thus, burrowing by isopods appears to have a variety of effects on the performance and fecundity of mangrove trees.

Dense isopod burrowing may also be preventing aerial roots from growing down into the sediment and anchoring the tree (Perry 1988, Perry and Brusca 1989). Rhizophora stylosa, with a higher percentage of boring in their aerial roots, had more 
broken aerial roots and fewer grounded roots to anchor the tree. Moreover, I observed several trees that had fallen over or that were leaning over; those trees had few grounded roots and high percentages of burrowed aerial roots (pers obs). Rehm and Humm (1973) and Rehm (1976), based on similar observations, speculated that the reduction of grounded roots from isopod burrowing may reduce stability of the tree and cause it to collapse, particularly during storms. Extensive burrowing by isopods may alter the morphology and thus facilitate the extirpation (uprooting) of $R$. stylosa. While I did not observe extirpated or severed trees of A. marina, some individuals were completely hollowed out or perforated from isopod burrowing. Very little force was necessary to break off sections from those damaged trees or to topple them. Furthermore, the presence of numerous burrowed stumps of A. marina may indicate the breakage of those trees, perhaps through water movement or storm events, was facilitated by isopod attack.

While I found evidence that isopod boring is related to damage in mangroves and lower metrics of performance and fecundity, the mensurative nature of this study limits conclusions to correlation rather than causation. An alternative hypothesis is that isopods may be attracted to roots or trees that are already dead or stressed (Plant-Stress Hypothesis, White 1969) and thus attack trees that already have depressed performance and fecundity. However, isopods frequently attack the root tips of red mangroves where the tissue is relatively soft and new (Estevez and Simon 1975, Perry 1988, pers obs). Similarly, insect wood-borers had greater effects to more vigorous and structurally complex red mangroves than the less vigorous and growth-stunted dwarf mangroves in Belize (Feller and Malthis 1997). I also did not observe any other borers within the 
sampled trees; however, I was unable to sample the primary branches of $R$. stylosa to examine if they harbored wood-boring insects. Future studies should investigate the potential interactive effects of wood-boring insects and isopods in mangroves. Another alternative hypothesis is that another factor, such as changes in hydrology, may have affected the mangroves negatively while promoting the colonization and burrowing of isopods. None of the measured environmental factors, including tidal inundation period, varied systematically across replicate trees or were associated with boring; therefore, they are unlikely to be confounding. However, I found the R. stylosa trees that were deeper in the mangrove stand were also less burrowed. These results suggest isopods were primarily attacking trees on the edge of the mangrove stand. Thus, isopods may be having the largest effects to the outermost mangroves and may limit the distribution of red mangroves. Estevez and Simon (1975) found S. terebrans in Florida primarily bore into trees within the first 2 meters of the edge of mangroves. In contrast, I found isopods up to 40 meter deep into the forest (unpublished data). The disparity between these results is likely due to site differences since the edge of the mangrove stand in Haomeiliao was relatively open with many openings and gaps (thus isopods could access many more trees than a denser stand). It is also possible that the age of the tree may confound these results, but the sampled A. marina trees were all within $600 \mathrm{~m}$ of each other and similar in size, and the R. stylosa were planted in the same two years (1993-94). While longerterm manipulative studies examining the effects of boring isopods on different ages of trees would be necessary to assign causality, results from this study suggest that increased boring by isopods can have negative effects on $R$. stylosa and A. marina. 
This research was conducted in a restored mangrove stand with trees that are likely smaller than those examined in other studies and in other locations. In other sites in Taiwan, the mangrove trees that wood-boring isopods attack are very large and the damage appears to be lower than the damage observed in this restored mangrove site (unpublished data). These differences may be due to differences in the relative size and age of the mangrove stands. I hypothesize that the magnitude of wood-borer damage depends on the size (hence age) of mangroves. Very large trees that have multiple roots buttressing the tree and large thick trunks are likely more resistant to isopod damage than the smaller, presumably younger trees observed in Haomeiliao. The damage that does occur to these larger trees was rare (pers obs) or was limited to the aerial root tips. Future studies should investigate if older trees are a biological refuge from wood-boring isopods.

The consequences of these boring effects may also be context- and scaledependent. In more mature forests, isopod boring may maintain the distinct ecotone between dense thickets of mangrove forest and open marine waters (Snedaker and Enright 1974). Such effects may be an important force in maintaining the balance between ecosystems (Snedaker and Enright 1974) when examined at a landscape or ecosystem scale.

The alteration of the physical structure of mangrove trees as well as extirpation or death can have implications for this ecosystem. The toppling of mangroves and changes to the physical structure of the root systems in both $R$. stylosa and A. marina may alter erosion and sedimentation regimes (Spenceley 1977, Kathiresan 2003) and affect commercial species that depend on mangroves as habitat (Primavera 1998, Kathiresan 
and Bingham 2001). Since mangroves provide numerous ecosystem services (Ronnback 1999, UNEP-WCMC 2005) and the abundance of mangroves has declined worldwide (Valiela et al. 2001), there is substantial interest in conserving or restoring mangroves. My study suggests that isopod attack can affect the survivorship and fecundity of trees in a restored mangrove stand, hence restoration success. Previous studies have also found that Sphaeroma terebrans can attack saplings of R. mangle in lab studies (Estevez 1978) in Florida and red mangroves saplings in a restoration site in the Philippines (Primavera, per comm). Boring beetles attacked and killed $73-89 \%$ of mangrove propagules and seedlings in a closed canopy site in Panama (Sousa et al. 2003). Thus, assessing the prevalence and abundance of the wood-boring community present in a proposed restoration site will be important to consider in future restoration efforts. 


\section{General Conclusions}

The boring effects of small crustaceans, while limited on a per capita basis, have drastic and potentially cascading effects on marine habitats and marine facilities when aggregated. Through a small scale experiment and corroborative field sampling, I have demonstrated the per capita effects of isopod borers were greatest to saltmarsh banks and expanded polystyrene foam floats. My subsequent field experiment found these small per capita effects scaled up to larger erosive effects in saltmarshes. In addition, I found boring by isopods can perforate polystyrene floats with burrows, facilitate their breakage, and in the boring process, produce thousands of microplastic particles per animal. Isopods were observed destroying floats in at least five countries but the wide distributions of isopods suggest many more docks are vulnerable to damage. These per capita erosive effects were further mediated by several small-scale factors such as the presence of conspecifics, biofilm, and light; these factors are likely important during the exploratory phase of colonization when isopods first decide where to excavate a burrow. These small scale factors prompt isopods to aggregate in dense colonies and are likely indirectly responsible for the extensive localized boring damage to marine habitats and structures. This localized damage itself may create a "weak link" in the physical structure of saltmarshes and mangrove trees and interact in destructive ways with other erosional forces.

Through biological erosion and thus changing the physical structure of a marine habitat, I found small burrowers can have ecosystem-level effects that may cascade throughout the local community. I found marshes infested by isopods experienced 
erosion rates 300\% higher than uninfested marshes. Thus, isopods can have an immediate bioerosive effect by excavating a burrow (Talley et al. 2001), but also the presence of dense aggregations of burrows appears to increase the rate of lateral erosion. This erosive action fundamentally alters the structure of this habitat by converting heterogeneous saltmarsh habitat into bare mudflats, and therefore changes the saltmarsh community. Similarly, in the tropical congener, S. terebrans, I found boring was negatively related to several indicators of performance and fecundity in two mangrove species in a restored mangrove stand. While previous experiments show isopods can affect the root growth of mangroves (Perry 1988, Perry and Brusca 1989, Brooks and Bell 2002), my results suggest isopods can also affect tree-level characteristics of mangroves such as performance, fecundity, and morphology. The alteration of the morphology and structure of these mangroves can also lead to concomitant effects to the surrounding community that depend on mangrove resources. I found evidence that isopod boring can substantially alter ecosystems, however, future work should empirically examine these relationships over longer time frames and in multiple sites. Specifically, multi-year experiments will be key to understanding how seasonal or yearly changes in demography or weather may interact with biological erosion rates. Disturbance is also likely a critical factor that can interact with biological erosion. I hypothesize that the effects of biological erosion interact synergistically with disturbance (especially extreme events) including storms, surges, seismic activity, or scouring by ice or other debris. Future studies should investigate the relative importance of the interaction of biological erosion and rare and extreme disturbance events on marine habitats. 
Seawater temperature had an important influence on the rate of biological erosion. If ocean temperatures rise as predicted by the IPCC $\left(1-2^{\circ} \mathrm{C}\right.$ in the next 90 years), the bioerosive effects of S. quoianum may increase $5.1-17.1 \%$ in some cold central California and Oregon bays where boring isopods have invaded. Since other borers and burrowers excavate substrata in a similar fashion as boring isopods and exhibit a similar response to changing temperatures, I hypothesize the effects of other borers will also increase. Future studies should investigate how other bioeroders are affected by changing temperatures in the field. In particular, studies investigating the role of coral bioeroders in degrading coral reefs will be very important in understanding how this ecosystem will interact with climate change.

My experiments in saltmarshes and mangroves and marine facilities indicate the erosive effects exceed the direct effects of the removal of material. These results suggest that biological erosion, when localized, may be non-linearly related to the degradation of marine habitats and facilities. Determining these thresholds will be important in managing possible detrimental effects of borers and burrowers on habitats and facilities. Quantitative experiments that allow the modeling of the non-linear relationship between biological erosion and the consequent loss of habitat will be helpful in predicting possible regime shifts in these habitats. Such models would also help predict the failure of docks and facilities affected by borers. A dual approach using both controlled lab experiments and long-term field studies will be critical to understanding the complex process of erosion and ecosystem change. 


\section{References}

Aldridge DC, Salazar M, Serna A, Cock J (2008) Density-dependent effects of a new invasive false mussel, Mytilopsis trautwineana (Tryon 1866), on shrimp, Litopenaeus vannamei (Boone 1931), aquaculture in Colombia. Aquaculture 281: $34-42$

Alvarez-Borrego J, Alvarez-Borrego S (1982) Temporal and spatial variability of temperature in two coastal lagoons. Cal COFI Report 23: 188-197

Andrews C, Williams RGB (2000) Limpet erosion of chalk shore platforms in southeast England. Earth Surface Processes and Landforms 25: 1371-1381

Arthur C, Baker J, Bamford H (2009) Proceedings of the International Research Workshop on the occurrence, effects and fate of micro-plastic marine debris. Sept 9-11, 2008. NOAA Technical Memorandum NOS-OR\&R-30

Ashton K, Holmes L, Turner A. (2010) Association of metals with plastic production pellets in the marine environment. Mar Pollut Bull 60: 2050-2055

Bakun A (1990) Global climate change and intensification of coastal ocean upwelling. Science 247: 198-201

Bane S (2002) Effects of an invasive isopod on erosion rates at Elkhorn Slough, California. MS thesis, San Jose State University, San Jose, CA

Baratti M, Filippelli M, Messana G (2011) Complex genetic patterns in the mangrove wood-borer Sphaeroma terebrans Bate, 1866 (Isopoda, Crustacea, Sphaeromatidae) generated by shoreline topography and rafting dispersal. J Exp Mar Biol Ecol 398:73-82

Baratti M, Goti E, Messana G (2005) High level of genetic differentiation in the marine isopod Sphaeroma terebrans (Crustacea Isopoda Sphaeromatidae) as inferred by mitochondrial DNA analysis. J Exp Mar Biol Ecol 315: 225- 234

Barnes DKA (2002) Invasions by marine life on plastic debris. Nature 416: 808-809

Barnes DKA, Galgani F, Thompson RC, Barlaz M (2009) Accumulation and fragmentation of plastic debris in global environments. Phil Trans R Soc B 364: 1985-1998

Barrales HL, Lobban CS (1975) The comparative ecology of Macrocystis pyrifera, with emphasis on the forests of Chubut, Argentina. J Ecol 63: 657-677 
Barrows, A. L. 1919. The occurrence of a rock-boring isopod along the shore of San Francisco Bay, California. University of California Publications in Zoology 19: 299-316.

Bate SC (1866) Carcinological gleanings. II. Annals and Magazine of Natural History 17: $24-30$

Beckman C, Menzies RJ (1960) The relationship of reproductive temperature and the geographical range of the marine woodborer Limnoria tripunctata. Bio Bull 118: 9-16

Beckman C, Menzies RJ (1960) The relationship of reproductive temperature and the geographical range of the marine woodborer Limnoria tripunctata. Bio Bull 118: 9-16

Beever JW, Simberloff D, King LL (1979) Herbivory and predation by the mangrove tree crab Aratus pisonii. Oecologia 43: 317-328

Behrens Yamada, S (1989) Are direct developers more locally adapted than planktonic developers? Mar Biol 103: 403-411

Belanger L, Bedard J (1994) Role of ice scouring and goose grubbing in marsh plant dynamics. J Ecol 82: 437-445

Benson LK, Rice SA, Johnson BR (1999) Evidence of cellulose digestions in the wood boring isopod Sphaeroma terebrans. Florida Scientist 62: 128-144

Bertness MD (1985) Fiddler crab regulation of Spartina alterniflora production on a New England salt marsh. Ecology 66: 1042-1055

Boerger CM, Lattin GL, Moore SL, Moore CJ (2010) Plastic ingestion by planktivorous fishes in the North Pacific Central Gyre. Mar Pollut Bull 60: 2275-2278

Boesch DF, Turner RE (1984) Dependence of fishery species on salt marshes: the role of food and refuge. Estuaries 7: 460-468

Borges LMS, Cragg SM, Busch S (2009) A laboratory assay for measuring feeding and mortality of the marine wood borer Limnoria under forced feeding conditions: A basis for a standard test method. International Biodeterioration \& Biodegradation 63: $289-296$

Bortolus A, Schwindt E, Iribarne O (2002) Positive plant-animal interactions in the high marsh of an Argentinean coastal lagoon. Ecology 83: 733-742 
Broecker WS, Sutherland S, Peng TH (1999) A possible 20th century slowdown of Southern Ocean deep water formation. Science 286: 1132-1135

Bromberg Gedan K, Silliman BR (2009) Patterns of salt marsh loss within coastal regions of North America. In: Silliman BR, Bertness, MD. Grosholz E (eds), Human impacts on salt marshes: a global perspective, University of California Press, Berkeley and Los Angeles

Brook HJ, Rawlings TA, Davies RW (1994) Protogynous sex change in the intertidal isopod Gnorimosphaeroma oregonense (Crustacea: Isopoda). Biol Bull 187: 99111

Brooks RA, Bell SS (2001) Colonization of a dynamic substrate: factors influencing recruitment of the wood-boring isopod, Sphaeroma terebrans, onto red mangrove (Rhizophora mangle) prop roots. Oecologia 127: 522-532

Brooks BA, Bell SS (2002) Mangrove response to attack by a root boring isopod root repair versus architectural modification Mar Ecol Prog Ser 231: 85-90

Brown JH (1984) On the relationship between abundance and distribution of species. The American Naturalist 124: 255-279

Browne MA, Dissanayake A, Galloway TS, Lowe DM, Thompson RC (2008) Ingested microscopic plastic translocates to the circulatory system of the mussel Mytilus edulis (L.). Environ Sci Technol 42: 5026-5031

Brown-Saracino, Peckol JP, Curran HA, Robbart ML (2007) Spatial variation in sea urchins, fish predators, and bioerosion rates on coral reefs of Belize. Coral Reefs 26: $71-78$

Bruggemann, JH, van Kessel AM, van Rooij JM, Breeman AM (1996) Bioerosion and sediment ingestion by the Caribbean parrotfish Scarus vetula and Sparisoma viride: implications of fish size, feeding mode and habitat use. Mar Ecol Prog Ser 134: $59-71$

Butler DR (1995) Zoogeomorphology: animals as geomorphic agents. Cambridge University Press, New York

Byrne M, Ho M, Selvakumaraswamy P, Nguyen HD, Dworjanyn SA, Davis AR (2009) Temperature, but not $\mathrm{pH}$, compromises sea urchin fertilization and early development under near-future climate change scenarios. Proc R Soc B 276: 1883-1888 
Canepuccia AD, MS Fanjul, E Fanjul, F Botto, O Iribarne (2008) The intertidal burrowing crab Neohelice (= Chasmagnathus) granulate positively affects foraging of rodents in South Western Atlantic salt marshes. Estuaries and Coasts 31:920-930

Cannicci S, Burrows D, Fratini S, Smith III TJ, Offenberg J, Dahdouh-Guebas F (2008) Faunal impact on vegetation structure and ecosystem function in mangrove forests: A review. Aquat Bot 89: 186-200

Carlton JT (1979) History, biogeography, and ecology of the introduced marine and estuarine invertebrates of the Pacific coast of North America. PhD Dissertation. University of California, Davis

Carlton JT (1996) Marine Bioinvasions: The alteration of marine ecosystems by nonindigenous species. Oceanography 9: 36-43

Carlton JT (2001) Introduced species in U.S. coastal waters: environmental impacts and management priorities. Pew Oceans Commission, Arlington, Virginia, 28 pp.

Carlton JT, Iverson EW (1981) Biogeography and natural history of Sphaeroma walkerii Stebbing (Crustacea: Isopoda) and its introduction into San Diego Bay, California. J Nat Hist 15: 31-48

Carlton JT, Ruckelshaus MH (1997) Nonindigenous marine invertebrates and algae. In: Strangers in Paradise: impact and management of nonindigenous species in Florida. Eds: Simberloff D, Schmitz DC, Brown TC. Washington, DC: Island Press. 187-202

Carlton JT, Ruiz GM (2005) The magnitude and consequences of bioinvasions in marine ecosystems: implications for conservation biology. In: Marine Conservation Biology: The science of maintaining the Sea's Biodiversity. Eds: Norse EA, Crowder LB. Island Press, Washington. 123-148

Carpenter EJ, Anderson SJ, Harvey GR, Miklas HP, Peck BB (1972) Polystyrene spherules in coastal water. Science 178: 749-750

Carreiro-Silva M, TR McClanahan (2001) Echinoid bioerosion and herbivory on Kenyan coral reefs: the role of protection from fishing. J Exp Mar Biol Ecol 262: $133: 153$ 
Chen TS, Lai GX, Xue ML (1995) Preliminary restoration results of Rhizophora stylosa. Mangrove ecosystem conference: 81-91. Taiwan Endemic Species Research Institute

Chilton C (1919) Destructive boring Crustacea in New Zealand. New Zealand Journ Sci Techn 2: 1-15

Clamp JC (2006) Redescription of Lagenophrys cochinensis Santhakumari \& Gopalan,1980 (Ciliophora, Peritrichia, Lagenophryidae), an ectosymbiont of marine isopods, including new information on morphology, geographic distribution, and intraspecific variation. J Eukaryotic Microbiology 53:58-64

Cohen AN, Carlton JT (1995) Nonindigenous aquatic species in a United States estuary: a case study of the biological invasion of San Francisco Bay and Delta. Biological study. Final report no. NOAA-NA36RG0467, FWS -14-48-0009-93-9 61. University of California, Berkeley. $246 \mathrm{pp}$

Cohen BF, McArthur MA, Parry GD (2001) Exotic marine pests in the Port of Melbourne, Victoria. Marine and Freshwater Resources Institute, Report No. 25, Queenscliff, Victoria. $68 \mathrm{pp}$

Connors PG, Smith KG (1982) Oceanic plastic particle pollution: suspected effect on fat deposition in red phalaropes. Mar Pollut Bull 13: 18-20

Conrad TA (1837) Descriptions of new marine shells, from Upper California: collected by Thomas Nuttall, Esq. Journal of the Academy of Natural Sciences Philadelphia 7: 227-268

Cookson LJ (1986) Marine borers and timber piling options. CSIRO Research Review 14 $\mathrm{pp}$

Cookson LJ (1994) Observations on the activities of Sphaeroma in Australia. The International Research Group on Wood Preservation. Document number: IRG/WP/94-10059

Cossins AR, Bowler K (1987) Temperature biology of animals. Chapman and Hill, London

Cragg SM (1993) Wood break-down in mangrove ecosystems: A review. Papua New Guinea Journal of Agriculture, Forestry, and Fisheries 36: 30-39 
Cragg SM, C Danjon, H Mansfield-Williams (2007) Contribution of hardness to the natural resistance of a range of wood species to attack by the marine borer Limnoria. Holzforschung 61: 201-206

Cragg SM, Pitman AJ, Henderson SM (1999) Developments in the understanding of the biology of marine wood boring crustaceans and in methods of controlling them. Int Biodeter Biodegrad 43: 197-205

Cragg SM, Danjon C, Mansfield-Williams H (2007) Contribution of hardness to the natural resistance of a range of wood species to attack by the marine borer Limnoria. Holzforschung 61: 201-206

Cragg SM (1993) Wood break-down in mangrove ecosystems: A review. Papua New Guinea Journal of Agriculture, Forestry, and Fisheries 36: 30-39

Daleo P, Iribarne O (2009) The burrowing crab Neohelice granulata affects the root strategies of the cordgrass Spartina densiflora in SW Atlantic salt marshes. J Exp Mar Biol Ecol 373: 66-71

Davidson TM (2008) Prevalence and distribution of the introduced burrowing isopod, Sphaeroma quoianum in the intertidal zone of a temperate northeast Pacific estuary (Isopoda, Flabellifera). Crustaceana 81: 155-167

Davidson TM, de Rivera CE (2010) Accelerated erosion of saltmarshes infested by the non-native burrowing crustacean Sphaeroma quoianum. Mar Ecol Prog Ser 419: $129-136$

Davidson TM, Shanks AL, Rumrill SS (2008a) Colonization and substratum preference of an introduced burrowing crustacean in a temperate estuary. J Exp Mar Biol Ecol 345: 144-149

Davidson TM, Hewitt CL, Campbell M (2008b) Distribution, density, and habitat use among native and introduced populations of the Australasian burrowing isopod Sphaeroma quoianum. Biol Invasions 10: 399-410

Davidson TM, Rumrill SS, Shanks AL ( 2010) The composition and density of fauna utilizing burrow microhabitats created by a non-native burrowing crustacean (Sphaeroma quoianum). Biological Invasions 12: 1403-1413

Davison P, Asch RG (2011) Plastic ingestion by mesopelagic fishes in the North Pacific Subtropical Gyre. Mar Ecol Prog Ser 432:173-180 
de la Huz R, Lastra M, Lopez J (2002) The influence of sediment grain size on burrowing, growth and metabolism of Donax trunculus L. (Bivalvia: Donacidae). J Sea Res 47: 85-95

Derraik JGB (2002) The pollution of the marine environment by plastic debris: A review. Mar Pollut Bull 44: 842-852

Dharmaraj K, Balakrishnan Nair N (1982) Destruction of laterite and hard clay embankments by boring sphaeromatids (Isopoda: Flabellifera). Indian J Mar Sci 11: 93-95

Dionne JC (1985) Tidal marsh erosion by geese, St. Lawrence estuary, Québec. Géographie physique et Quaternaire 39: 99-105

Dutton CD, Conroy C (1998) Effects of burrowing Chinese mitten crabs (Eriocheir sinensis) on the Thames Tideway. Environment Agency, London. 21 pp

Eakin CM (1996) Where have all the carbonates gone? A model comparison of calcium carbonate budgets before and after the 1982-1983 El Nino at Uva Island in the eastern Pacific. Coral Reefs 15: 109-199

Ellison AM, Farnsworth EJ (1990) The ecology of Belizean mangrove-root fouling communities: I. Epibenthic fauna are barriers to isopod attach of red mangrove roots. J Exp Mar Biol Ecol 142: 91-104

Ellison AM, Farnswoth EJ, Twilley RR (1996) Facultative mutualism between red mangroves and root-fouling sponges in Belizean mangal. Ecology 77: 2431-2444

Eltringham SK (1965) The effect of temperature upon the boring activity and survival of Limnoria (Isopoda). J Applied Ecol. 2: 149-157

Ericsson C, Burton H (2003) Origins and biological accumulation of small plastic particles in fur seals from Macquarie Island. AMBIO: A Journal of the Human Environment 32: 380-384

Escapa M, Minkoff DR, Perillo GME, Iribarne O (2007) Direct and indirect effects of burrowing crab Chasmagnathus granulatus activities on erosion of southwest Atlantic Sarcocornia-dominated marshes. Limnol Oceanog 52: 2340-2349

Estevez ED, JL Simon (1975) Systematics and ecology of Sphaeroma (Crustacea: Isopoda) in the mangrove habitats of Florida, p286-304. In: Proceedings of the International Symposium on Biology and Management of Mangroves. Walsh, G. E., S. C. Snedaker, and H. J. Teas (eds). University of Florida, Gainsville. 
Estevez ED. (1978) Ecology of Sphaeroma terebrans Bate, a wood boring isopod, in a Florida mangrove forest. PhD Dissertation. University of South Florida

Evans JW (1968) Growth rate of the rock-boring clam Penitella penita (Conrad 1837) in relation to hardness of rock and other factors. Ecology 49: 619-628.

Fabricius KE, Hoegh-Guldberg O, Johnson J, McCook L, Lough J (2007) Vulnerability of coral reefs of the Great Barrier Reef to climate change. In: Climate Change and the Great Barrier Reef: A Vulnerability Assessment. pp 515-554

Fabry VJ, Seibel BA, Feely RA, Orr JC (2008) Impacts of ocean acidification on marine fauna and ecosystem processes. ICES. J. Mar. Sci. 65: 414-432

Feagin RA, Lozada-Bernard SM, Ravens TM, Moller I, Yeager KM, Baird AH (2009) Does vegetation prevent wave erosion of salt marsh edges? PNAS 106: 1010910113

Feller IC (2002) The role of herbivory by wood-boring insects in mangrove ecosystems in Belize. Oikos 97: 167-176

Feller IC, Mathis WN (1997) Primary herbivory by wood-boring insects along an architectural gradient of Rhizophora mangle. Biotropica 29:440-451

Fernandez M, Iribarne O, Armstrong D (1993) Habitat selection by young-of-the-year Dungeness crab Cancer magister and predation risk in intertidal habitats. Mar Ecol Prog Ser 92: 171-177

Gabet EJ (1998) Lateral migration and bank erosion in a saltmarsh tidal channel in San Francisco Bay, California, Estuaries 21: 745-753

Gaines SD, Denny MW (1993) The largest, smallest, highest, lowest, longest, and shortest: extremes in ecology. Ecology 74: 1677-1692

Gerdol V, Hughes RG (1994) Effect of Corophium volutator on the abundance of benthic diatoms, bacteria and sediment stability in two estuaries in southeastern England. Mar Ecol Prog Ser 114: 109-115

Geyer H (1981) Effects of wood-inhabiting marine fungi on food selection, feeding intensity and reproduction of Limnoria tripunctata Menzies (Crustacea: Isopoda). The International Research Group on Wood Preservation. Document number: IRG/WP/480 
Glynn PW (1997) Bioerosion and coral reef growth: A dynamic balance. p 69-98. In: Life and Death of Coral Reefs. Ed: Birkeland C. Chapman and Hall, New York.

Glynn PW, Wellington GW, Birkeland C. (1979) Coral growth in the Galapagos: limitation by sea urchins. Science 203: 47-49

Goodier K (1961). Making and using an expanded plastic. New Scientist 240: 706-707

Gooding R, Harley CDG, Tang E (2009) Elevated water temperature and carbon dioxide concentration increase the growth of a keystone echinoderm. PNAS 106: 93169321

Graham ER, Thompson JT (2009) Deposit- and suspension-feeding sea cucumbers (Echinodermata) ingest plastic fragments. J Exp Mar Biol Ecol 368: 22-29

Grant J (1983) The relative magnitude of biological and physical sediment reworking in an intertidal community. J Mar Res 41:673-989

Gregory MR (1996) Plastic 'scrubbers' in hand cleansers: a further (and minor) source for marine pollution identified. Mar Pollut Bull 32: 867-871

Gregory MR (2009) Environmental implications of plastic debris in marine settingsentanglement, ingestion, smothering, hangers-on, hitch-hiking and alien invasions. Phil Trans R Soc B 364: 2013-2025

Grosberg RK (1981) Competitive ability influences habitat choice in marine invertebrates. Nature 290: 700-702

Guyer H (1981) The influence of wood inhabiting marine fungi on the food selection, feeding activity and reproduction of Limnoria tripunctata Menzies (Crustacea, Isopoda). Int J Wood Pres 2: 77-89

Haderlie CM, JC Mellor (1973) Settlement, growth rates and depth preference of the shipworm Bankia setacea (Tryon) in Monterey Bay. The Veliger 15: 265-286

Haderlie EC (1981) Growth rates of Penitella penita (Conrad, 1837), Chaceia ovoidea (Gould, 1851) (Bivalvia: Pholadidae) and other rock boring bivalves in Monterey Bay. The Veliger 24: 109-114

Hansen B, Bjornsen PK, Hansen PJ (1994) The size ratio between planktonic predators and their prey. Limnol Ocean 39: 395-403 
Harley CDG, Hughes R, Hultgren KM, Miner BG, Sorte CJB, Thornber CS, Rodriguez LF, Tomanek L,Williams SL (2006) The impacts of climate change in coastal marine systems. Ecol Lett 9: 228-241

Harmelin-Vivien, ML (1994) The effects of storms and cyclones on coral reefs: a review. J Coast Res Special Issue 12: 221-231

Harrison K, Holdich DM (1984) Hemibranchiate sphaeromatids (Crustracea: Isopoda) from Queensland, Australia, with a world-wide review of the genera discussed. Zool J Linn Soc 81: 275-387

Hass CG, Knott B (1998) Sphaeromatid isopods from the Swan River, Western Australia: diversity, distribution, and geographic sources. Crustaceana 71: 36-46

Hays GC, Richardson AJ, Robinson C (2005) Climate change and marine plankton. Trends Ecol Evol 20: 337-344

Heck KL, Wetstone GS (1977) Habitat complexity and invertebrate species richness and abundance in tropical seagrass meadows. J Biogeog 4: 135-142

Hedley C (1901) Marine woodborers of Australiasia and their work. Proc Aust Assoc Adv Set viii: $237-255$

Heneberg P (2009) Soil penetrability as a key factor affecting the nesting of burrowing birds. Ecological Research 24: 453-459

Hengeveld R (1993) Ecological biogeography. Progress in Physical Geography 17: 448460

Higgins CG (1956) Rock-boring isopod. Bulletin of the Geological Society of America 67: 1770

Highsmith RC (1982) Induced settlement and metamorphosis of sand dollar (Dendraster ecentricus) larvae in predator-free sites: adult sand dollar beds. Ecology 63: 329337

Hill C, Kofoid CA (1927) Marine borers and their relation to marine construction on the Pacific Coast. Final Report of the San Francisco Bay Marine Piling Committee, San Francisco: 357 pp

Hill, M.S. 1996. Symbiotic zooxanthellae enhance boring and growth rates of the tropical sponge Anthosigmella varians forma varians. Marine Biology 125: 649-654 
Hoegh-Goldberg, O, Mumby PJ, Hooten AJ, Steneck RS, Greenfield P, Gomez E, Harvell CD, Sale PF, Edwards AJ, Caldeira K, Knowlton N, Eakin CM, IglesiasPrieto R, Muthiga N, Bradbury RH, Dubi A, Hatziolos ME (2007) Coral Reefs under Rapid Climate Change and Ocean Acidification. Science 318: 1737-1742

Huang Q, Zhou S, Li F (1996) Ecological studies on mangrove boring animals Fujian. Journal of Oceanography in Taiwan 15: 305-309

Hughes TP, Baird AH, Bellwood DR, Card M, Connolly SR, Folke, C (2003) Climate change, human impacts, and the resilience of coral reefs. Science 301: 929-933

Hurley DE, Jansen KP (1977) The marine fauna of New Zealand: Family Sphaeromadtidae (Crustacea: Isopoda: Flabellifera). Mem N Z Ocean Inst 63: 195

Hutchings PA (1983) Cryptofaunal communities of coral reefs. pp 200-208. In: Perspectives on coral reefs. Ed: Barnes DJ. Australian Institute of Marine Science, Townsville

Hutchings PA (1986) Biological destruction of coral reefs. A review. Coral Reefs 4: 239252

Hutchings PA, Ahyong S, Byrne M, Przeslawski R, Wörheide G (2007) Vulnerability of benthic invertebrates of the Great Barrier Reef to climate change. In: Climate Change and the Great Barrier Reef: A Vulnerability Assessment. pp 309-356

Hutchinson GE (1957) Concluding remarks. Cold Spring Harbor Symposia on Quantitative Biology 22: 415-427

Ibrahim JV (1981) Season of settlement of a number of shipworms (Mollusca: Bivalvia) in six Australian harbours. Austral J Mar Fresh Res 32: 591-604

IPCC (2007) Contribution of Working Groups I, II and III to the Fourth Assessment Report of the Intergovernmental Panel on Climate Change. Core Writing Team, Pachauri RK and Reisinger A (eds). IPCC, Geneva, Switzerland. 104 pp

Irwin M (1953) Science looks into it: Steel boring sea urchins. Pacific Discovery 6: 26-27

Jansen KP (1971) Ecological studies on intertidal New Zealand Sphaeromatidae (Isopoda: Flabellifera). Mar Bio 11: 262-285 
Jefferies RL, Jano AP, Abraham KF (2006) A biotic agent promotes large-scale catastrophic change in the coastal marshes of Hudson Bay. J Ecol 94: 234-242

Jenner HA, Rajagopal S, Van der Veldeb G, Daud MS (2003) Perforation of ABS pipes by boring bivalve Martesia striata: a case study. Int Biodeter Biodegrad 52: 229232

Jones CG, Lawton JH, Shachak M (1994) Organisms as ecosystem engineers. Oikos 69: 373-386

Jones MB, Simon MJ (1982) Habitat preferences of two estuarine burrowing crabs Helice crassa Dana (Grapsidae) and Macrophthalmus hirtipes (Jacquinot) (Ocypodidae). J Exp Mar Biol Ecol 56: 49-62

Jurgens JA, Blanchett RA (2005) Characterization of wood destroying microorganisms in archaeological woods from marine environments. International Academy of Wood Science Annual Meeting, Chile

Kathiresan K, Bingham BL (2001) Biology of mangrove and mangrove ecosystems. Advances in Marine Biology 40: 81-251

Keough MJ, Downes BJ (1981) Recruitment of marine invertebrates: The role of active choices and early mortality. Oecologia 54 : 348-352

Khalaji-Pirbalouty V, Wagele JW (2010) A new record of Sphaeroma annandalei Stebbing, 1911 (Crustacea: Isopoda: Sphaeromatidae) from the Persian Gulf, and description of a new related species (Sphaeroma silvai nov. sp.) from the South Atlantic Ocean. Zootaxa 2508: 30-44

Kim YS, Singh AP, Nilsson T (1996) Bacteria as important degraders in waterlogged archaeological woods. Holzforschung 50: 389-392

Kirwan, ML, Murray AB, Boyd WS (2008) Temporary vegetation disturbance as an explanation for permanent loss of tidal wetlands. Geophysical Research Letters 35: L05403.

Kofoid C, Miller R (1927) Occurrence of rock boring molluscs in concrete. In: Marine Borers and their relation to marine construction on the Pacific Coast. Eds: Hill CL;, Kofoid CA. Final Report of the San Francisco Bay Marine Piling Committee, San Francisco. 301-305 
Kordas RL, Harley CDG, O'Connor MI (2011) Community ecology in a warming world: the influence of temperature on interspecific interactions. J Exp Mar Biol Ecol 400

Kristensen E, Alongi DM (2006) Control by fiddler crabs (Uca vocans) and plant roots (Avicennia marina) on carbon, iron, and sulfur biogeochemistry in mangrove sediment. Limnol Oceanogr 51: 1557-1571

Laist DW (1997) Impacts of marine debris: Entanglement of marine life in debris including a comprehensive list of species with entanglement and ingestion records. 99-139. In: Marine Debris; Eds: Coe JM, Rogers DB. Springer: Berlin

Lee SY (1997) Potential trophic importance of the faecal material of the mangrove sesarmine crab Sesarma messa. Mar Ecol Progr Ser 159: 275-284

Lenihan HS, F Micheli (2001) Soft-sediment communities. p253-287. In: Marine Community Ecology. Bertness, M. D., S. D. Gaines, and M. E. Hay (eds). Sinauer Associates, Inc. Sunderland, MA

Levin L, Blair N, DeMaster D, Plala FW, Martin C, Thomas C (1997) Rapid subduction of organic matter by maldanid polychaetes on the North Carolina slope. J Mar Res 55: 595-611

Li SW, Chan BKK (2008) Adaptations to barnacle fouling in the mangroves Kandelia obovata and Aegiceras corniculatum. Mar Biol 155: 263-271

Linscombe G, Kinler N (1997) A survey of vegetative damage caused by nutria herbivory in the Barataria and Terrebonne basins. Barataria-Terrebonne National Estuary Program, Thibodaux, LA

Luna F, Antinuchi CD (2006) Cost of foraging in the subterranean rodent Ctenomys talarum: effect of soil hardness. Canadian Journal of Zoology 84: 661-667

Manzello DP, Kleypas JA, Budd DA, Eakin CM, Glynn PW, Langdon C (2007) Poorly cemented coral reefs of the eastern tropical Pacific: Possible insights into reef development in a high-CO2 world. PNAS 105: 10450-10455

Masselink G, Hughes MC (2003) Introduction to Coastal Processes and Geomorphology. Hodder Arnold, London

Mato Y, Isobe T, Takada H, Kanehiro H, Ohtake C, Kaminuma T (2001) Plastic resin pellets as a transport medium for toxic chemicals in the marine environment. Environ Sci Technol 35: 308-324 
McClintock JB, Baker BJ (2001) Marine chemical ecology. CRC Press, Boca Raton, FL. $624 \mathrm{pp}$

McLean RF (1967) Measurement of beachrock erosion by some tropical marine gastropods. Bulletin of Marine Science 17: 551-561

Meadows PS, Tait J (1989) Modification of sediment permeability and shear strength by two burrowing invertebrates. Mar Biol 101: 75-82

Meehl GA, Stocker TF, Collins WD, Friedlingstein P, Gaye AT, Gregory JM, Kitoh A, Knutti R, Murphy JM, Noda A, Raper SCB, Watterson IG, Weaver AJ, Zhao ZC (2007) Global climate projections. Climate change 2007: The physical science basis. 747-845. Contribution of working group I to the fourth assessment report of the Intergovernmental Panel on Climate Change. Eds: Solomon S, Qin D, Manning M, Chen Z, Marquis M, Averyt KB, Tignor M, Miller HL. Cambridge University Press, Cambridge, United Kingdom and New York

Messana G (2004) How can I mate without an appendix masculina? The case of Sphaeroma terebrans Bate, 1866 (isopoda, Sphaeromatidae). Crustaceana 77:499505

Messana G, Bartolucci V, Mwaluma J, Osore M (1994) Preliminary observations on parental care in Sphaeroma terebrans Bate 1866 (Isopoda Sphaeromatidae), a mangrove wood borer from Kenya. Ethol Ecol Evol 3: 125-129

Meyer A (2006) The impacts of nutria on vegetation and erosion in Oregon. MS thesis, University of Colorado, Boulder, CO

Miller RC (1926) Ecological relations of marine wood-boring organisms in San Francisco Bay. Ecology: 7: 247-254

Miller RC, Boynton LC (1926) Digestion of wood by the shipworm. Science: 63: 524

Mills PR (1978) Sphaeroma quoyana on treated poles in New Zealand. Int Biodeterior Bull 14: 35-36

Milne Edwards H (1840) Histoire Naturelle des Crustaes 3: 1-605 Librairie Encyclopedique de Roret: Paris

Mitsch WJ, Gosselink JG (1993) Wetlands. Van Nostrand Reinhold, New york

Morris RH, Abbott DP, Haderlie EC (1980) Intertidal Invertebrates of California, Stanford University Press, Stanford, CA 
Morton B (1991) Notes on the first mangrove shipworm, Lyrodus singaporeana, recorded from Hong Kong. J Mollus Stud 57: 295-296

Murata Y, Wada K (2002) Population and reproductive biology of an intertidal sandstone-boring isopod, Sphaeroma wadai Nunomura, 1994. J Nat Hist 36: 2535

Murray F, Cowie PR (2011) Plastic contamination in the decapod crustacean Nephrops norvegicus (Linnaeus, 1758). Mar Poll Bull 62: 1207-1217

Nagelkerken I, Blaber SJM, Bouillon S, Green P, Haywood M, Kirton LG, Meynecke JO, Pawlik J, Penrose HM, Sasekumar A, Somerfield PJ (2008) The habitat function of mangroves for terrestrial and marine fauna: A review. Aquat Bot 89: 155-185

National Oceanic and Atmospheric Administration (2011a) National Estuarine Research Reserve system-wide monitoring program. Centralized Data Management Office, Baruch Marine Field Lab, University of South Carolina http://cdmo.baruch.sc.edu. accessed Sept 11, 2011

National Oceanic and Atmospheric Administration (2011b) National Oceanographic Data Center. Coastal Temperature Guide. Long-term monthly mean water temperatures for the North Pacific coast. http://www.nodc.noaa.gov/dsdt/cwtg/npac.html accessed Sept 11, 2011

Neily RM (1927) Historical development of marine structures in San Francisco Bay. Pages 13-32, Marine borers and their relation to marine construction on the Pacific Coast. Eds: Hill CL and C. A. Kofoid. Final Report of the San Francisco Bay Marine Piling Committee, San Francisco, 357 pp

Neumann AC (1966) Observations on coastal erosion in Bermuda and measurement of the boring rate of the, Cliona lampa. Limnol Oceanog 11: 92-108

Nicholls RJ, Wong PP, Burkett VR, Codignotto JO, Hay JE, McLean RF, Ragoonaden S, Woodroffe CD (2007) Coastal systems and low-lying areas. Climate change 2007: Impacts, adaptation and vulnerability. 315-356. Contribution of Working group II to the fourth assessment report of the Intergovernmental Panel on Climate Change. Eds: Parry ML, Canziani OF, Palutikof JF, van der Linden PJ, Hanson CE. Cambridge University Press, Cambridge, UK

North, WJ (1954) Size distribution, erosive activities, and gross metabolic efficiency of the marine intertidal snails Littorina planaxis and Littorina scutulata. Bio Bull 106: $187-197$ 
Odum WE, Heald EJ (1975) The detritus-based food web of an estuarine mangrove community. p 265-286. In: Estuarine Research. Ed: Cronin LE. Academic Press, New York,

Offenberg J, Nielsen MG, Macintosh DJ, Havanon S, Aksornkoae S (2005) Lack of ant attendance may induce compensatory plant growth. Oikos 111: 170-178

Orr JC, Fabry VJ, Aumont O, Bopp L, Doney SC, et al. (2005) Anthropogenic ocean acidification over the twenty-first century and its impact on calcifying organisms. Nature 437: 681-86

Orvain F, Sauriau P, Bacher C, Prineau M (2006) The influence of sediment cohesiveness on bioturbation effects due to Hydrobia ulvae on the initial erosion of intertidal sediments: a study combining flume and model approaches. J Sea Res 55: 54-73

Paalvast P, Velde G van der (2011) New threats of an old enemy: The distribution of the shipworm Teredo navalis L. (Bivalvia: Teredinidae) related to climate change in the Port of Rotterdam area, the Netherlands. Mar Pollut Bull 62:1822-1829

Palomo G, Botto F, Navarro D, Escapa M, Iribarne O (2008) Does the presence of the SW Atlantic burrowing crab Chasmagnathus granulatus Dana affect predatorprey interactions between shorebirds and polychaetes? J Exp Mar Ecol 290: 211228

Paramor OAL, Hughes RG (2004) The effects of bioturbation and herbivory by the polychaete Nereis diversicolor on loss of saltmarsh in south-east England. J Appl Ecol 41: 449-463

Peck LS, Webb KE, Bailey DM (2004) Extreme sensitivity of biological function to temperature in Antarctic marine species. Functional Ecology 18: 625-630

Peng GD, Lai GX, Huang ZQ, Liu KY, Xue ML (1993) Restoration results of Rhizophora stylosa and Lumnizera racemosa. Research program implementation results of Taiwan endemic Species Research Institute

Perry AL, Low PJ, Ellis JR, Reynolds JD (2005) Climate change and distribution shifts in marine fishes. Science 308: 1912-1915

Perry D (1988) Effects of associated fauna on growth and productivity in the red mangrove. Ecology 69: 1064-1075

Perry D, Brusca RC (1989) Effects of the root-boring isopod Sphaeroma peruvianum on red mangrove forests. Mar Ecol Prog Ser 57: 287-292 
Petraitis PS (1992) Effects of body size and water temperature on grazing rates of four intertidal gastropods. Austral J Ecol 17: 409-414

Pettit TN, Grant GS, Whittow GC (1981) Ingestions of plastics by Laysan ablatross. Auk 98: $839-840$

Pilditch CA, Widdows J, Kuhn NJ, Pope ND, Brinsley BD (2008) Effects of low tide rainfall on the erodibility of intertidal cohesive sediments. Con Shelf Res 28: 1854-1865

Pinn EH, CA Richardson, RC Thompson, SJ Hawkins (2005) Burrow morphology, biometry, age and growth of piddocks (Mollusca: Bivalvia: Pholadidae) on the south coast of England. Mar Biol 147: 943-953

Pinn EH, Thompson RC, Hawkins SJ (2008) Piddocks (Mollusca: Bivalvia: Pholadidae) increase topographical complexity and species diversity in the intertidal. Mar Ecol Prog Ser 355: 173-182

Primavera, J.H. (1998). Mangroves as nurseries: shrimp populations in mangrove and nonmangrove habitats. Estuarine, Coastal and Shelf Science 46: 457-464

Ray DL (1959) Marine Boring and Fouling Organisms. University of Washington Press, Seattle, WA

Redfield AC (1972) Development of a New England salt marsh. Ecol Monogr 42: 201237

Rehm A (1996) The effects of the wood-boring isopod Sphaeroma terebrans on the mangrove communities of Florida. Envir Conserv 3: 47-57

Rehm A, Humm HJ (1973) Sphaeroma terebrans: a threat to the mangroves of southwestern Florida. Science 182:173-174

Rhoads DC, DG Young (1970) The influence of deposit-feeding organisms on sediment stability and community trophic structure. J Mar Res 28: 150-178

Rhoads DC, Young DG (1970) The influence of deposit-feeding organisms on sediment stability and community trophic structure. J Mar Res 28: 150-178

Rice S, Johnson B, Estevez E (1990) Wood-boring marine and estuarine animals in Florida. Florida Sea Grant College Program, Report SGEB-15, Gainesville, Florida. 28 pp 
Riegel JA (1959) Some aspects of osmoregulation in two species of Sphaeromid isopod crustacea. Bio Bull 116: 272-284

Rios LM, Moore C, Jones PR (2007) Persistent organic pollutants carried by synthetic polymers in the ocean environment. Mar Pollut Bull 54: 1230-1237

Rittschof, D, Costlow JD (1989) Bryozoan and barnacle settlement in relation to initial surface wettability: A comparison of laboratory and field studies. Sci Mar 53: 411-416

Roast SD, Widdows J, Pope ND, Jones MB (2004) Sediment-biota interactions: mysid feeding activity enhances water turbidity and sediment erodability. Mar Ecol Prog Ser 281: $145-154$

Robinson TB, Griffiths CL, McQuaid CD, Rius M (2005) Marine alien species of South Africa - status and impacts. African Journal of Marine Science 27: 297-306

Roch F (1932) Einige Beobachtungen zur Ökologie und Physiologie von Teredo navalis L. Ark Zool 24: 1-17

Ross P (2006) Macrofaunal loss and microhabitat destruction: The impact of trampling in a temperate mangrove forest, NSW Australia. Wetlands Ecology and Management 14: 167-184

Rotramel G (1972) Iais californica and Sphaeroma quoyanum, two symbiotic isopods introduced to California. (Isopoda: Janiridae and Sphaeromatidae) Crustaceana, Suppl III 13: 193-197

Rotramel G (1975a) Filter-feeding by the marine boring isopod, Sphaeroma quoyanum H. Milne Edwards, 1840 (Isopoda, Sphaeromatidae). Crustaceana 28:7-10

Rotramel GL (1971) Symbiotic relationships of Sphaeroma quoyanum and Iais californica (Crustcea: Isopoda). PhD Dissertation. University of California, Berkeley. 65 pp

Rotramel GL. (1975b) Observations on the commensal relations of Iais californica (Richardson, 1904) and Sphaeroma quoyanum H.Milne Edwards, 1840 (Isopoda). Crustaceana 28:247-256

Rudnick DA, Chan V, Resh VH. (2005) Morphology and impacts of the burrows of the Chinese mitten crab, Eriocheir sinensis H. Milne Edwards (Decapoda, Grapsoidea), in South San Francisco Bay, California, U.S.A. Crustaceana.78:787807 
Russ, JC (2007) The image processing handbook. CRC Press. Boca Raton, FL. 838 pp

Rutzler K (2002) Impact of crustose clionid sponges on Caribbean reef corals. Acta Geologica Hispanica 37: 61-72

Ryan PG (1987) The effects of ingested plastic on seabirds: correlations between plastic load and body condition. Environmental Pollution 46: 119-125

Ryan PG (1988) Effects of ingested plastic on seabird feeding: evidence from chickens. Mar Pollut Bull 19: 125-128

Ryan PG, Connell AD, Gardener BD (1988) Plastic ingestion and PCBs in seabirds: Is there a relationship? Mar Pollut Bull 19: 174-176

Sammarco PW (1980) Diadema and its relationship to coral spat mortality: grazing, competition, and biological disturbance. J Exp Mar Biol Ecol 45: 245-272

Sammarco PW (1982) Echinoid grazing as a structuring force in coral communities: whole reef manipulations. J Exp Mar Biol Ecol 61: 31-55

Sanchez-Salazar ME, Griffiths CL, Seed R (1987) The effect of size and temperature on the predation of cockles Cerastomaderma edule (L.) by the shore crab Carcinus maenas (L.). J Exp Mar Biol Ecol 111: 181-193

Sanford E (1999) Regulation of keystone predation by small changes in ocean temperature. Science 283: 2095-2097

Sanford E (2002) Water temperature, predation, and the neglected role of physiological rate effects in rocky intertidal communities. Integ and Comp Biol 42: 881-891

Santhakumari V (1991) Destruction of mangrove vegetation by Sphaeroma terebrans along Kerala Coast. Fishery Technology 28: 29-32

Scavia D, Field JC, Boesch DF, Buddemeier RW, Burkett V, Cayan DR, Fogarty M, Harwell MA, Howarth RW, Mason C, Reed DJ, Royer TC, Sallenger AH, Titus JG (2002) Climate change impacts on U.S. coastal marine ecosystems. Estuaries 25: $149-164$

Scheltema RS, Truitt RV (1956) The shipworm Teredo navalis in Maryland coastal waters. Ecology 37: 841-843

Schneider J, Toruski H (1983) Biokarst on limestone coasts, morphogenesis and sediment production. Mar Ecol 4: 45-63 
Schneider MR (1976) Population Dynamics of the Symbiotic Marine Isopods, Sphaeroma quoyana and Iais californica. Masters Thesis. Biology, San Francisco State University, San Francisco

Schneider J, Toruski H (1983) Biokarst on limestone coasts, morphogenesis and sediment production. Mar Ecol 4: 45-63.

Schoppe S, Werding B (1996) The boreholes of the sea urchin genus Echinometra (Echinodermata: Echinoidea: Echinometridae) as a microhabitat in tropical South America. Mar Ecol 17: 181-186

Semeniuk V (1980) Mangrove zonation along an eroding coastline in King Sound, NorthWestern Australia. J Ecol 68: 789-812

Sgro L, Mistri M, Widdows J (2005) Impact of the infaunal Manila clam, Ruditapes philippinarum, on sediment stability. Hydrobiologia 550: 175-182

Shuster SM (1989) Male alternative reproductive strategies in a marine isopod crustacean (Paracerceis sculpta): the use of genetic markers to measure differences in fertilization success among alpha, beta, and gamma males. Evolution 43: 16831698

Si A, Bellwood O, Alexander CG (2002) Evidence for filter-feeding by the wood-boring isopod, Sphaeroma terebrans (Crustacea: Peracarida).256:463-471

Siegrist HG, Bowman RG, Randall RH, Stifel PB (1992) Diagenetic effects related to hot-water effluent in a modem reef on Guam. Pacific Science 46: 379

Silliman BR, van de Koppel J, Bertness MD, Stanton L, Mendelssohn, I (2005) Drought, snails, and large-scale die-off of southern U.S. salt marshes. Science 310: 18031806

Simberloff D, Brown BJ, Lowrie S (1978) Isopod and insect root borers may benefit Florida mangroves. Science 201: 630-632

Singh Chauhan PP (2009) Autocyclic erosion in tidal marshes. Geomorphology 110: 4557

Smith III TJ, Boto KG, Frusher SD, Giddins RL (1991) Keystone species and mangrove forest dynamics: the influence of burrowing by crabs on soil nutrient status and forest productivity. Est Coast Shelf Sci 33: 419-432 
Smith TB (2008) Temperature effects on herbivory for an Indo-Pacific parrotfish in Panamá: implications for coral-algal competition. Coral Reefs 27: 397-405

Snedaker SC, Enright JT (1974) Mangroves, Isopods, and the Ecosystem. Science 183: 1036-1038

Soomere T (2005) Fast ferry traffic as a qualitatively new forcing factor of environmental processes in non-tidal sea areas: a case study in Tallinn Bay, Baltic Sea. Environmental Fluid Mechanics 5: 293-323

Sorte CJB, Williams SL, Carlton JT (2010a) Marine range shifts and species introductions: comparative spread rates and community impacts. Global Ecol Biogeog 19: 303-316

Sorte CJB, Williams SL, Zerebecki RA (2010b) Ocean warming increases threat of invasive species in a marine fouling community. Ecology 91: 2198-2204

Sousa WP, Quek SP, Mitchell BJ (2003) Regeneration of Rhizophora mangle in a Caribbean mangrove forest: interacting effects of canopy disturbance and a stemboring beetle. Oecologia 137: 436-445

Spear LB, Ainley DG, Ribic CA (1995) Incidence of plastic in seabirds from the tropical Pacific, 1984-91: relation with distribution of species, sex, age, season, year and body weight. Mar Environ Res 40: 123-146

Spenceley AP (1977) The role of pneumatophores in sedimentary processes. Mar Geol 24: M31-M37

Sprules WG, Jin EH, Herman AW, Stockwell JD (1998) Calibration of an Optical Plankton Counter for Use in Fresh Water. Limnol Ocean 43: 726-733

Stachowicz JJ, Terwin JR, Whitlatch RB, Osman RW (2002) Linking climate change and biological invasions: ocean warming facilitates non-indigenous species invasion. PNAS 99: 15497-15500

Stanhope MJ, Connelly MM, Hartwick B (1992) Evolution of a crustacean chemical communication channel: Behavioral and ecological genetic evidence for a habitatmodified, race-specific pheromone. J Chem Ecol 18: 1871-1887

Svavarsson J, Osore MK, Olafsson E (2002) Does the wood-borer Sphaeroma terebrans (Crustacea) shape the distribution of the mangrove Rhizophora mucronata? Ambio 31: 574-579 
Talley TS, Crooks JA, Levin LA (2001) Habitat utilization and alteration by the invasive burrowing isopod, Sphaeroma quoyanum, in California salt marshes. Mar Biol 138: $561-573$

Teuten EL, Rowland SJ, Galloway TS, Thompson RC (2007) Potential for plastics to transport hydrophobic contaminants. Environ Sci Technol 41: 7759-7764

Teuten EL, Saquing JM, Knappe DRU, et al. (2009) Transport and release of chemicals from plastics to the environment and to wildlife. Phil Trans R Soc B 364: $2027-$ 2045

Thiel M (1999) Reproductive biology of a wood-boring isopod, Sphaeroma terebrans, with extended parental care. Mar Bio 135: 321-333

Thompson RC, Olsen Y, Mitchell RP, Davis A, Rowland SJ, John A WG, McGonigle D, Russell A (2004) Lost at sea: Where is all the plastic? Science 304: 838

Tryon GW Jr. (1863) Monograph of the family Teredidae. Academy of Natural Sciences of Philadelphia, Proceedings 14: 453-480

Turner RD (1966) A survey and illustrated catalogue of the Teredinidae. Cambridge, Mass: Museum of Comparative Zoology, Harvard University. 265 pp

Underwood AJ (1981) Techniques of analysis of variance in experimental marine biology and ecology. Oceanogr Mar Biol Annu Rev 19: 513-605

Underwood AJ, Keough MJ (2001) Supply-side ecology: the nature and consequences of variations in recruitment of intertidal organisms. In: Marine community ecology. Eds: Bertness MD, Gaines SD, Hay ME. Sinauer, Sunderland, MA, p 183-200

UNEP-WCMC (2006) In the front line: shoreline protection and other ecosystem services from mangroves and coral reefs. UNEP-WCMC, Cambridge, UK 33 pp

Valentich-Scott P (2003) A taxonomic, distributional, and bibliographic checklist of Hong Kong marine bivalve molluscs and research published on them from 19712000. In: Proceedings of an International workshop reunion conference Hong Kong, 21-26, Oct 2001. Ed: Morton B. Hong Kong: Hong Kong University Press

Walker CH, Sibly RM, Hopkin SP, Peakall DB (2006) Principles of Ecotoxicology. 3rd ed. CRC Press. Boca Raton, FL. 344 pp 
Wang J, Tang L, Zhang X, Wang C, Gao Y, Jiang L, Chen J, Li B (2009) Fine-scale environmental heterogeneities of tidal creeks affect distribution of crab burrows in a Chinese salt marsh. Ecological Engineering 35: 1685-1692

Warme JE (1971) Communities of bioeroders on submarine outcrops of Pacific Coast. AAPG Bulletin 55: 368-369

Warme JE, Marshall NF (1969) Marine borers in calcareous terrigenous rocks of the Pacific Coast. Am Zool 9: 765-774

Wasson K, Zabin CJ, Bedinger L, Diaz MC, Pearse JS (2001) Biological invasions of estuaries without international shipping: the importance of intraregional transport. Biol Conserv 102: 143-153

Wetzer, R (2011) Sphaeromatid isopod Worldwide. http://isopods.nhm.org/. accessed Nov 3, 2011

Widdicombe S, Spicer JI (2008) Predicting the impact of Ocean acidification on benthic biodiversity: What can physiology tell us? J Exp Mar Biol Ecol 366: 187-197

Widdows J, Brinsley M (2002) Impact of biotic and abiotic processes on sediment dynamics and the consequences to the structure and functioning of the intertidal zone. J Sea Res 48: 143-156

Widdows J, Brinsley MD, Pope ND (2009) Effect of Nereis diversicolor density on the erodability of estuarine sediment. Mar Ecol Prog Ser 378: 135-143

Widdows J, Brinsley MD, Salkeld PN, Lucas CH (2000) Influence of biota on spatial and temporal variation in sediment erodability and material flux on a tidal flat (Westerschelde Netherlands). Mar Ecol Prog Ser 194: 23-37

Wilkinson LL (2004) The biology of Sphaeroma terebrans in Lake Ponchartrain, Louisiana with emphasis on burrowing. MS thesis, University of New Orleans, 62 $\mathrm{pp}$

Wisenden BD (2000) Olfactory assessment of predation risk in the aquatic environment. Phil Trans R Soc Lond B 355: 1205-1208

Yager PL, Nowell ARM, Jumars PA (1993) Enhanced deposition to pits: A local food source for benthos. J Mar Res 51: 209-236 
Ye S, Andrady AL (1991) Fouling of floating plastic debris under Biscayne Bay exposure conditions. Mar Pollut Bull 22: 608-613

Zitko V (1993) Expanded polystyrene as a source of contaminants. Mar Pollut Bull 26: 584-585 